\title{
PRE-TREATMENT OF FLAX FIBERS FOR USE IN ROTATIONALLY MOLDED BIOCOMPOSITES
}

\author{
A Thesis Submitted to the \\ College of Graduate Studies and Research \\ in Partial Fulfillment of the Requirements \\ for the Degree of Master of Science \\ in the Department of Agricultural and Bioresource Engineering \\ University of Saskatchewan \\ Saskatoon, Saskatchewan \\ by \\ Bei Wang
}

(C) Copyright Bei Wang, July 2004. All rights reserved 


\section{PERMISSION TO USE}

In presenting this thesis in partial fulfilment of the requirements for a Postgraduate

degree from the University of Saskatchewan, I agree that the Libraries of this University may make it freely available for inspection. I further agree that permission for copying of this thesis in any manner, in whole or in part, for scholarly purposes may be granted by the professor or professors who supervised my thesis work or, in their absence, by the Head of the Department or the Dean of the College in which my thesis work was done. It is understood that any copying or publication or use of this thesis or parts thereof for financial gain shall not be allowed without my written permission. It is also understood that due recognition shall be given to me and to the University of Saskatchewan in any scholarly use which may be made of any material in my thesis.

Requests for permission to copy or to make other use of material in this thesis in whole or part should be addressed to:

Head of the Department of Agricultural and Bioresource Engineering University of Saskatchewan

57 Campus Drive, Saskatoon, Saskatchewan, S7N 5A9

CANADA 


\begin{abstract}
Flax fibers can be used as environmentally friendly alternatives to conventional reinforcing fibers (e.g., glass) in composites. The interest in natural fiber-reinforced polymer composites is growing rapidly due to its high performance in terms of mechanical properties, significant processing advantages, excellent chemical resistance, low cost and low density. These advantages place natural fiber composites among the high performance composites having economic and environmental advantages. In the field of technical utilization of plant fibers, flax fiber-reinforced composites represent one of the most important areas. On the other hand, lack of good interfacial adhesion and poor resistance to moisture absorption make the use of natural fiber-reinforced composites less attractive. In order to improve their interfacial properties, fibers were subjected to chemical treatments, namely, mercerization, silane treatment, benzoylation, and peroxide treatment. Selective removal of non-cellulosic compounds constitutes the main objective of the chemical treatments of flax fibers to improve the performance of fiber-reinforced composites. The objective of this study was to determine the effects of pre-treated flax fibers on the performance of the fiber-reinforced composites.
\end{abstract}

Short flax fibers were derived from Saskatchewan-grown flax straws, for use in fiberreinforced composites. Composites consisting of high-density polyethylene (HDPE) or linear low-density polyethylene (LLDPE) or HDPE/LLDPE mix, chemically treated fibers and additives were prepared by the extrusion process. Extrusion is expected to improve the interfacial adhesion significantly as opposed to simple mixing of the two 
components. The extruded strands were then pelletized and ground. The test samples were prepared by rotational molding. The fiber surface topology and the tensile fracture surfaces of the composites were characterized by scanning electron microscopy to determine whether the modified fiber-matrix interface had improved interfacial bonding. Mechanical and physical properties of the composites were evaluated. The differential scanning calorimetry technique was also used to measure the melting point of flax fiber and composite.

Overall, the scanning electron microscopy photographs of fiber surface characteristics and fracture surfaces of composites clearly indicated the extent of fiber-matrix interface adhesion. Chemically treated fiber-reinforced composites showed better fiber-matrix interaction as observed from the good dispersion of fibers in the matrix system. Compared to untreated fiber-reinforced composites, all the treated fiber-reinforced composites had the same tendency to slightly increase the tensile strength at yield of composites. Silane, benzoylation, and peroxide treated fiber-reinforced composites offered superior physical and mechanical properties. Strong intermolecular fiber-matrix bonding decreased the high rate of water absorption in biocomposites. The incorporation of $10 \%$ untreated or chemically treated flax fibers also increased the melting point of composites. Further investigation is required to address the effect of increase in fiber content on the performance of composites. 


\section{ACKNOWLEDGEMENTS}

I would like to acknowledge Professor L. G. Tabil, my supervisor, for his guidance, encouragement and patience during all stages of this project.

I am also grateful to S. Panigrahi, my graduate committee member, for following the progress and providing his technical guidance and valuable contributions throughout the research program.

Special thanks to my graduate committee Charles Maulé, the chair, for providing a motivating and enthusiastic environment during the many discussions and his helpful feedback and suggestions. The critique of this thesis by Dr. Chris Zhang, external examiner, is acknowledged.

I acknowledge the financial support from Saskatchewan Flax Development Council, Agriculture Development Fund of Saskatchewan Agriculture, Food and Rural Revitalization and the University of Saskatchewan Graduate Scholarship. I also would like to acknowledge the Departments of Civil Engineering, Electrical Engineering and Biology at the University of Saskatchewan and the Northern Alberta Institute of Technology (NAIT) and the Centre for Agri-Industrial Technology (CAIT) in Edmonton, $\mathrm{AB}$ for the use of their facilities and equipment. The support of Norwesco Canada Ltd. and the Canada Saskatchewan Agri-Food Innovation Fund (AFIF) is also acknowledged.

I am grateful to the faculty, staff and my colleagues in the Department of Agricultural and Bioresource Engineering for their assistance in every aspect of my program. I am indebted to my supervisor, the Department of Agricultural and Bioresource Engineering, and the College of Graduate Studies and Research for the travel award and financial support throughout my studies. 


\section{DEDICATION}

I dedicate this thesis to my loving family who encouraged me to excel in a scholarly career. I wish to express my gratitude to my parents for the love and support during my studies. 


\section{TABLE OF CONTENTS}

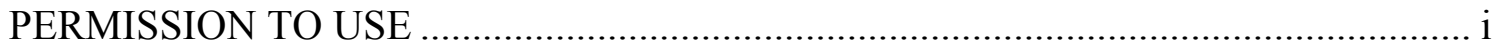

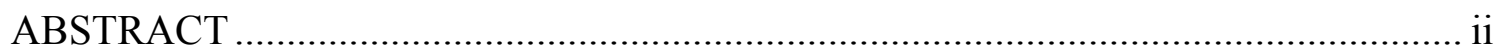

ACKNOWLEDGEMENTS ............................................................................. iv

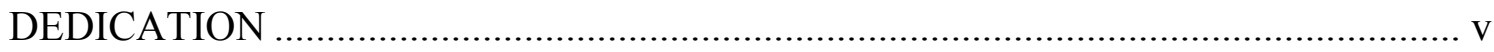

TABLE OF CONTENTS .................................................................................... vi

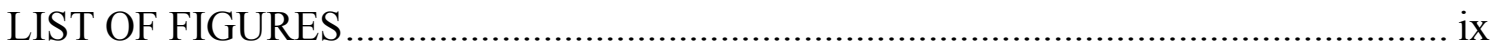

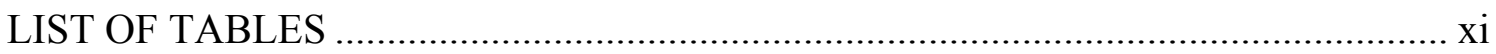

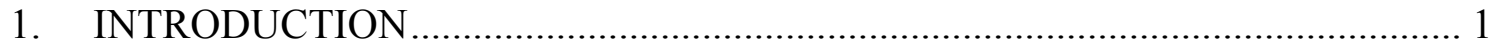

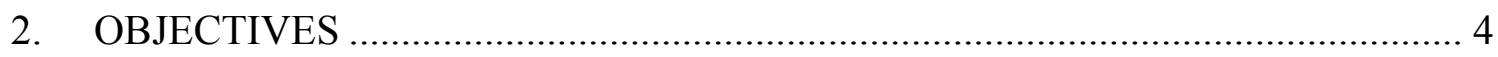

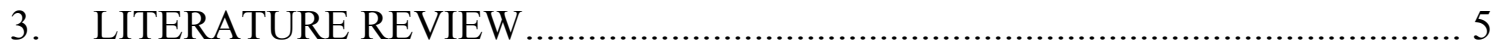

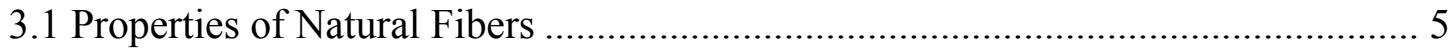

3.1.1 Physical properties of natural fibers .................................................... 5

3.1.2 Chemical composition of natural fibers .................................................... 7

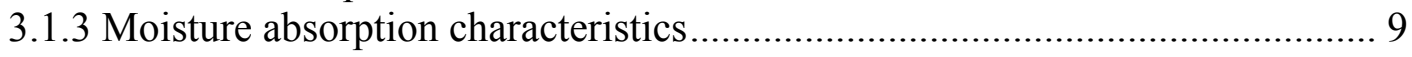

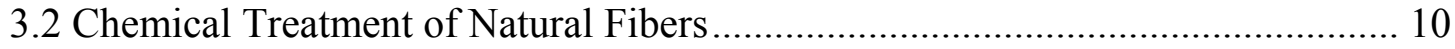

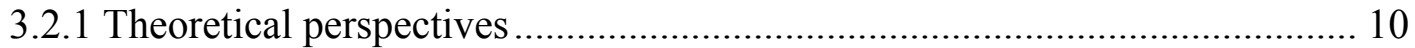

3.2.2 Surface chemical modifications of natural fibers....................................... 11

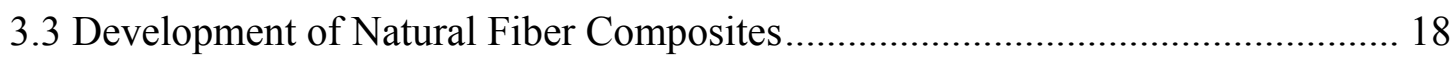

3.4 Characteristics of Thermoplastic Polymers.................................................. 20

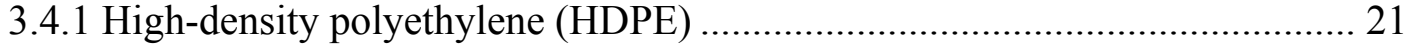

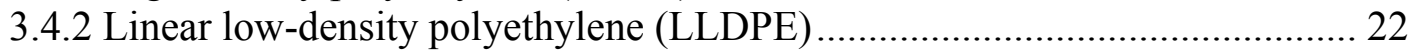

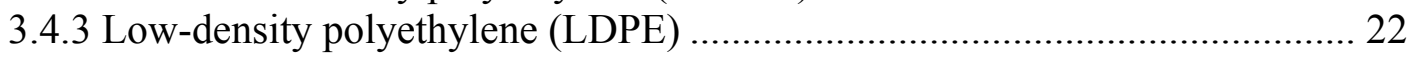

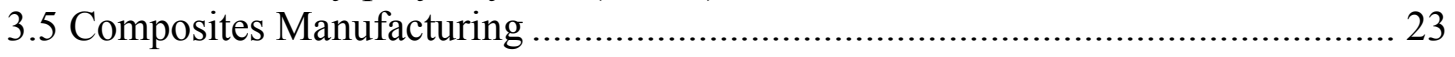

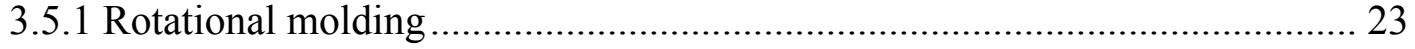

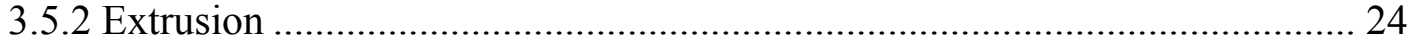

3.6 Effects of Fiber Surface Modifications on the Fibers ...................................... 24

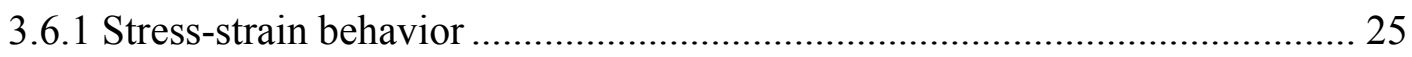

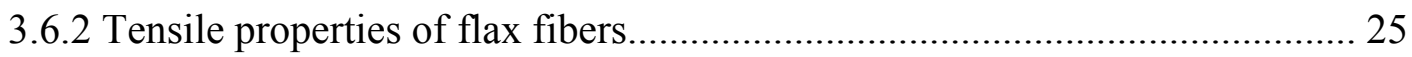

3.7 Effects of Fiber Surface Modifications on the Composite Properties.................. 26

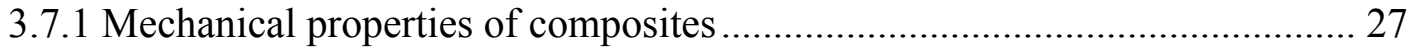

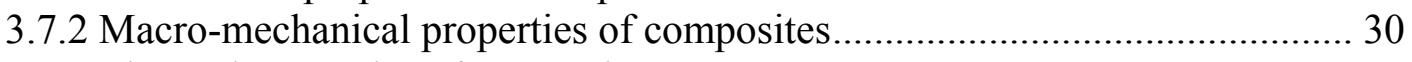

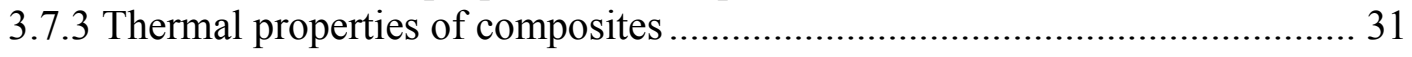




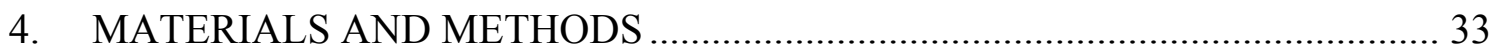

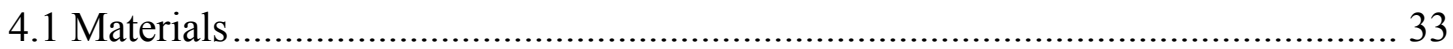

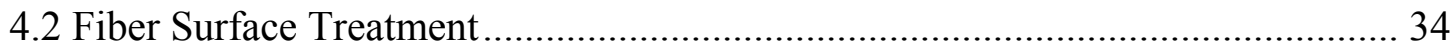

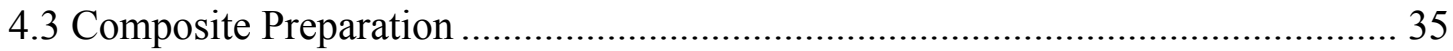

4.4 Biocomposites Manufacturing by Rotational Molding …................................ 37

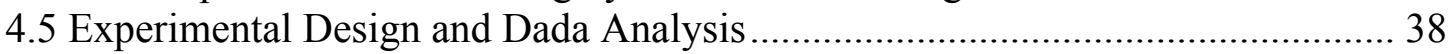

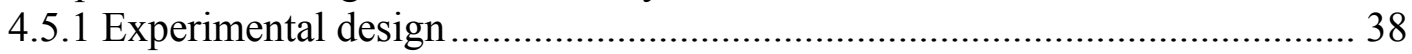

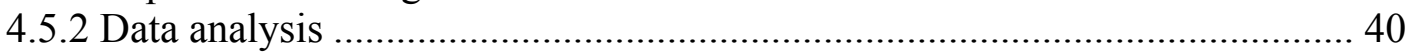

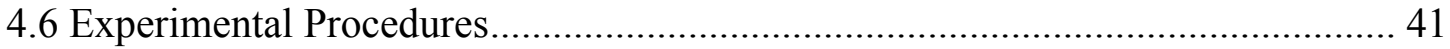

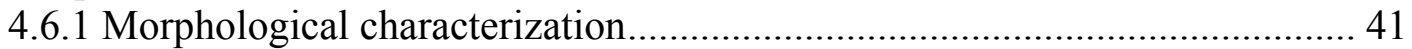

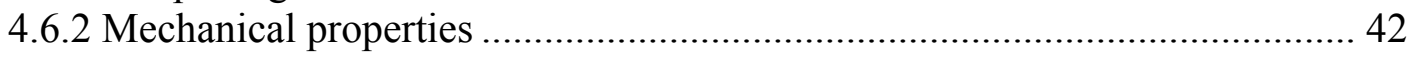

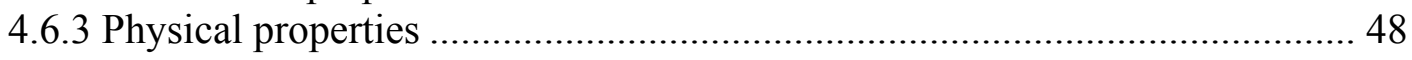

4.6.4 Melting points of composites .......................................................... 50

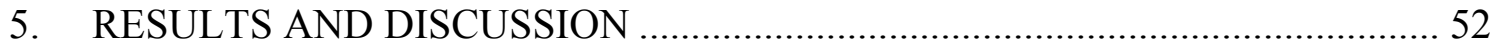

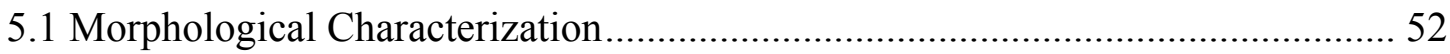

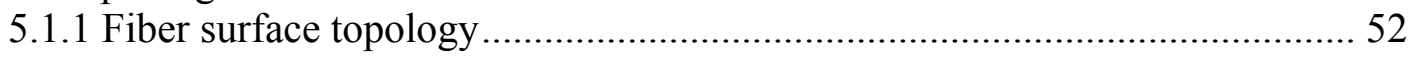

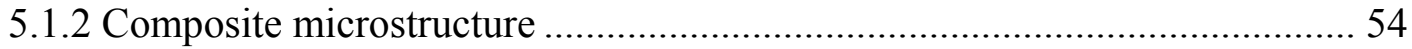

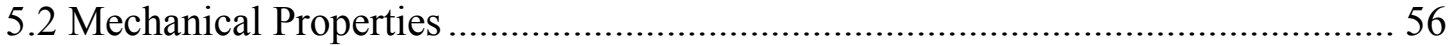

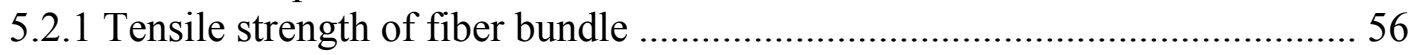

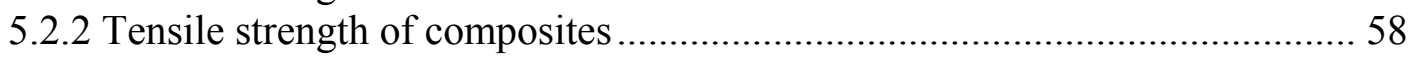

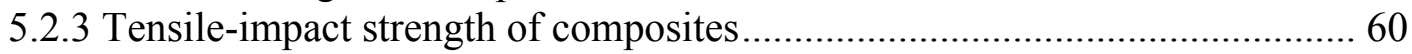

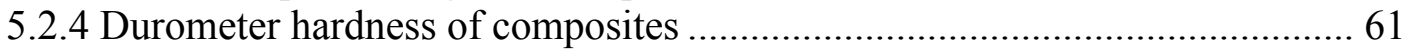

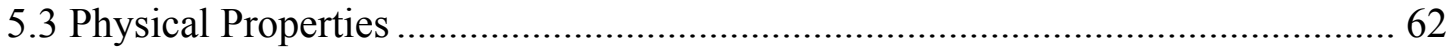

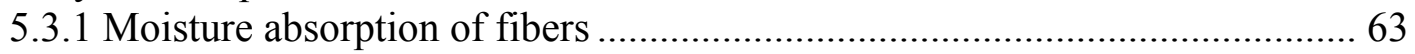

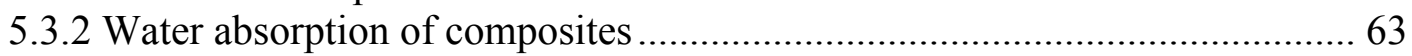

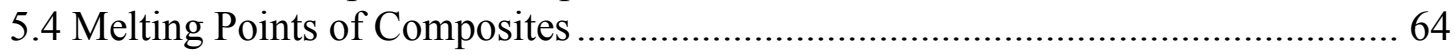

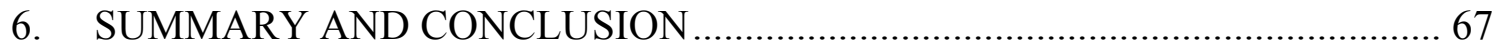

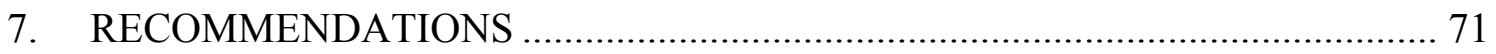

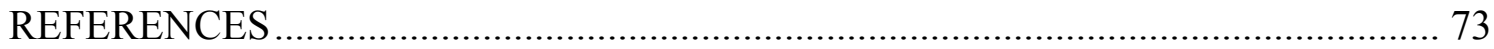

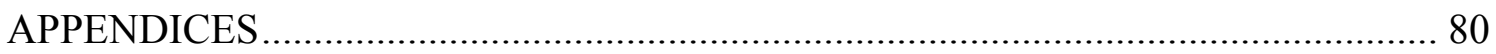

APPENDIX A

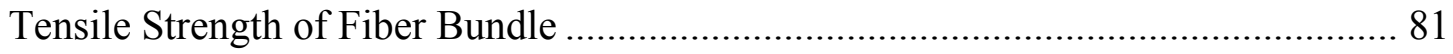

APPENDIX B

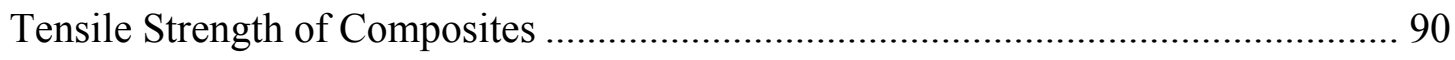

APPENDIX C

Tensile-Impact Strength of Composites 
APPENDIX D

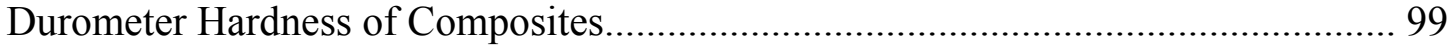

APPENDIX E

Moisture Absorption of Flax Fibers .................................................................... 102

APPENDIX F

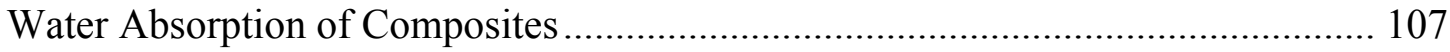

APPENDIX G

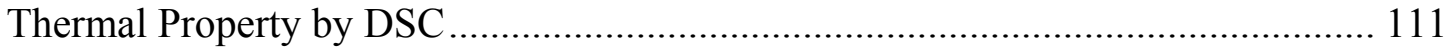

APPENDIX H

The SEM Micrographs of the Cross-session of HDPE and LLDPE/HDPE Flax Fiberreinforced Composites. 


\section{LIST OF FIGURES}

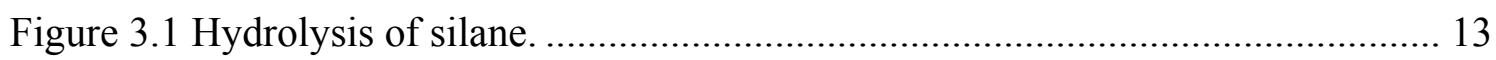

Figure 3.2 Hypothetical reaction of fiber and silane................................................... 14

Figure 3.3 A possible reaction between cellulosic-OH groups and benzoyl chloride. ... 15

Figure 3.4 Peroxide treatment reaction. ................................................................ 15

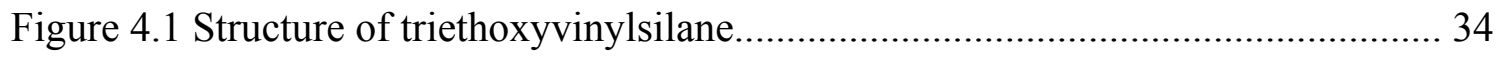

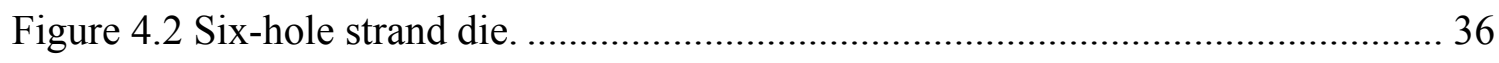

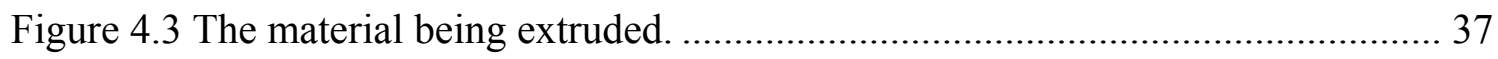

Figure 4.4 Rotational molding manufacturing process. ................................................ 38

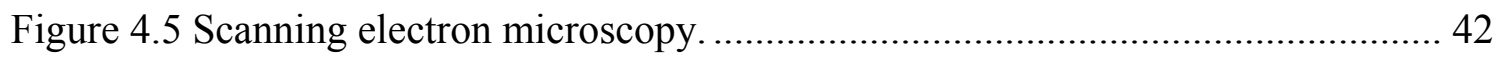

Figure 4.6 Set up for the tensile strength of fiber bundle............................................. 44

Figure 4.7 Force-deformation curve of a valid individual test...................................... 44

Figure 4.8 Tensile strength test of a composite sample using the Instron Universal

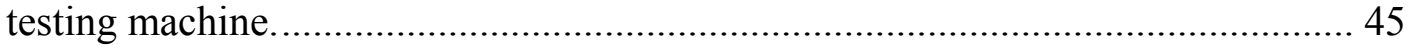

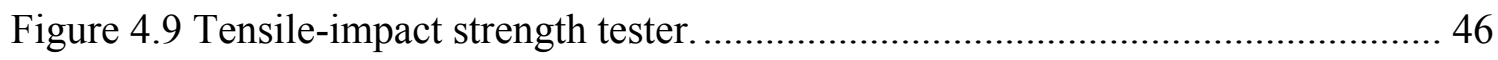

Figure 4.10 Type L tensile-impact specimens.............................................................. 47

Figure 4.11 Durometer hardness testing................................................................ 48

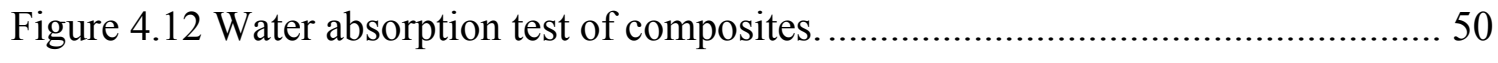

Figure 4.13 DSC melting point test of composites. ……….......................................... 51

Figure 5.1 SEM photographs of fiber surfaces after chemical treatment........................ 53

Figure 5.2 SEM micrographs of LLDPE with 10\% treated flax in composites.............. 55

Figure 5.3 Average unit break of flax fiber bundle................................................... 58 
Figure 5.4 Comparison of tensile strength at yield of $10 \%$ fiber with different

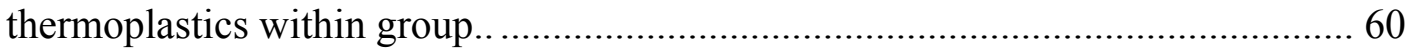

Figure 5.5 Tensile-impact strength of $10 \%$ pre-treated flax fibers compared to untreated flax fibers composites within group.

Figure 5.6 Durometer Hardness of 10\% flax fibers composites with different

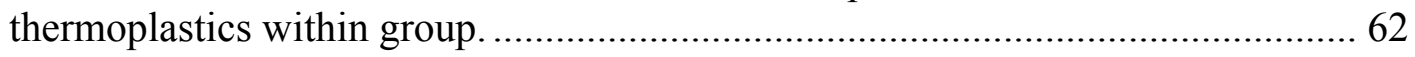

Figure 5.7 Moisture absorption of untreated and treated flax fibers at different

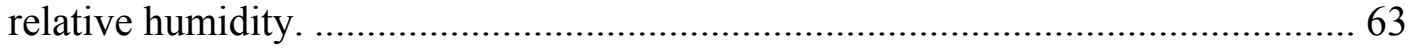

Figure 5.8 Water absorption of 10\% fiber-based composites within group.................... 64 


\section{LIST OF TABLES}

Table 3.1. Comparative properties of natural fibers and conventional man-made fibers 7

Table 3.2. Chemical composition and structural parameters of natural fibers................ 8

Table 3.3. Typical properties of three major thermoplastics.................................... 21

Table 4.1. Experimental design for three types of treated fibers. ................................ 39

Table 4.2. Property tests conducted on sample composites.................................... 40

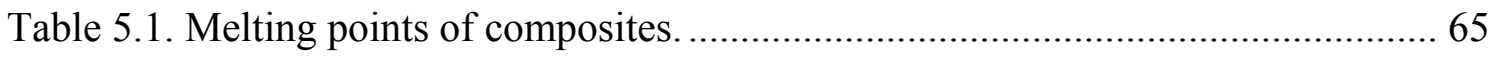




\section{INTRODUCTION}

Agriculture is an important sector in Western Canadian economy. Traditionally, agricultural materials have been shipped away for processing, or disposed of postharvest. Diversification of the industry is crucial in encouraging economic stability and growth. Value-added processing within Western Canada helps in agricultural diversification. Flax is an oilseed crop grown mostly in Saskatchewan and Manitoba. While the seed is processed for its high oil content, the biomass left behind tends to be a problem as it has strong fibers which breakdown very slowly under natural conditions. Traditionally, flax straw has been burned by farmers. Thus, the goal of this research has been to find a more environmentally responsible use for flax straw.

Traditional plastic materials are reinforced by glass fibers, which are both expensive and harmful to the environment. A flax-based biocomposite material contains polymers reinforced with flax fiber. There are a number of advantages of using flax fibers in biocomposites, among which are: a) flax fiber will make the material partially biodegradable; b) glass fiber is relatively expensive to make; c) flax is currently disposed of by burning; and d) flax has high tensile strength. Over the past decade, cellulosic fillers have been of greater interest as they give composites improved mechanical properties compared to those containing non-fibrous fillers. In recent years, thermoplastic materials have been increasingly used for various applications (Folkes 
1982). Natural fiber-reinforced thermoplastic composites form a new class of materials which seem to have good potential in the future as a substitute for wood-based material in many applications. However, lack of good interfacial adhesion and poor resistance to moisture absorption makes the use of natural fiber-reinforced composites less attractive. Various fiber surface treatments like mercerization, isocyanate treatment, acrylation, latex coating, permanagante treatment, acetylation, silane treatment and peroxide treatment have been carried out which may result in improving composite properties. Research on a cost effective modification of natural fibers is necessary since the main attraction for today's market of biocomposites is the competitive cost of natural fiber. Interfaces play an important role in the physical and mechanical properties of composites. Reinforcing fibers are normally given surface treatments to improve their compatibility with the polymer matrix. This thesis attempts to address the following question: do chemical treatments of flax fibers have any influence on the composite properties?

The creation of fiber-reinforced composites is a multi-step process. First the flax fiber is collected as straw and then, chemical and/or physical treatments are used to reduce it to its fibrous form. Next it is chopped to appropriate size and combined with synthetic polymer materials. A series of steps including extrusion and plastic molding techniques are used to develop the final product.

Flax fiber-reinforced composite has material properties similar to that of conventional plastic products. The environmental benefits of the fiber-reinforced composite are 
appealing to producers, consumers, and industry alike. The goal of this study is to determine the effects of pre-treated flax fibers on the performance of fiber-reinforced LLDPE, HDPE and HDPE/LLDPE composites. The vision is to develop an industry centered on the processing of flax fiber.

The objectives of this thesis follow the introduction. The chapter three contains a review of published literature relating to this subject. The literature review was used to guide this thesis in terms of its design, analysis, and expected trends. The methodology for the experimental work conducted is detailed in chapter four. The results and discussion on the effects of pre-treated flax fiber on the performance of composites follows. This thesis ends with a discussion on the results including conclusions and recommendations for future work. Data of tests appear in the Appendices. 


\section{OBJECTIVES}

Most of the research reviewed indicated that only a limited work had been done on silane, benzoylation and peroxide-treatment of natural fibers for use in composites. The overall goal of the project was to focus on these three chemical treatments of flax fibers for use in fiber-reinforced LLDPE, HDPE and HDPE/LLDPE biocomposites to achieve improved properties of composites. The specific objectives of this study were to:

1. investigate suitable fiber pre-treatment methods such as silane, benzoylation and peroxide treatment on their effects of flax fiber property;

2. explore a new method of manufacturing fiber-reinforced composites with the use of extrusion and rotational molding; and

3. study the effects of fiber surface modifications on the performance of flax fiberreinforced composites. 


\section{LITERATURE REVIEW}

This chapter presents a review of literature on pre-treatment of flax fibers for use in composites. In addition, the details of different chemical treatments of natural fibers, characteristics of thermoplastic, composite manufacturing processes and the effects of fiber modification on the composites is discussed.

\subsection{Properties of Natural Fibers}

To better understand the properties of natural fiber-reinforced composite materials, it is necessary to know the physical and chemical properties of natural fibers.

\subsubsection{Physical properties of natural fibers}

Depending on their origin, natural fibers can be grouped into seed, bast, leaf and fruit qualities. The bast and leaf (the hard fibers) types are the most commonly used in composite applications (Williams and Wool 2000). Examples of bast fibers include hemp, jute, flax, ramie and kenaf. Leaf fibers include sisal and banana.

Flax fiber is an important bast fiber from the dicotyledonous Linum usitatissimum plant native to the Middle East. Its color is pale cream to brown. It has been used for centuries in the manufacture of fine linens (Edwards et al. 1997). Flax is a plant with a single stem, nearly one meter in height. The diameter at the base varies between 1 to $2 \mathrm{~mm}$. 
The length of a fibril is around 15-20 mm. Vegetable fibers have density of about half that of glass fibers. These fibers can withstand processing temperatures up to $250^{\circ} \mathrm{C}$ (Sreekala et al. 2000). They are fully combustible without the production of either noxious gases or solid residues.

The strength characteristics of fiber depend on the properties of the individual constituents, the fibrillar structure and the lamellae matrix (Joseph et al. 2000). For an understanding of the mechanical properties and durability of fibers, the structural components of the fibers (cellulose, hemicellulose and lignin) will be examined. Additional characteristics include fiber strength, fiber fitness, the polymerization of the cellulose, cleanness or purity and homogeneity of the sample, but these are not essentially genotype dependent.

Jähn et al. (2002) reported that plant fiber properties directly influence the physical parameters of the fiber-reinforced composites. Flax fiber properties are controlled by the molecular fine structure of the fibers which is affected by growing conditions and the fiber processing technique used. Flax fibers possess moderately high specific strength and stiffness and can be used as reinforcement in polymeric resin matrix to make useful composite materials.

Natural fibers exhibit considerable variation in diameter along with the length of individual filaments. Quality and other properties of fibers depend on factors such as size, maturity and processing methods adopted for the extraction of fiber (Mohanty et al. 
2001). Properties such as density, electrical resistivity, ultimate tensile strength and initial modulus are related to the internal structure and chemical composition of fibers (Mohanty et al. 2001). Desirable properties for fibers include excellent tensile strength and modulus, high durability, low bulk density, good moldability and recyclability. Natural fibers have an advantage over glass fibers in that they are less expensive, abundantly available from renewable resources and have a high specific strength. Table 3.1 shows a comparison of properties of natural fibers and conventional man-made fibers.

Table 3.1. Comparative properties of natural fibers and conventional man-made fibers (Mohanty et al. 2000a).

\begin{tabular}{cccccc}
\hline Fiber & $\begin{array}{c}\text { Density } \\
\left(\mathbf{g} / \mathbf{c m}^{\mathbf{3}}\right)\end{array}$ & $\begin{array}{c}\text { Diameter } \\
(\boldsymbol{\mu m})\end{array}$ & $\begin{array}{c}\text { Tensile Strength } \\
(\mathbf{M P a})\end{array}$ & $\begin{array}{c}\text { Young's } \\
\text { Modulus }(\mathbf{G P a})\end{array}$ & $\begin{array}{c}\text { Elongation at } \\
\text { Break }(\%)\end{array}$ \\
\hline Jute & $1.3-1.45$ & $20-200$ & $393-773$ & $13-26.5$ & $7-8$ \\
Flax & 1.5 & - & $345-1100$ & 27.6 & $2.7-3.2$ \\
Hemp & - & - & 690 & - & 1.6 \\
Ramie & 1.5 & - & $400-938$ & $61.4-128$ & $1.2-3.8$ \\
Sisal & 1.45 & $50-200$ & $468-640$ & $9.4-22$ & $3-7$ \\
PALF & - & $20-80$ & $413-1627$ & $34.5-82.51$ & 1.6 \\
Cotton & $1.5-1.6$ & - & $287-800$ & $5.5-12.6$ & $7-8$ \\
Coir & 1.15 & $100-450$ & $131-175$ & $4-6$ & $15-40$ \\
E-glass & 2.5 & - & $2000-3500$ & 70 & 2.5 \\
S-glass & 2.5 & - & 4570 & 86 & 2.8 \\
Aramid & 1.4 & - & $3000-3150$ & $63-67$ & $3.3-3.7$ \\
Carbon & 1.7 & - & 4000 & $230-240$ & $1.4-1.8$ \\
\hline
\end{tabular}

\subsubsection{Chemical composition of natural fibers}

Natural fibers are complex in structure. They are generally lignocellulosic, consisting of helically wound cellulose micro fibrils in an amorphous matrix of lignin and hemicellulose. Table 3.2 shows natural fibers and their chemical and structural composition. 
Mechanical properties are determined by the cellulose content and microfibril angle. A high cellulose content and low microfibril angle are desirable properties of a fiber to be used as reinforcement in polymer composites (Williams and Wool 2000).

Table 3.2. Chemical composition and structural parameters of natural fibers (Mohanty et al. 2000a).

\begin{tabular}{|c|c|c|c|c|c|c|c|c|c|}
\hline Fiber & $\begin{array}{c}\text { Cellulose } \\
(\%)\end{array}$ & $\begin{array}{l}\text { Hemi- } \\
\text { cellulose } \\
(\%)\end{array}$ & $\begin{array}{c}\text { Lignin } \\
(\%)\end{array}$ & $\begin{array}{c}\text { Extra- } \\
\text { ctives } \\
(\%)\end{array}$ & $\begin{array}{l}\text { Ash } \\
(\%)\end{array}$ & $\begin{array}{c}\text { Pectin } \\
(\%)\end{array}$ & $\begin{array}{l}\text { Wax } \\
(\%)\end{array}$ & $\begin{array}{c}\text { Microfibril } \\
\text { /spiral } \\
\text { angle }\left(^{\circ}\right)\end{array}$ & $\begin{array}{c}\text { Moisture } \\
\text { content } \\
\text { (\% w. b.) }\end{array}$ \\
\hline \multicolumn{10}{|l|}{ BAST } \\
\hline Jute & $61-71.5$ & $13.6-20.4$ & $12-13$ & - & - & 0.2 & 0.5 & 8.0 & 12.6 \\
\hline Flax & $71-78.5$ & $18.6-20.6$ & 2.2 & 2.3 & 1.5 & 2.2 & 1.7 & 10.0 & 10.0 \\
\hline Hemp & $70.2-74.4$ & $17.9-22.4$ & $3.7-5.7$ & 3.6 & 2.6 & 0.9 & 0.8 & 6.2 & 10.8 \\
\hline Ramie & $68.6-76.2$ & $13.1-16.7$ & $0.6-0.7$ & - & - & 1.9 & 0.3 & 7.5 & 8.0 \\
\hline Kenaf & 31-39 & 15-19 & 21.5 & 3.2 & 4.7 & - & - & - & - \\
\hline \multicolumn{10}{|l|}{ LEAF } \\
\hline Sisal & $67-78$ & $10-14.2$ & $8-11$ & - & - & 10.0 & 2.0 & 20.0 & 11.0 \\
\hline PALF & $70-82$ & - & $5-12$ & - & - & - & - & 14.0 & 11.8 \\
\hline Henequen & 77.6 & $4-8$ & 13.1 & - & - & - & - & - & - \\
\hline \multicolumn{10}{|l|}{ SEED } \\
\hline Cotton & 82.7 & 5.7 & - & - & - & - & 0.6 & - & - \\
\hline \multicolumn{10}{|l|}{ FRUIT } \\
\hline Coir & $36-43$ & $0.15-0.25$ & $41-45$ & - & - & $3-4$ & - & $41-45$ & 8.0 \\
\hline \multicolumn{10}{|l|}{ WOOD } \\
\hline Soft & $40-44$ & $25-29$ & $25-31$ & 5 & 0.2 & - & - & - & - \\
\hline Hard & $43-47$ & $25-35$ & $16-24$ & $2-8$ & 0.4 & - & - & - & - \\
\hline
\end{tabular}

The cells of flax fiber consist mostly of pure cellulose, being cemented as fascicle bundles by means of non-cellulosic incrusting such as lignin, hemicellulose, pectin, protein or mineral substances, resins, tannins, dyers and a small amount of waxes and fat (Mustată 1997). A mature flax cell wall consists of about $70 \%$ to $75 \%$ cellulose, $15 \%$ hemicellulose and pectic materials. Cellulose is a natural polymer with high strength and stiffness per weight, and it is the building material of long fibrous cells.

Selective removal of non-cellulosic compounds constitutes the main objective of fiber 
chemical treatment. Both the hemicellulosic and pectic materials play important roles in fiber bundle integration, fiber bundle strength and individual fiber strength as well as water absorbency, swelling, elasticity and wet strength. The production of individual fibers without the generation of kink bands will generate fibers with much higher intrinsic fiber strength which is very useful for composite application (Mooney et al. 2001).

\subsubsection{Moisture absorption characteristics}

Natural fibers are hygroscopic in nature and they absorb or release moisture depending on environmental conditions. A major limitation of using natural fibers in durable composite applications is their high moisture absorption and poor dimensional stability (swelling) (Panigrahi et al. 2002). Swelling of fibers can lead to micro-cracking of the composite and degradation of mechanical properties. This problem can be overcome by treating these fibers with suitable chemicals to decrease the hydroxyl group in the fibers.

Stamboulis et al. (2000) reported that the moisture absorption and swelling of the treated flax fiber composites is approximately $30 \%$ lower than that of composites based on untreated flax fibers.

Strong intermolecular fiber-matrix bonding decreases the rate of moisture absorption in biocomposite. To increase the interface adhesion between the fiber and matrix, the fiber surface must be cleaned and chemically modified and the surface roughness must be increased (Yuan et al. 2002). 


\subsection{Chemical Treatment of Natural Fibers}

Natural fibers are amenable to modification as they bear hydroxyl groups from cellulose and lignin. The hydroxyl groups may be involved in the hydrogen bonding within the cellulose molecules thereby reducing the activity towards the matrix. Chemical modifications may activate these groups or can introduce new moieties that can effectively interlock with the matrix.

\subsubsection{Theoretical perspectives}

In principle, natural fiber-reinforced composites could offer specific properties comparable to those of conventional fiber composites; however, low interfacial properties between fiber and polymer matrix often reduce the potential of natural fibers as reinforcing agents (Mohanty et al. 2001). Interfaces play an important role in the physical and mechanical properties of composites (Joseph et al. 2000). In order to improve natural fiber-matrix adhesion, the matrix should be commonly modified to better match fiber surface properties. Conversely, simple chemical treatments can be applied to the fibers with the aim of changing surface tension and polarity through modification of fiber surface (Scandola et al. 2000).

Several classes of compounds are known to promote adhesion, by chemically coupling the adhesive to the material. Silane coupling agents are one of many ingredients in commercial sizing that are applied to fibers. The chemical composition of coupling agents allows them to react with the fiber surface and forms a bridge of chemical bonds

between the fiber and matrix (Al-Moussawi et al. 1993). Generally, coupling agents are 
molecules possessing two functions. The first function is to react with $\mathrm{OH}$ groups of cellulose and the second is to react with functional groups of the matrix. The selection of a coupling agent that can combine both strength and toughness to a considerable degree is important for a composite material to facilitate the optimum stress transfer at the interface between fiber and matrix. Several processes have been developed to modify polymers and fiber surfaces including chemical treatments, photochemical treatments, plasma treatments and surface grafting.

\subsubsection{Surface chemical modifications of natural fibers}

Several studies have shown the influence of various type of chemical modification on the performance of natural fiber and fiber-reinforced composites. The different surface chemical modifications of natural fibers such as mercerization, isocyanate treatment, acrylation, latex coating, permanganate treatment, acetylation, silane treatment and peroxide treatment with various coupling agents and others, have achieved various levels of success in improving fiber strength, fiber fitness and fiber-matrix adhesion in natural fiber composites. Brief descriptions of some important fiber chemical modifications are summarized in the following sub-sections.

\subsubsection{Mercerization (alkali treatment)}

Alkali treatment of cellulosic fibers, also called mercerization, is the usual method to produce high quality fibers (Ray et al. 2001). Alkali treatment improves the fiber-matrix adhesion due to the removal of natural and artificial impurities (Mishra et al. 2001a). Moreover, alkali treatment leads to fibrillation which causes the breaking down of the 
composite fiber bundle into smaller fibers. In other words, alkali treatment reduces fiber diameter and thereby increases the aspect ratio. Therefore, the development of a rough surface topography and enhancement in aspect ratio offer better fiber-matrix interface adhesion and an increase in mechanical properties (Joseph et al. 2000). Alkali treatment increases surface roughness resulting in better mechanical interlocking and the amount of cellulose exposed on the fiber surface. This increases the number of possible reaction sites and allows better fiber wetting.

The following reaction takes place as a result of alkali treatment:

Fiber- $\mathrm{OH}+\mathrm{NaOH}-$ Fiber- $\mathrm{O}^{-} \mathrm{Na}^{+}+\mathrm{H}_{2} \mathrm{O}$

Jähn et al. (2002) found that the cellulosic fine structure of the flax fibers was directly influenced by mercerization treatment. Moreover, alkali treatment influenced the chemical composition of the flax fibers, degree of polymerization and molecular orientation of the cellulose crystallites due to cementing substances like lignin and hemicellulose which were removed during the mercerization process. Consequently, mercerization or more general alkali treatment had a lasting effect on the mechanical behavior of flax fibers, especially on fiber strength and stiffness (Gassan and Bledzki 1999). Several other studies were conducted on alkali treatment (Mishra et al. 2002; Joseph et al. 2000; Sreekala et al. 2000). They reported that mercerization led to the increase in the amount of amorphous cellulose at the expense of crystalline cellulose and the removal of hydrogen bonding in the network structure. 


\subsubsection{Silane treatment}

Coupling agents usually improve the degree of cross-linking in the interface region and offer a perfect bonding result. Silane coupling agents were found to be effective in modifying the natural fiber-matrix interface. Various silanes were effective in improving the interface properties of wood-polypropylene (Coutinho et al. 1997), mineral-filled elastomers (González et al. 1997), fiber-reinforced epoxies (Culler et al. 1986) and phenolics composites (Ghatge and Khisti 1989). Alkoxy silanes are able to form bonds with hydroxyl groups. Coupling agents such as toluene dissocyanate and triethoxyvinyl silane were tested in fiber treatment in order to improve the interface properties. Silanes undergo hydrolysis, condensation and bond formation stage. Silanols can form polysiloxane structures by reaction with hydroxyl group of the fibers. The reaction schemes are given in Figure 3.1 and 3.2.

In the presence of moisture, hydrolyzable alkoxy group leads to the formation of silanols.

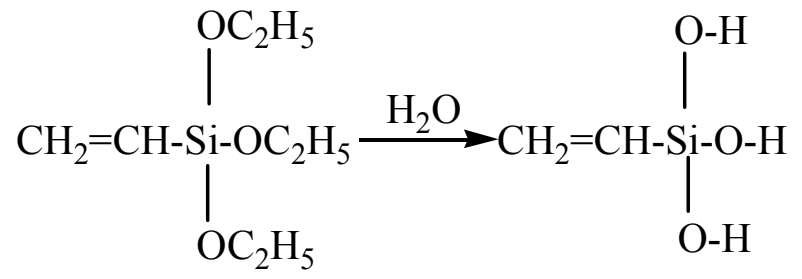

Figure 3.1 Hydrolysis of silane (Sreekala et al. 2000). 


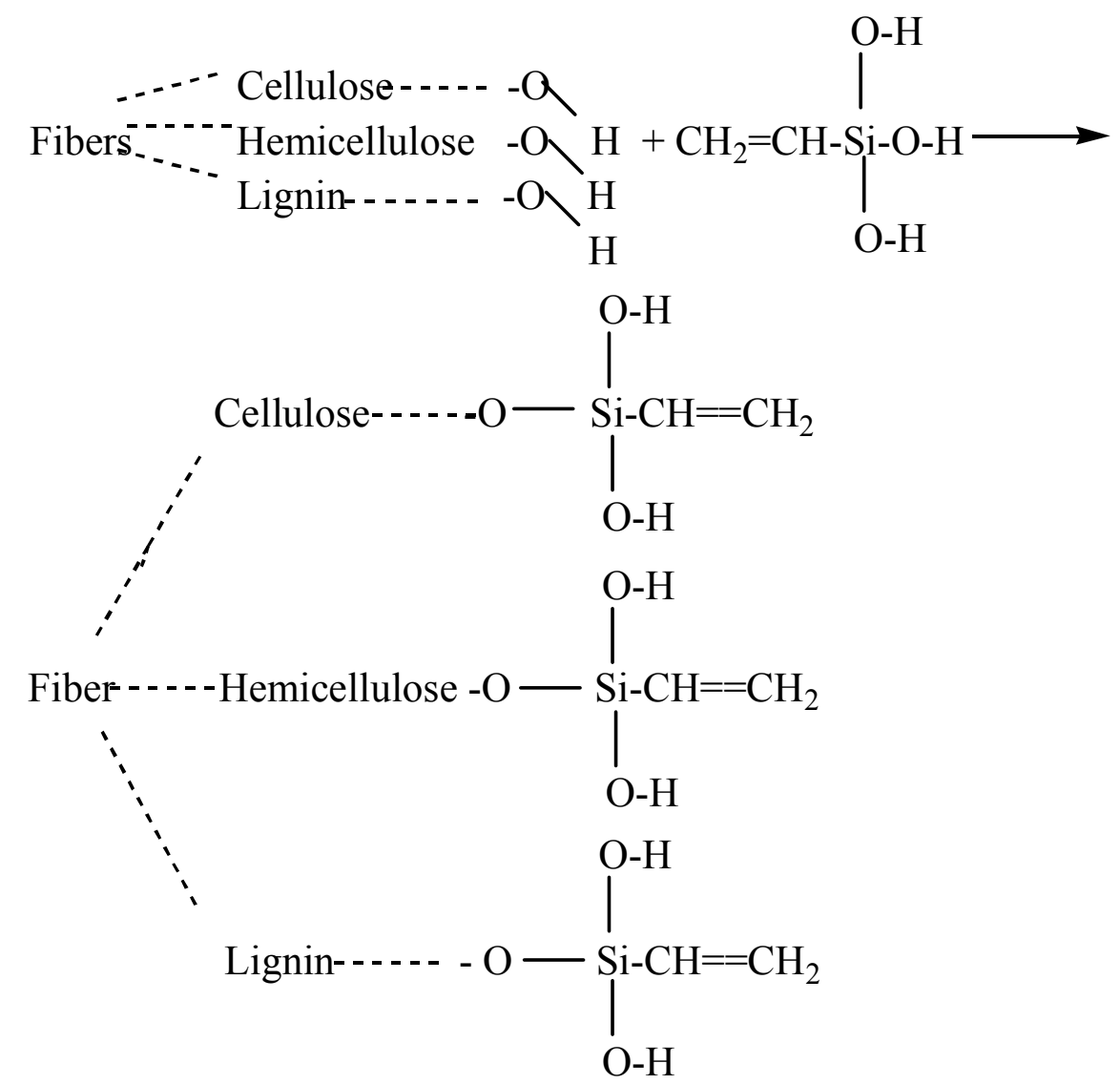

Figure 3.2 Hypothetical reaction of fiber and silane (Sreekala et al. 2000).

González et al. (1997) investigated the effect of silane coupling agent on the interface performance of henequen fiber-reinforced high-density polyethylene composites. The fiber-surface silanization resulted in better interfacial load transfer efficiency but did not improve the wetting of the fiber. Hydrogen and covalent bonding mechanisms could be found in the natural fiber-silane system. It was assumed that the hydrocarbon chains provided by the silane application influenced the wettability of the fibers, thus improving the chemical affinity to polyethylene.

Silane treatment of cellulosic fibers can increase the interfacial strength and therefore the mechanical properties of the composite (George et al. 1998; Bataille et al. 1989). 
Silane treatment also enhanced the tensile strength of the composite (Joseph et al. 2000).

\subsubsection{Benzoylation}

Manikandan Nair et al. (1996) reported that benzoylation of the fiber improved fiber matrix adhesion, thereby, considerably increasing the strength of composite. Joseph et al. (2000) studied the benzoylation treatment on the surface of fibers. A fixed amount of washed fiber $(35 \mathrm{~g})$ was soaked in $18 \% \mathrm{NaOH}$ solution for $0.5 \mathrm{~h}$, filtered and washed with water. The treated fiber was suspended in $10 \% \mathrm{NaOH}$ solution and agitated with 50 $\mathrm{ml}$ benzoyl chloride. The reaction between the cellulosic $-\mathrm{OH}$ group of sisal fiber and benzoyl chloride is shown in Figure 3.3 as follows:

$$
\text { Fiber }-\mathrm{OH}+\mathrm{NaOH} \longrightarrow \text { Fiber }-\mathrm{O}^{-} \mathrm{Na}^{+}+\mathrm{H}_{2} \mathrm{O}
$$

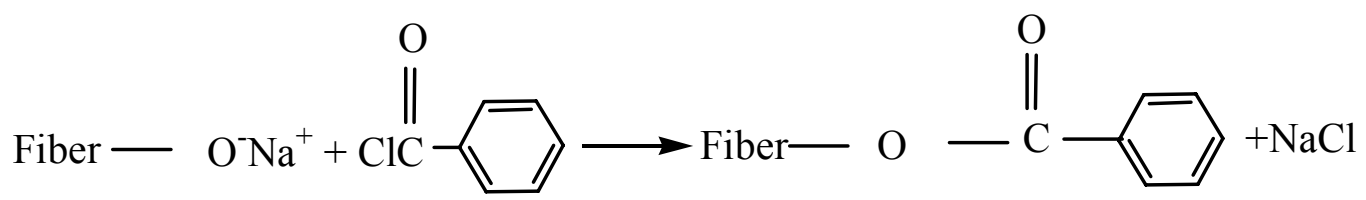

Figure 3.3 A possible reaction between cellulosic-OH groups and benzoyl chloride (Joseph et al. 2000).

\subsubsection{Peroxide treatment}

The decomposition of the peroxide and the subsequent reaction at the interface is expected at the time of curing of composites. Figure 3.4 shows the decomposition of the peroxides.

$$
\begin{gathered}
\mathrm{RO}-\mathrm{OR} \longrightarrow 2 \mathrm{RO} . \\
\text { RO.+ Cellulose }-\mathrm{H} \longrightarrow \mathrm{R}-\mathrm{OH}+\text { Cellulose. }
\end{gathered}
$$

Figure 3.4 Peroxide treatment reaction (Sreekala et al. 2000). 
Peroxide-induced adhesion in cellulose fiber-reinforced thermoplastic composites has attracted the attention of various researchers due to easy processability and improvement in mechanical properties. Sapieha et al. (1990) indicated that the addition of a small amount of benzoyl peroxide or dicumyl peroxide to cellulose-polymer (LLDPE) systems during processing improved the composite mechanical properties. The improvement of mechanical properties is attributed to the peroxide-induced grafting of polyethylene onto cellulose surfaces.

Joseph et al. (2000) investigated benzoyl peroxide treatment on short sisal fiberreinforced polyethylene composites. They reported that peroxide-treated composites showed an enhancement in tensile properties due to the peroxide-induced grafting. Sreekala et al. (2000) also studied benzoyl peroxide treatment on oil palm fiberreinforced phenol formaldehyde composites. Fibers were coated with benzoyl peroxide from acetone solution after alkali pre-treatments. High temperature was favored for decomposition of the peroxide. They reported that peroxide-treated fiber composites could withstand the tensile stress to higher strain level.

\subsubsection{Other chemical treatment methods}

Several interface modification methods were reported in literature. Acetylation of natural fibers is a well-known esterification method to introduce plasticization to cellulosic fibers. Acetylation has been extensively applied to wood cellulose to stabilize the cell wall, improving dimensional stability and environmental degradation. One of the modification techniques employed by the Okura Company in Japan was to produce 
esterified woods (Mohanty et al. 2001), which would be molded into plastic sheets by hot pressing.

Another effective method of surface chemical modification of natural fibers is graft copolymerization. Optimized vinyl grafted natural fibers, consisting of the orderly arrangement of grafted moieties, act as compatible reinforcing fibers with several resin systems to obtaining better fiber-matrix adhesion of the resulting biocomposites (Mohanty et al. 2001; Ghosh and Ganguly 1993).

Isocyanate has a functional group $-\mathrm{N}=\mathrm{C}=\mathrm{O}$ which is very susceptible to reaction with the hydroxyl group of cellulose and lignin in the fibers and forms strong covalent bonds, thereby creating better compatibility with the binder resin in the composites. Kokta et al. (1990a) and Raj et al. (1988) pointed to the performance of isocyanate as a coupling agent. Isocyanates provided better interaction with thermoplastics resulting in superior properties. Isocyanates could act as a promoter or as an inhibitor of interaction.

The radical enhances the chemical interlocking at the interface. Permanganate treatment was carried out to improve the bonding at the fiber-polymer interface. Joseph et al. (2000) and Sreekala et al. (2000) investigated the fibers which were pre-treated with alkali and then dipped in permanganate solution in acetone. Tensile strength values of the composite showed a marginal increase with permanganate treatment.

Mustată (1997) studied the sodium chlorite treatment on the surface of bleached flax. 
The experiment focused on the links of fibers formed between lignin and carbohydrates. The stability of pluricellular fibers were subjected to mechanical stresses. Removal of a part of the flax fibers' noncellulosic compounds by chemical treatments was reflected in the mechanical and physical characteristics of the surface state, as well as in the fibers' behavior during processing and wearing.

Acrylation treatment, maleated polypropylene/maleic anhydride treatment and titanate treatment of cellulosic fibers have also been reported (Sreekala et al. 2000; Mohanty et al. 2001; Monte and Sugerman 1984). Acrylation treatment resulted in high strain values of the composites. The composites ability to withstand the applied flexural stress is manifested by higher strain values, which indicate the elastic nature of the material. Maleated polypropylene or maleic anhydride grafted polypropylene (MAPP) has been widely used as a coupling agent or a compatibilizer in natural fiber reinforced polypropylene composites. The treatment of natural fibers with MAPP copolymer provides covalent bonds across the interface. Through such treatment, the surface energy of the fibers is increased, thereby providing better wettability and high interfacial adhesion. Many other compounds such as chromium complexes and titanates can be used as coupling agents. The processing of composites with titanate coupling agents found that the deposition of a monolayer of organ functional titanate eliminated the water of hydration. This enhanced the dispersion and compatibility at the interface.

\subsection{Development of Natural Fiber Composites}

Since 1941, the study on composites, particularly natural fiber-reinforced plastics has 
gained increasing attention of researchers and manufacturers (Joseph et al. 2000). The increased interest in natural fiber-reinforced composites is due to the high performance in mechanical properties, significant processing advantages, excellent chemical resistance, low cost and low density. They have long served many useful purposes but the application of material technology for the utilization of natural fibers as reinforcement in polymer matrix has taken place in recent years. Biocomposite consists of a polymer as the matrix material and a natural fiber as the reinforcing element. The use of fibers derived from annually renewable resources, such as reinforcing fibers, provide positive environmental benefits with respect to ultimate disposability and raw material utilization.

Recent studies indicate that plant-based natural fibers can be used as reinforcement in polymer composites, replacing the expensive and non-renewable synthetic fibers such as glass, because of their potential for recyclability (Mohanty et al. 2001). Vegetable fibers can serve as excellent reinforcing agent for plastics because of their moderately high specific strength and stiffness which is used as reinforcing materials in polymeric resin matrices to make useful structural composite materials (Joseph et al. 2000). Cellulosebased natural fibers are a potential resource for making low cost composite materials. Cellulosic fillers of a fibrous nature have been of greater interest, because they would give composites with improved mechanical properties compared to those containing non-fibrous fillers. Lignocellulosic fibers like jute, sisal, coir, and pineapple have been reportedly used as reinforcements in polymer matrix (Joseph et al. 2000). 
Published data (Zaini et al. 1996; Woodhams et al. 1984) show that various commercial wood fibers have good potential as reinforcements in thermoplastics. Biocomposites can make more value-added products from bioplastics and will get more attention in the future.

\subsection{Characteristics of Thermoplastic Polymers}

Thermoplastic polymers constitute an important class of materials with a wide variety of applications (Kokta et al. 1983). They are capable of being re-melted without any change in chemical structure or properties. Polyethylene, polypropylene, polystyrene and polyvinyl chloride are the most common thermoplastic polymers and are frequently called commodity polymers (Crawford and Throne 2000). As long as processing does not mechanically damage the thermoplastic polymer structure, these polymers are considered recyclable. Besides the use of "pure" polymer for structural purposes, it is also used as a matrix for fiber-reinforced composites. These composites are mostly based on the traditional reinforcement fibers such as glass fibers. However, natural fibers can also be used as reinforcement. Polymers have a different affinity towards the fiber owing to the difference in their chemical structure. In the search for the most suitable thermoplastic matrix for a flax fiber-reinforced composite, density and temperature related properties seems to be limiting criteria (Mohanty et al. 2001).

Low-density polyethylene (LDPE), high-density polyethylene (HDPE) and linear lowdensity polyethylene (LLDPE) will be used as major matrix for reinforcement. These thermoplastic polymers are widely used and have a melting point compatible with 
natural fibers. Their low melting points also allow processing below the degradation temperature of the fibers. Table 3.3 lists typical properties of three major thermoplastics.

Table 3.3. Typical properties of three major thermoplastics (www.azom.com).

\begin{tabular}{|c|c|c|c|c|c|c|c|}
\hline $\begin{array}{l}\text { Polymer } \\
\text { Type }\end{array}$ & $\begin{array}{l}\text { Density } \\
\left(\mathrm{g} / \mathrm{cm}^{3}\right)\end{array}$ & $\begin{array}{c}\text { Degree of } \\
\text { Crystallinity }\end{array}$ & $\begin{array}{c}\text { Glass } \\
\text { Transition } \\
\text { Temperature } \\
\left({ }^{\circ} \mathrm{C}\right)\end{array}$ & $\begin{array}{c}\text { Crystal } \\
\text { Melting } \\
\text { Temperature } \\
\left({ }^{\circ} \mathrm{C}\right)\end{array}$ & $\begin{array}{c}\text { Tensile } \\
\text { Strength } \\
\text { (MPa) }\end{array}$ & $\begin{array}{c}\text { Elongation } \\
\text { at Break } \\
(\%)\end{array}$ & $\begin{array}{c}\text { Flexural } \\
\text { Modulus } \\
\text { (GPa) }\end{array}$ \\
\hline $\begin{array}{l}\text { High-density } \\
\text { polyethylene } \\
\text { (HDPE) }\end{array}$ & $0.95-0.97$ & high & -120 & 137 & $20-30$ & $10-1,000$ & $1-1.5$ \\
\hline $\begin{array}{l}\text { Low-density } \\
\text { polyethylene } \\
\text { (LDPE) }\end{array}$ & $0.92-0.93$ & moderate & -120 & 110 & $8-20$ & $100-650$ & $0.25-0.35$ \\
\hline $\begin{array}{l}\text { Linear low- } \\
\text { density } \\
\text { polyethylene } \\
\text { (LLDPE) }\end{array}$ & $0.91-0.94$ & high & -74 & $122-124$ & 20 & $100-500$ & 0.35 \\
\hline
\end{tabular}

\subsubsection{High-density polyethylene (HDPE)}

High-density polyethylene (HDPE), also known as linear polyethylene or low-pressure polyethylene, is the preferred polyethylene for chemical containers of all sizes primarily due to its exceptional environment stress crack resistance (Crawford and Throne 2000). It has excellent stiffness from room temperature to the boiling point of water. Even though HDPE is frequently called linear polyethylene, it still has some short chain branching. Nevertheless, its linear nature and its high backbone mobility allow it to crystallize from $75 \%$ to $90 \%$ of theoretical. The crystalline structure causes the product to have a milky, translucent appearance. Since the crystallite is more ordered and more tightly packed than the amorphous phase, the density of HDPE is typically around 960 $\mathrm{kg} / \mathrm{m}^{3}$ approaching the theoretical value of $1000 \mathrm{~kg} / \mathrm{m}^{3}$. Many HDPEs are formulated for extrusion and blow molding applications (Crawford and Throne 2000). 


\subsubsection{Linear low-density polyethylene (LLDPE)}

LLDPE has side chains similar to those of LDPE but with proper catalysts and coreactive agents, the chains are dramatically reduced in length (Crawford and Throne 2000). LLDPE has a density range of $910 \mathrm{~kg} / \mathrm{m}^{3}$ to about $940 \mathrm{~kg} / \mathrm{m}^{3}$, and is $65 \%$ to $75 \%$ crystalline at room temperature. Competitive with LDPE, the 'linear low' materials have found rapid acceptance because of their high toughness (at low, normal and high temperatures), improved stiffness, chemical resistance, tensile strength, elongation at break and puncture resistance. However, it has somewhat poorer impact strength when compared with LDPE and MDPE. Suppliers have emphasized more specifically the improved resistance to environmental stress cracking (Brydson 1989).

In Lee and Joo's study (1999), a thermoplastic LLDPE resin was used as the matrix for fiber composites. Its low processing temperature (less than $130^{\circ} \mathrm{C}$ ) made composite fabrication possible without partial melting or annealing of the fibers. The high toughness of LLDPE yielded a good impact-resistant composite and had advantages of thermoplastic composite processing, such as short processing time, unlimited storage time and solvent free processing.

\subsubsection{Low-density polyethylene (LDPE)}

Low-density polyethylene (LDPE), also referred to as high-pressure polyethylene or branched polyethylene, has extensive side chains, up to about 100 ethylene units in length. The long branches tend to inhibit molecular organization during cooling. As a

result, LDPEs typically have relatively low densities of $910 \mathrm{~kg} / \mathrm{m}^{3}$ to $925 \mathrm{~kg} / \mathrm{m}^{3}$ and 
relatively low crystallinity of $45 \%$ to $66 \%$. LDPEs are relatively soft polyethylene with flexural modulus ranging between 0.24 and $0.35 \mathrm{GPa}$. Owing to the high number of tertiary hydrogen, LDPE does not have good environmental stress crack resistance (ESCR). Nevertheless, LDPEs mold well at low temperatures that accurately replicate mold surfaces (Crawford and Throne 2000).

\subsection{Composites Manufacturing}

A systematic study of the process variables for composites based on different natural fibers like flax, jute, sisal, ramie, and pineapple has been made with a view to determine the most suitable processing conditions for such composites by some researchers. Some major methods of molding are rotational molding, compression molding, injection molding and extrusion. Alternative processing methods of natural fiber-reinforced composites are an important advancement necessary for their increased use.

\subsubsection{Rotational molding}

Rotational molding is a process for manufacturing hollow plastic products. Rotational molding involves power mixing, melting, sintering and melt solidification. Various aspects of the rotational molding process have been studied by several researchers (Throne 1979; Crawford 1992). Fundamental research on rotational molding has been directed to reduce the molding cycle time and to optimize the mechanical properties of final parts. Polyethylene accounts for more than $80 \%$ of the total production (Bellehumeur and Vlachopoulos 1998). Rotational molding has particular advantages in terms of relatively low levels of residual stresses and inexpensive molds. Rotational 
molding also has few competitors for the production of large $\left(>2 \mathrm{~m}^{3}\right)$ hollow objects in one piece. Currently, the rotational molding industry is in its exciting development. Important new market sectors are opening up as rotational molders are able to deliver high quality parts at competitive prices.

\subsubsection{Extrusion}

The extrusion process basically consists of continuously shaping a fluid polymer through the orifice of a suitable tool (die), and subsequently solidifying it into a product (Hensen 1997). In the case of thermoplastics, the feed material, in powder or pellet form, is now most commonly heated to a fluid state and pumped into the die. Oladipo et al. (1999) investigated the composite (aspen wood fiber/HDPE) manufacturing process. The components were fed at pro-determined mass flow rates, based on the desired wood fiber mass fraction in the composite, into a ZSK-30 Werner \& Pfleiderer extruder (Werner \& Pfleiderer Ltd., Marple, Cheshire, UK) having $28 \mathrm{~mm}$ co-rotating twin screws. The extruder was operated at a working temperature of $150^{\circ} \mathrm{C}$ and a screw speed of $100 \mathrm{rpm}$. This temperature ensured that while the polymer was fully melted (melting point is $\left.120-135^{\circ} \mathrm{C}\right)$, the wood fibers were not burned.

\subsection{Effects of Fiber Surface Modifications on Fibers}

The chemical modification directly influences the cellulosic fine structure of natural fiber. This section reviews the effects of fiber modification on the stress-strain behaviour and tensile properties of flax fibers. 


\subsubsection{Stress-strain behavior}

The mechanical performance of fibers is dependent upon its chemical composition, chemical structure and cellular arrangement. Sreekala et al. (2000) performed tensile stress-strain test for untreated and modified oil palm fiber. Each individual fiber was composed of fibrils held together by non-cellulosic substances, such as lignin and pectin. Failure of the fiber was gradual upon the application of tensile stress. It showed intermediate behavior between brittle and amorphous. As stress gradually increased, some of the fibrils may have slipped out. The total of the stress was then sheared by fewer cells. Further increase of stress led to the rupture of cell walls and decohesion of cells. This resulted in a catastrophic failure of the fiber. Modifications led to major changes on the fibrillar structure of the fiber. It removed the amorphous components. This changed the deformation behavior of the fibers. The brittleness of the fiber was substantially reduced upon treatments.

\subsubsection{Tensile properties of flax fibers}

Sreekala et al. (2000) measured the tensile properties of untreated and modified fibers, such as tensile strength, Young's modulus and elongation at break. Many of the modifications decreased the strength properties due to the breakage of the bond structure, and also due to the disintegration of the non-cellulosic materials. Some of the treatments, like silane and acrylation, led to strong covalent bond formation and thereby the strength was enhanced marginally. Optimum mechanical performance was observed for silane-treated and acrylated fiber. The reinforcing ability of the fibers did not just depend upon the mechanical strength of the fibers but on many other features, such as 
polarity of the fiber, surface characteristics and presence of reactive centers. These factors control interfacial interaction. The Young's modulus of the fibers improved upon acrylation, alkali and silane treatment. The improved stiffness of the fibers was attributed to the crystalline region (cellulosic) of the fiber. The fiber also showed very good elongation properties, with values increasing upon modifications. Lower elongation of the untreated fiber may be due to the three dimensionally cross-linked networks of cellulose and lignin. Treatment broke this network structure giving the fiber higher elongation and lower strength properties.

Mishra et al. (2001b) investigated the tensile properties of untreated, chemically modified and AN-grafted sisal fibers. Chemically modified fibers showed an appreciable decrease in the tensile properties. This decrease was attributed to the substantial delignification and degradation of cellulosic chains during chemical treatment. The extension at break of these fibers did not change much. In all the cases of grafting, it has been found that the tensile strengths were higher than that of untreated fiber.

\subsection{Effects of Fiber Surface Modifications on Composite Properties}

Chemical treatments will be necessary to strengthen the interface between fiber and matrix. Several studies have been conducted on the influence of various types of chemical modifications on the properties of natural fiber-reinforced thermoplastic composites (Mansour et al. 1983; Manrich and Agnelli 1989; Kenaga et al. 1962). This section reviews the effects of fiber modification on the mechanical properties, thermal properties and macro-mechanical properties of composites. 


\subsubsection{Mechanical properties of composites}

The mechanical properties of a natural fiber-reinforced composite depend on many parameters, such as fiber strength, modulus, fiber length and orientation, in addition to the fiber-matrix interfacial bond strength. A strong fiber-matrix interface bond is critical for high mechanical properties of composites. A good interfacial bond is required for effective stress transfer from the matrix to the fiber whereby maximum utilization of the fiber strength in the composite is achieved (Karnani et al. 1997). Modification to the fiber also improves resistance to moisture-induced degradation of the interface and the composite properties (Joseph et al. 2000). In addition, factors like processing conditions/techniques have significant influence on the mechanical properties of fiberreinforced composites (George et al. 2001).

Sapieha et al. (1989; 1990) have found that by the addition of a small amount of dicumyl peroxide or benzoyl peroxide into the cellulosic fiber-polymer (LDPE) systems during processing significantly improved the mechanical properties of the composite. Kokta et al. (1990a; 1990b) have extensively studied the effect of different chemical modifications, such as silane treatment and grafting, on the mechanical properties and dimensional stability of cellulosic fiber-thermoplastic composites. They found that the chemically modified cellulosic fiber-reinforced thermoplastic composites offered superior physical and mechanical properties under extreme conditions even after recycling. Ray et al. (2001) have employed the technique on jute and found that the improvements occurred on the fiber properties. Münker and Holtmann (1998) studied different natural fibers (flax, ramie, curaua) and matrices (polyester, polypropylene). 
Their findings showed that mechanical properties of natural fiber-reinforced composites could be improved by the use of different coupling agents.

\subsubsection{Tensile properties of composites}

Natural fiber-reinforced composites often show enhancement in tensile properties upon different modifications owing to the increased fiber-matrix adhesion. Tensile properties can be explained on the basis of the changes in chemical interactions at the fiber-matrix interface. The tensile strength of flax fiber-reinforced composites is determined both by the tensile strength of the fibers and the presence of weak lateral fiber bonds.

Sreekala et al. (2000) performed one of the pioneering studies on the mechanical performance of treated oil palm fiber-reinforced composites. They studied the tensile stress-stain behavior of composites having $40 \%$ by weight fiber loading. Isocyanante-, silane-, acrylated, latex coated and peroxide-treated composite withstood tensile stress to higher strain level. Isocyanate treated, silane treated, acrylated, acetylated and latex coated composites showed yielding and high extensibility. Tensile modulus of the composites at $2 \%$ elongation showed slight enhancement upon mercerization and permanganate treatment. The elongation at break of the composites with chemically modified fiber was attributed to the changes in the chemical structure and bondability of the fiber. Alkali treated (5\%) sisal-polyester biocomposite showed about $22 \%$ increase in tensile strength (Mishra et al. 2002). Ichazo et al. (2001) found that adding silanetreated wood flour to PP produced a sustained increase in the tensile modulus and tensile strength of the composite. Joseph and Thomas (1993) studied the effect of chemical 
treatment on the tensile and dynamic mechanical properties of short sisal fiberreinforced low density polyethylene composites. It was observed that the CTDIC (cardanol derivative of toluene diisocyanate) treatment reduced the hydrophilic nature of the sisal fiber and enhanced the tensile properties of the sisal-LDPE composites. They found that peroxide and permanganate treated fiber-reinforced composites showed an enhancement in tensile properties. They concluded that with a suitable fiber surface treatment, the mechanical properties and dimensional stability of sisal-LDPE composites could be improved. Mohanty et al. (2000b) studied the influence of different surface modifications of jute on the performance of the biocomposites. More than a $40 \%$ improvement in the tensile strength occurred as a result of reinforcement with alkali treated jute. Jute fiber content also affected the biocomposite performance and about $30 \%$ by weight of jute showed optimum properties of the biocomposites.

\subsubsection{Impact properties of composites}

Fibers have a significant effect on the impact resistance through the principle of stress transfer. When an impact load is applied perpendicular to the reinforcing fibers, good fiber-matrix adhesion is required for even moderate impact strength (Nielsen 1974). The impact properties of the polymeric materials are directly related to the overall toughness of the material (Shah 1998). Toughness is defined as the ability of the polymer to absorb applied energy. Impact resistance is the ability of a material to resist breaking under a shock loading or the ability to resist fracture under stress applied at high speed.

Detailed studies have already been done on the impact resistance of short fiber- 
reinforced composites (Kau 1990; Jang et al. 1990; Reed and Bevan 1993). The impact resistance of fiber-reinforced composite depends on fiber rigidity, interfacial stress resistance and fiber aspect ratio. The strength of the matrix, the weakest part of the material, should be related to the failure process. The involvement of fibers in the failure process is related to their interaction with the crack formation in the matrix and their stress transferring capability. The total energy dissipated in the composite before final failure occurs is a measure of its impact resistance. The total energy absorbed by the composite is the sum of the energy consumed during plastic deformation and the energy needed for creating new surfaces.

\subsubsection{Macro-mechanical properties of composites}

The macro-mechanical properties of composites are attributed to an increase in the interfacial shear strength (ISS) of the modified composites. The ability to control the chemical and mechanical properties of the fiber-matrix interphase is crucial. Interface studies of untreated and surface treated sisal-polyester composites has been investigated to determine fiber splitting, fiber pullout, debonding, matrix cracking and fiber-matrix interaction using scanning electron microscopy (Mishra et al. 2002). Scanning electron micrographs of the tensile fracture of the composites revealed the failure mechanisms and impact fracture morphology. Fiber breakage was the main failure criteria observed. They also reported that in the untreated sisal composite, a clean pullout of fibers without any adhering resin matrix was observed. This proved that there was very poor adhesion between fiber and matrix. The 5\% alkali-treated sisal composite showed better fibermatrix interaction as observed from the good dispersion of fibers in the matrix system 
predicting micropores at the interface. Morphological studies showed that the MAPP and silane treatment improved the polymer-wood flour (WF) adhesion and the dispersion of the particles while the alkaline treatment only improved the dispersion (Ichazo et al. 2001).

\subsubsection{Thermal properties of composites}

A quick method for determining the threshold values for processing temperature is done by thermal analysis. Thermogravimetric (TG) analyses are carried out with a thermal balance. The thermo gravimetric degradation curve provides information about the thermal stability of a material (Shah 1998).

Wielage et al. (1999) used differential scanning calorimetry (DSC) to determine the melting point of the flax-reinforced polypropylene and to collect caloric data. DSC is a thermo-analytical technique in which the heat flow is measured as a function of temperature or time. They subjected the flax-reinforced polypropylene to a defined temperature regime under controlled atmosphere and reported that the melting range of the polymer matrix was displayed as an endothermic peak. An increased heating rate leads to a displacement of the melting range to higher temperatures. Powell et al. (2002) considered the effect of the matrix on the heating of flax fiber-reinforced composites. They reported that pure HDPE showed degradation beginning at approximately 410$430^{\circ} \mathrm{C}$. Therefore, the matrix absorbed a great amount of heat, taking the thermal stress off of the flax fiber. 


\subsection{Summary}

Most research reviewed indicated the effect of alkali treatment, isocyanate treatment, acrylation, latex coating, permanganate treatment, acetylation on the fiber-reinforced composite. Only few studies in literature were related to silane treatement, benzoylation and peroxide treatment in improving fiber strength, fiber-matrix adhesion and the performance of the natural fiber composites. The results of these studies were limited. This research was conducted on three chemical modifications. There is a lack of measurement of fiber bundle tensile strength. The method used in this research involved measuring the thermal properties of the composite using the differential scanning calorimetry. A multi-step process of production of fiber-reinforced composites by rotational molding was reviewed. In this research, the effect of chemical modification on the performance of the fiber-reinforced composites was studied. 


\section{MATERIALS AND METHODS}

In this chapter, the materials and devices, experimental procedures and data acquisition used to complete the experiments are presented. Data used throughout the development of this thesis to obtain the tables and figures presented can be found in its original form in the Appendices.

\subsection{Materials}

Flax fibers were derived from linseed flax grown in Saskatchewan and decorticated on a standard scutching mill at Durafiber in Canora, SK. The fibers were first washed thoroughly with $2 \%$ detergent water and dried in an air oven at $70^{\circ} \mathrm{C}$ for $24 \mathrm{~h}$. The dried fibers were designated as untreated fibers. Flax fibers were then subjected to sequential extraction with 1:2 mixture of ethanol and benzene for $72 \mathrm{~h}$ at $50^{\circ} \mathrm{C}$, followed by washing with double distilled water and air drying to remove waxes and water soluble ingredients prior to chemical treatments. Reagent grade chemicals were used for fiber surface modifications, namely, sodium hydroxide $(\mathrm{NaOH})$, benzoyl chloride, ethanol, dicumyl peroxide, acetone and alcohol. The structure of coupling agent, triethoxyvinylsilane (Aldrich Chemical Co. Ltd.) is shown in Figure 4.1.

In this series of experiments, high-density polyethylene, linear low-density polyethylene (HDPE 8761.27 and LLDPE 8460.29, Exxon Mobil, Toronto, ON) and LLDPE/HDPE 
25087 (NOVA Chemicals Ltd., Calgary, AB) were used as polymer matrix materials.

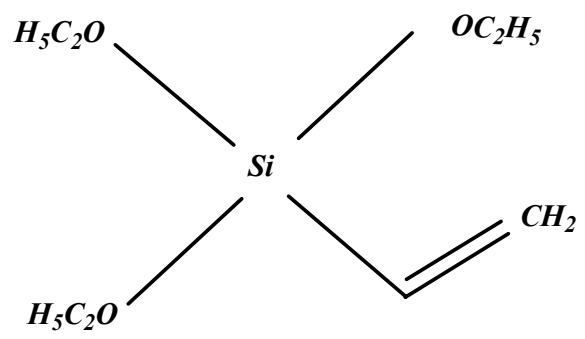

Figure 4.1 Structure of triethoxyvinylsilane (Aldrich Chemical Co. Ltd.).

\subsection{Fiber Surface Treatment}

Generally, the first step in chemical treatment is the mercerization process (pretreatment process) of all the fiber samples which cause changes in the crystal structure of cellulose. Fibers were soaked in 5-18\% $\mathrm{NaOH}$ (silane treatment: $5 \%$, benzoylation: $18 \%$, peroxide treatment: $10 \%$ ) for about half an hour in order to activate the $\mathrm{OH}$ groups of the cellulose and lignin in the fiber. The appropriate concentration of $\mathrm{NaOH}$ solution used in mercerization before each type of chemical treatment was completed in the initial work. Sreekala et al. (2000) indicated that a 10-30\% sodium hydroxide solution produced the best effects on natural fiber properties. Flax fibers were soaked into 2.5, 5, $10,13,15,18,20,25$, or $30 \% \mathrm{NaOH}$ solutions before the chemical treatment. It was found that $5 \%, 18 \%$ or $10 \%$ of sodium hydroxide solution were the appropriate concentrations for mercerization before silane, benzoylation or peroxide treatment, respectively. The fibers were then washed many times in distilled water and finally dried. The different chemicals can then be used on the surface in order to improve their interfacial properties. 
Silane treatment: The pre-treated fibers were dipped in an alcohol water mixture (60:40) containing triethoxyvinylsilane coupling agent. The $\mathrm{pH}$ of the solution was maintained between 3.5 and 4, using the METREPAK Phydrion buffers and $\mathrm{pH}$ indicator strips. Fibers were washed in double distilled water and dried in the oven at $80^{\circ} \mathrm{C}$ for $24 \mathrm{~h}$.

Benzoylation: The pre-treated fibers were suspended in $10 \% \mathrm{NaOH}$ solution and agitated with benzoyl chloride. The mixture was kept for $15 \mathrm{~min}$, filtered, washed thoroughly with water and dried between filter papers. The isolated fibers were then soaked in ethanol for $1 \mathrm{~h}$ to remove the benzoyl chloride and finally was washed with water and dried in the oven at $80^{\circ} \mathrm{C}$ for $24 \mathrm{~h}$.

Peroxide treatment: Fibers were coated with dicumyl peroxide from acetone solution after alkali pre-treatments. Saturated solution of the peroxide in acetone was used. Soaking of the fibers in the solution was conducted at a temperature of $70^{\circ} \mathrm{C}$ for $30 \mathrm{~min}$. High temperatures were favored for decomposition with the peroxide. The chemically treated fibers were washed with distilled water and placed in an oven at $80^{\circ} \mathrm{C}$ for $24 \mathrm{~h}$.

\subsection{Composite Preparation}

The silane coupling agent was processed in the lab. The liquid form of triethoxyvinylsilane was blended with the thermoplastic powder and fed to the laboratory mixing extruder (LME) (Dynisco, Franklin, MA). The extruded strands were pelletized and ground into powder form. Then the silane coupling agent was added 
during the dry compounding of fiber/thermoplastic at a rate of $5 \%$ by mass as "resin additive".

Pre-treated and untreated fibers were ground by the grinding mill (Falling Number, Huddinge, Sweden) and oven dried at $80^{\circ} \mathrm{C}$ for $24 \mathrm{~h}$ to reduce the moisture content to less than $2 \%$. Mixtures of thermoplastic powder and $10 \%$ by weight of flax fibers were prepared by using a food blender (Waring Products Corporation, New York, NY). This was done to aid in the homogeneous mixing of fibers and polymer matrix during the extrusion process. The blend was fed into the twin-screw extruder (Werner \& Pfleiderer Engineers, Ramsey, NJ) located at the Centre for Agri-Industrial Technology (CAIT) in Edmonton, $\mathrm{AB}$ using a barrel to die temperature profile of $175^{\circ} \mathrm{C}$, a screw speed of 125 rpm and feed rate to the extruder of $20 \mathrm{~kg} / \mathrm{hr}$. Blends prepared in this manner were extruded using a six-hole strand die (Figure 4.2). Figure 4.3 shows the material being extruded. Extruded strands were then pelletized. The pellets were ground using a grinding mill (Retsch GmbH 5657 HAAN, West Germany) and the ground product was used in rotational molding.

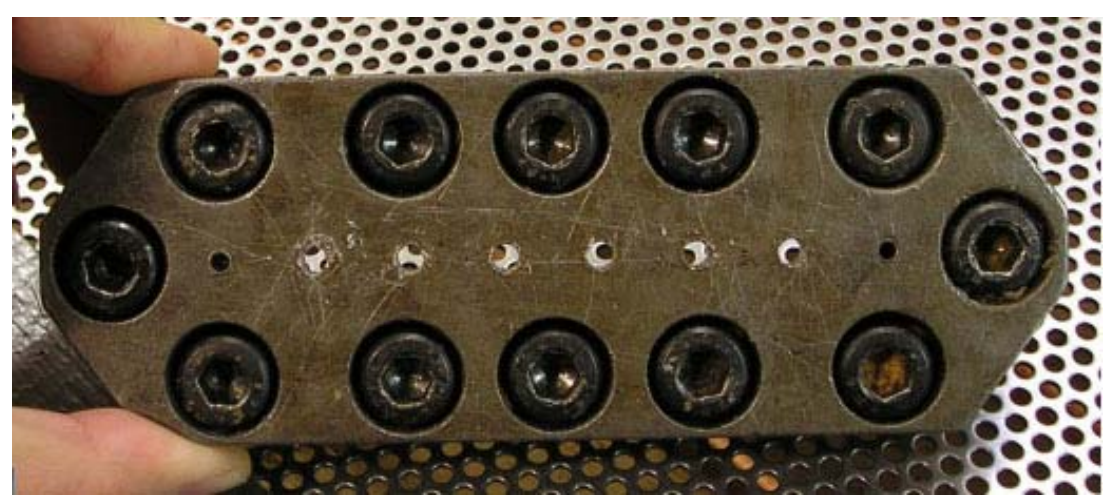

Figure 4.2 Six-hole strand die. 


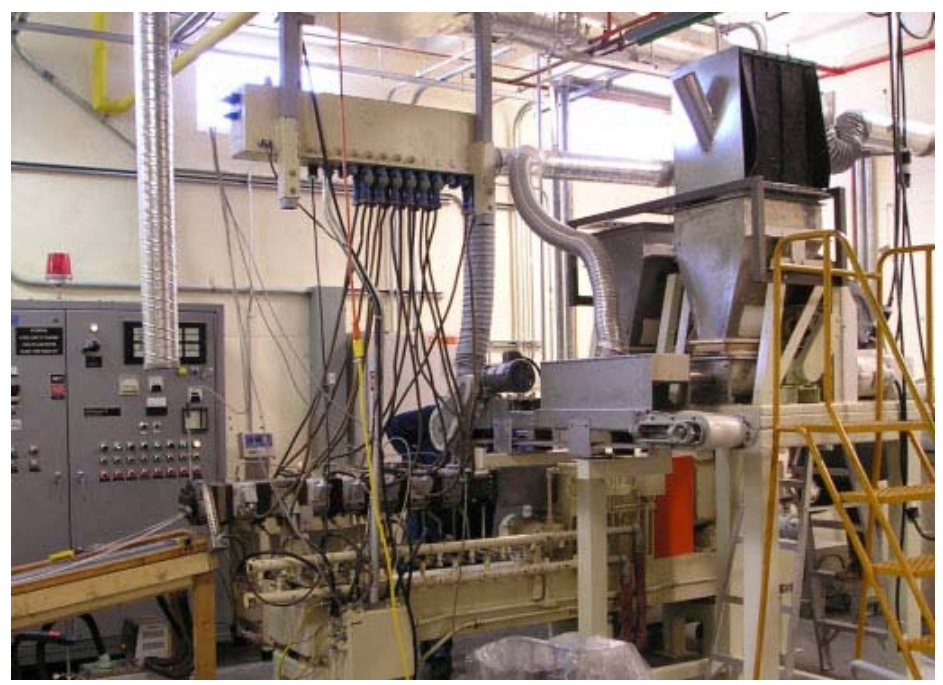

Figure 4.3 The material being extruded.

In the initial stage of this research, two types of extruders were compared. The singlescrew extruder (CW Brabender Instruments Inc., South Hackensack, NJ) at the Northern Alberta Institute of Technology (NAIT) in Edmonton, AB was used in the extrusion process to compare with the output from a twin-strew extruder, as previously detailed. Swelling of extruded strands was observed when the single-strew extruder was used. Therefore, the twin-screw extruder offers a superior mixing and compounding compared to the single-screw extruder.

\subsection{Biocomposites Manufacturing by Rotational Molding}

The powder of fiber/thermoplastic was dried in an air-circulating oven for $24 \mathrm{~h}$ at $70^{\circ} \mathrm{C}$ before rotational molding. Test samples were prepared from ground extruded strands using a rotational molding machine located at Norwesco Canada Ltd. in Saskatoon, SK. It is a carousel-type molding machine with four separate arms that can each rotate at two separate axes, while completely enclosed in an oven at $250^{\circ} \mathrm{C}$ for $30 \mathrm{~min}$. Single large 
mold cavities can be placed on each arm or many smaller shapes. Rotational molding manufacturing process is shown in Figure 4.4.

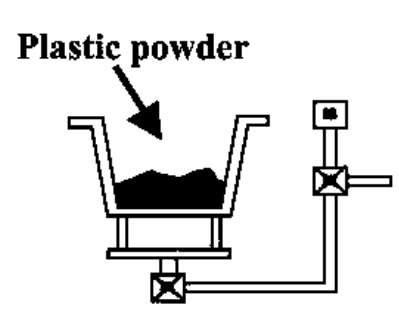

(a) Charging

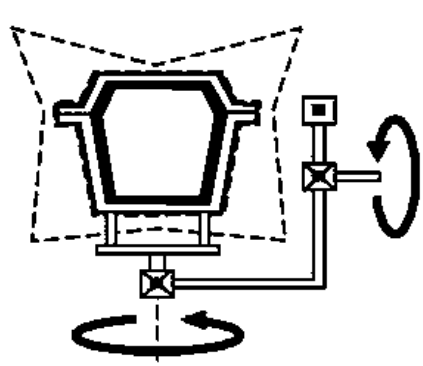

(c) Cooling

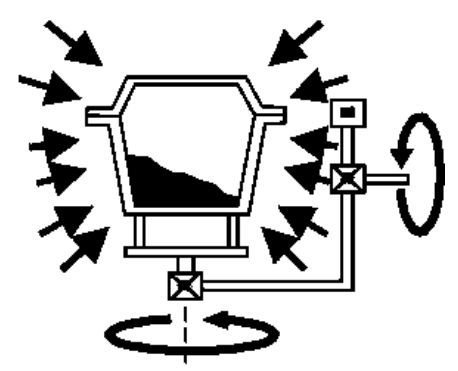

(b) Heating

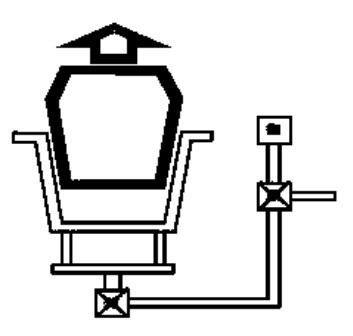

(d) Demolding

Figure 4.4 Rotational molding manufacturing process (Beall 1998).

\subsection{Experimental Design and Data Analysis}

The study was broken into two phases. The first phase focused on the effect of chemical modifications on the flax fibers, while the second phase focused on the effect of pretreated flax fibers on the performance of the fiber-reinforced composite.

\subsubsection{Experimental design}

The experimental design is a factorial arrangement of treatments conducted in a randomized design. Table 4.1 shows the outline of the experimental design for three types of treated fibers. 
Main treatment: $\mathrm{T}_{1}$ (Untreated); $\mathrm{T}_{2}$ (Silane treatment);

$\mathrm{T}_{3}$ (Benzoylation); $\mathrm{T}_{4}$ (Peroxide treatment $)=4$

Sub-treatment: $\mathrm{S}_{1}(\mathrm{LLDPE}) ; \mathrm{S}_{2}(\mathrm{HDPE}) ; \mathrm{S}_{3}(\mathrm{HDPE} / \mathrm{LLDPE})=3$

Treatment combination $=4$ types of fiber $\times 3$ types of thermoplastic $=12$

$\left(T_{1} S_{1}, T_{1} S_{2}, T_{1} S_{3}, T_{2} S_{1}, T_{2} S_{2}, T_{2} S_{3}, T_{3} S_{1}, T_{3} S_{2}, T_{3} S_{3}, T_{4} S_{1}, T_{4} S_{2}, T_{4} S_{3}\right)$

Total tests conducted $=12 \times 5$ (replicates $)=60$ tests

Table 4.1. Experimental design for three types of treated fibers.

\begin{tabular}{cccc}
\hline Fiber & Polymer & Fiber Content & $\begin{array}{c}\text { Silane Coupling } \\
\text { Agent (\%) }\end{array}$ \\
\hline Untreated & LLDPE & 10 & 5 \\
$(2 \%$ detergent water) & HDPE & 10 & 5 \\
& HDPE/LLDPE & 10 & 5 \\
\hline Silane treated & LLDPE & 10 & 5 \\
(triethoxyvinylsilane & HDPE & 10 & 5 \\
coupling agent) & HDPE/LLDPE & 10 & 5 \\
\hline Benzoylation treated & LLDPE & 10 & 5 \\
(benzoyl chloride) & HDPE & 10 & 5 \\
& HDPE/LLDPE & 10 & 5 \\
\hline Peroxide treated & LLDPE & 10 & 5 \\
(dicumyl peroxide) & HDPE & 10 & 5 \\
& HDPE/LLDPE & 10 & 5 \\
\hline
\end{tabular}

Data for each test appear in Appendices A-G. In each test, the experimental parameters and conditions are listed. The number of replicates in each test is listed in Table 4.2. According to the appropriate ASTM standard, five samples were replicated for tensile strength at yield test of composites.

This research studies the effect of fiber surface modifications on the performance of composites focused on four properties, namely, morphological characterization, mechanical, physical and thermal property. Table 4.2 shows the property tests performed 
on each composite sample and the number of replicates.

Table 4.2. Property tests conducted on sample composites.

\begin{tabular}{clc}
\hline Property & \multicolumn{1}{c}{ Test } & Replicates \\
\hline Morphological & Fiber surface topology (SEM) & 1 \\
Characterization & Composite microstructure (SEM) & 1 \\
\hline \multirow{3}{*}{ Mechanical } & Fiber bundle tensile strength test (Instron) & 50 \\
& Tensile strength at yield of composites (Instron) ASTM: D638 & 5 \\
& Tensile-impact strength of composites (ASTM: D1822-93) & 5 \\
& Durometer hardness of composites (ASTM: D2240-97) & 10 \\
\hline \multirow{2}{*}{ Physical } & Moisture absorption of flax fibers (Environmental test & 3 \\
& chamber) & 3 \\
\hline \multirow{2}{*}{ Thermal } & Water absorption of composites (ASTM: D570-99) & 1 \\
\hline
\end{tabular}

\subsubsection{Data analysis}

The number of replicate specimens varied for each test type. The data constitute a sample of certain observations from the population of all loads obtainable by these techniques. Deviation in the observed properties arises from variability in the manufacturing of the composites, in the machine administering the load, in the experimenter's technique, and in a host of other, possibly unknown factors. It is clear that we cannot hope to obtain a mean $(\mu)$ and standard deviation $(\sigma)$ for this abstract population, but we can estimate them. A one-way analysis of variance (ANOVA) was used to study the difference between the tests and between treatments and the results are shown in Appendices A-G. The Duncan's multiple range test was also used to compare the paired means.

In each of the test, the sample mean value $(\overline{\mathrm{Y}})$, standard deviation $(\mathrm{s})$, the standard error 
of the mean $\left(\mathrm{s}_{\mathrm{Y}}\right)$, the coefficient of variation $(\mathrm{CV})$ and $95 \%$ confidence interval of the mean were calculated. The description of the statistical analysis of each test is also listed in the Appendices. All the data analysis was generated using the program in SPSS statistical software (SPSS Inc., Chicago, IL).

\subsection{Experimental Procedures}

Morphological characterization test of fiber and the composites were carried by a scanning electron microscope (SEM). Mechanical property test focused on tensile strength of fiber bundle, tensile strength of composites, tensile-strength test of composites and Durometer hardness test of composites. Physical property test focused on moisture absorption test of fibers and water absorption test of composites. Thermal property measurement was conducted by a differential scanning calorimetry (DSC).

\subsubsection{Morphological characterization}

The treated fiber and the composites were examined by a scanning electron microscopy (SEM505 Philips Electron Optics, Eindhoven, the Netherlands). The sample surfaces were vacuum coated with a thin layer of gold on the surface using an Edwards S150B sputter coater (BOC Edwards, Wilmington, MA) to provide electrical conductivity and did not significantly affect the resolution. One set of sample from each type of fibers/composite was examined. Figure 4.5 shows the SEM used in this study located in the Department of Biology at the University of Saskatchewan.

As a supplementary tool, the microscopic examination of treated and untreated fiber 
surface was carried out with a scanning electron microscope at the accelerating voltage of $10 \mathrm{KV}$. The microstructure of the fiber-matrix interface of composites was examined at the accelerating voltage of $30 \mathrm{KV}$.

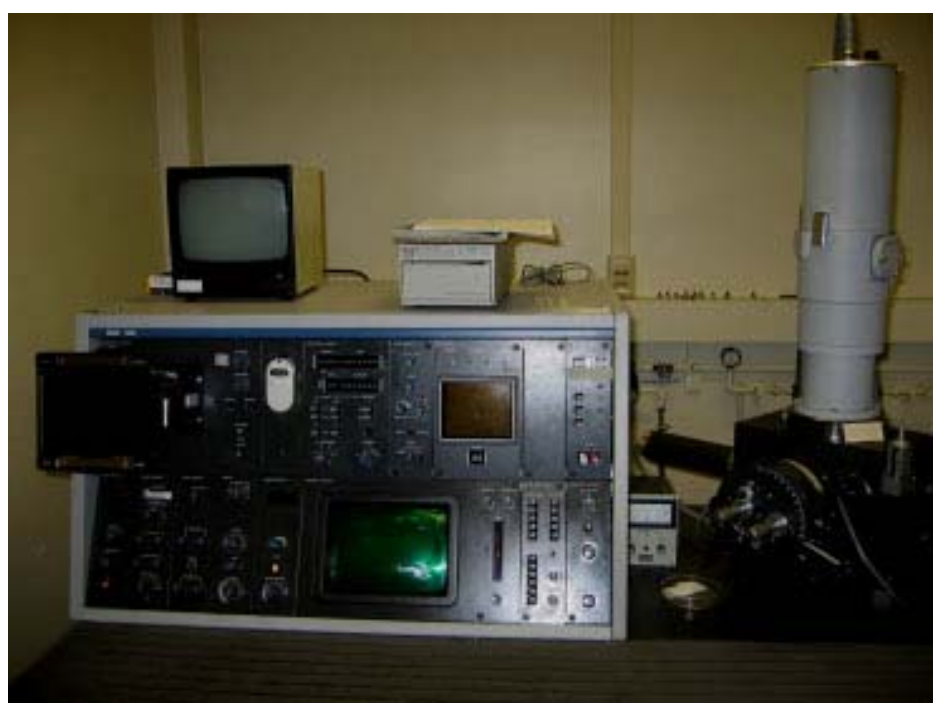

Figure 4.5 Scanning electron microscope.

\subsubsection{Mechanical properties}

Specimens were conditioned for 7 days at standard laboratory atmosphere prior to performing mechanical tests. The appropriate ASTM methods were followed. At least five replicate specimens were tested and the results were presented as an average of tested specimens. The tests were conducted at a standard laboratory atmosphere of $23^{\circ} \mathrm{C}$ and $50 \%$ relative humidity.

\subsubsection{Tensile strength of fiber bundle}

Tensile test is a measurement of the ability of material to withstand forces that tend to pull it apart. It determines to what extent the material stretches before breaking. Flax fiber bundle tensile strength tests were preformed by a computer-controlled Instron 
Model 1011 (Instron Corporation, Canton, MA) with a gauge length of $40 \mathrm{~mm}$ and at a crosshead speed of $5 \mathrm{~mm} / \mathrm{min}$. Figure 4.6 shows how the apparatus appeared once it has been clamped and ready for testing. The round bars were covered with surgical glove fingers, and the flax was clamped at the top and bottom. The fiber bundle was wrapped one revolution around each of the two bars and was spread out over the entire gauge length in a parallel. For each set of chemical treatment, a minimum of fifty specimens were tested for determining the fiber tensile strength. According to ASTM standard D1294 and D1445 (1995), linear density or more commonly tex is calculated by:

$$
\mathrm{D}=\frac{\mathrm{W}}{\mathrm{L}}
$$

Where: $\mathrm{D}=$ linear density or tex $(\mathrm{mg} / \mathrm{m})$

$$
\begin{aligned}
& \mathrm{W}=\text { mass of fibers }(\mathrm{mg}) \\
& \mathrm{L}=\text { length of fiber }(\mathrm{m})
\end{aligned}
$$

Also the unit break was calculated by:

$$
\mathrm{UB}=\frac{\mathrm{F}}{\mathrm{D}}
$$

Where: $\mathrm{F}=$ maximum breaking load $(\mathrm{mN})$

$$
\begin{aligned}
\mathrm{D} & =\text { linear density or tex }(\mathrm{mg} / \mathrm{m}) \\
\mathrm{UB} & =\text { unit break }(\mathrm{mN} / \mathrm{tex})
\end{aligned}
$$

The Instron was set up to display a force-deformation curve at loading and to read the load at maximum or the break point. By inspecting the shape of this curve, one could check the accuracy of each individual test. If the sample was tensioned unevenly, more 
than one peak will appear on the graph. This is caused when some fibers are initially tensioned more than others. These fibers will break first, then the remaining fibers will break, causing an invalid test with two or more break points or graph peaks. Figure 4.7 shows how the graph can distinguish the valid results. With a valid test, there is one distinct peak that shows the true break force.

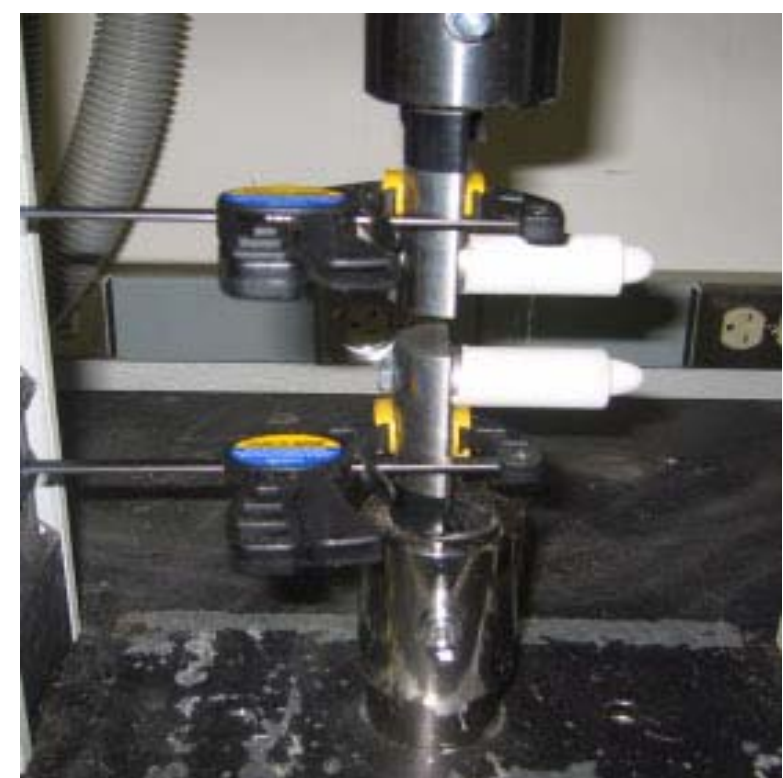

Figure 4.6 Set up for the tensile strength of fiber bundle.

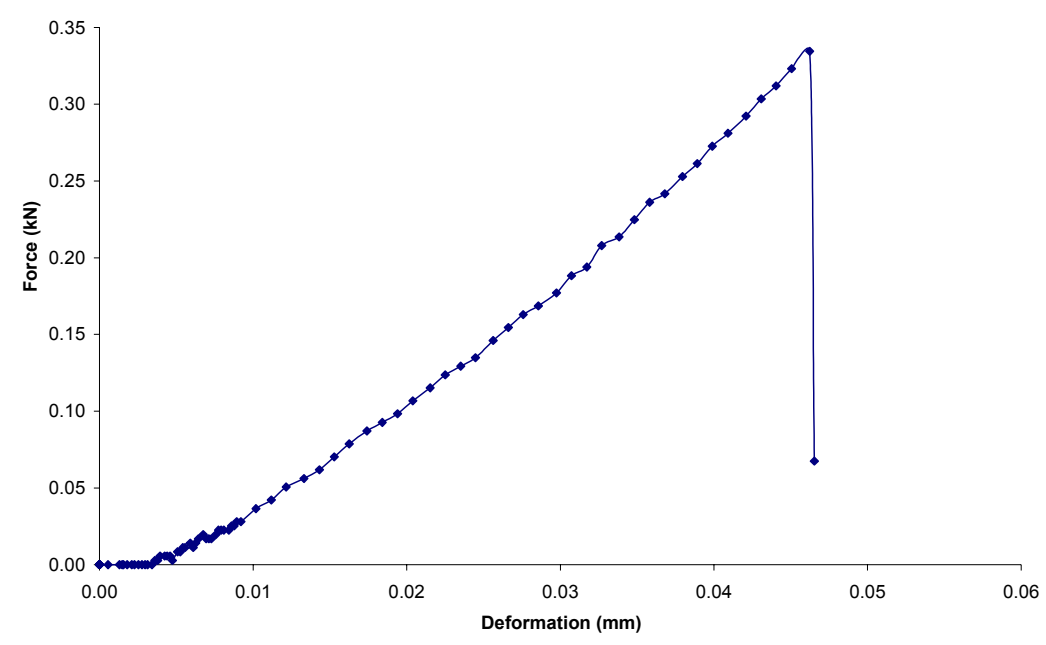

Figure 4.7 Force-deformation curve of a valid individual test. 


\subsubsection{Tensile strength of composites}

Tensile property data are more useful in preferential selection of a particular type of plastic from a large group of plastic materials. The familiar dog-bone shape of the rotationally molded sample was utilized in the testing procedure. This type I specimen is the preferred specimen and should be used where sufficient material having a thickness of $7 \mathrm{~mm}$ or less is available. An Instron Universal testing machine (SATEC Systems, Inc., Grove City, PA) (Figure 4.8) was used to perform the tensile strength test at a crosshead speed of $5 \mathrm{~mm} / \mathrm{min}$ as described in ASTM procedure D638-99 (ASTM 1999), and each test was performed until tensile failure occurred. The maximum (peak) load value (force) $\left(\mathrm{F}_{\max }\right)$ was recorded by the instrument, which can be recalled after the completion of the test. The tensile strength at yield $\left(\sigma_{\mathrm{ty}}\right)$ is calculated from the following:

$$
\sigma_{\mathrm{ty}}=\frac{\mathrm{F}_{\max }}{\mathrm{A}}
$$

Where $\mathrm{A}$ is the cross sectional area.

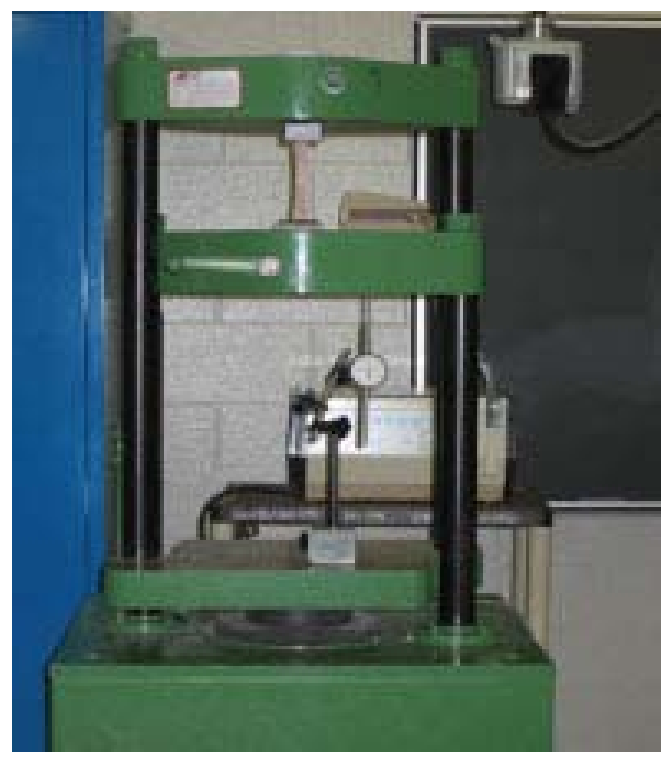

Figure 4.8 Tensile strength test of a composite sample using the Instron Universal testing machine. 


\subsubsection{Tensile-impact strength of composites}

The impact properties of the polymeric materials are directly related to the overall toughness of the material. The tensile-impact strength test was developed to overcome the deficiencies of flexural impact tests. Tensile-impact energy is the energy required to break a standard tension-impact specimen in tension by a single swing of a standard calibrated pendulum under a set of standard conditions.

Tensile-impact strength test was conducted according to ASTM D1822-93 (ASTM 1993). The tensile impact testing machine consists of a rigid massive base with a suspending frame. The pendulum is specially designed to hold the dumbbell-shaped specimen so that the specimen is not under stress until the moment of impact. Figure 4.9 shows the tensile impact tester (Tinius Olsen Testing Machines Co., Willow Grove, PA) used in the test.

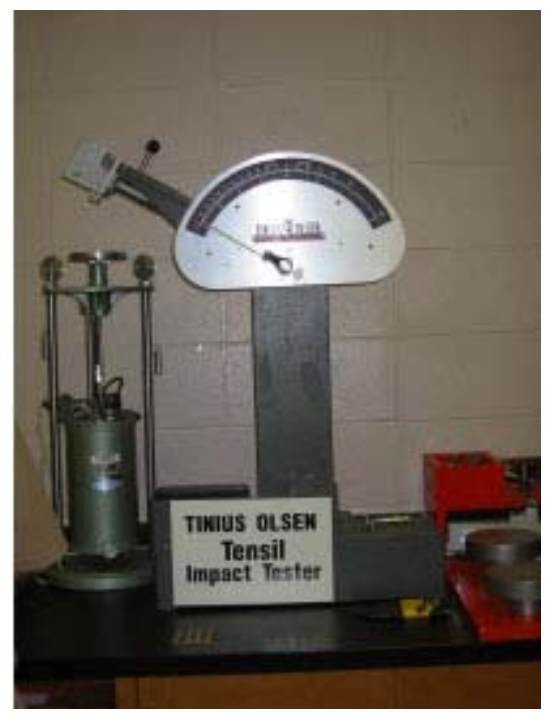

Figure 4.9 Tensile-impact strength tester. 
The specimens were prepared by rotational molding to the desired shape from a sheet. The type L (long) specimen extension is comparatively high. Type L specimens provide a greater differentiation between materials. Type L (long) specimens were prepared using the shape shown in Figure 4.10.

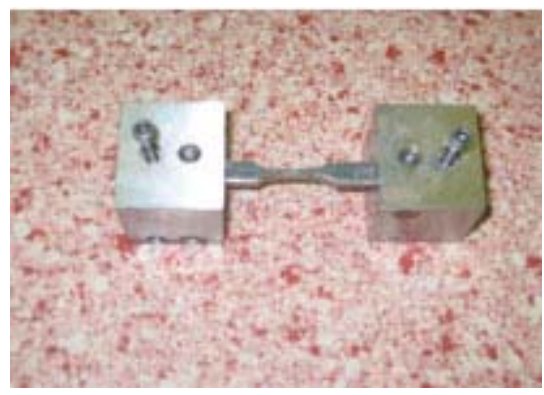

Figure 4.10 Type L tensile-impact specimens.

\subsubsection{Durometer hardness of composites}

Hardness is defined as the resistance of a material to deformation, particularly permanent deformation, indentation, or scratching. The Durometer hardness test is used for measuring the relative hardness of soft materials. The test method is based on the penetration of a specified indentor forced into the material, under specified conditions. Higher Durometer hardness readings are considered positive results.

Durometer readings were performed according to ASTM D2240-97 (ASTM 1998). The Durometer hardness tester (Shore Instrument and MFG Co., Freeport, NY) consists of a pressure foot, an indentor, and an indicating device. Two types of durometers are most commonly used: Type A and Type D. Due to the slightly harder sample being examined, the Type D gauge was used. The test was carried out by first placing a specimen on a 
hard, flat surface. The pressure foot of the instrument was pressed on to the specimen, making sure that it was parallel to the surface of the specimen. The Durometer hardness was read within $1 \mathrm{~s}$ after the pressure foot was in firm contact with the specimen. Each specimen was subjected to ten Durometer hardness readings, at designated positions on the sample bases. Values for these readings were then averaged. The Durometer hardness measuring instrument is shown in Figure 4.11.

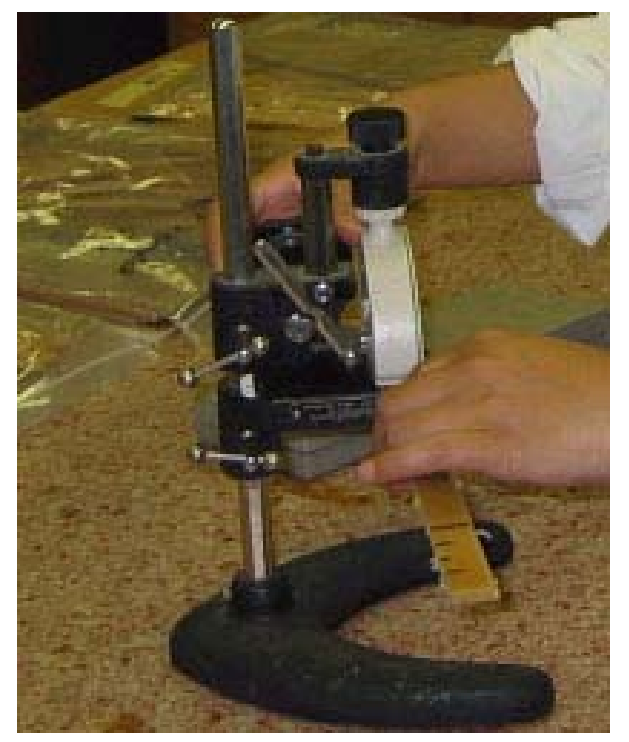

Figure 4.11 Durometer hardness testing.

\subsubsection{Physical properties}

Water absorption is generally considered to be disadvantages, especially in composites. Migration of water through the polymer can lead to a disturbance of the fiber-matrix interface, reducing the overall strength and resulting in the dimensional instability of composites. 


\subsubsection{Moisture absorption of fibers}

Prior to testing, the fibers were dried in an oven at $70^{\circ} \mathrm{C}$ for $24 \mathrm{~h}$. Each sample was placed in the conditioning chamber for $72 \mathrm{~h}$. Conditioning was conducted in the environmental test chamber (Angelantoni, ACS, Massa Martana, Italy) at $23^{\circ} \mathrm{C}$ and relative humidity values of 33, 66 and 100\%, respectively. The mass of fibers was measured at different time intervals and the moisture absorption was calculated by the

$$
\text { Increase in mass }(\text { percent })=\left(\frac{M_{t}-M_{0}}{M_{0}}\right) \times 100
$$

mass difference. The percent increase in mass was calculated according to the following equation:

Where: $\mathrm{M}_{\mathrm{t}}=$ mass of the sample after conditioning ( $\mathrm{g}$ ) (wet weight)

$$
\mathrm{M}_{0}=\text { mass of the sample before conditioning (g) (dry weight) }
$$

\subsubsection{Water absorption of composites}

Water absorption characteristics of composites are altered by the addition of additives such as flax fibers because these additives showing a greater affinity to water. Rectangular specimens were cut from each sample with dimensions of $25.4 \mathrm{~mm} \times 76.2$ $\mathrm{mm}$. The samples were dried in an oven at $50^{\circ} \mathrm{C}$ for $24 \mathrm{~h}$, cooled in a desiccator, and immediately weighed to the nearest $0.001 \mathrm{~g}$. In order to measure the water absorption of composites, all samples were immersed in water for about $24 \mathrm{~h}$ at room temperature as described in ASTM procedure D570-99 (ASTM 1999). Excess water on the surface of the samples was removed before weighing. The percentage increase in mass during immersion, was calculated to the nearest $0.01 \%$ as follows: 


$$
\text { Increase in mass }(\text { percent })=\frac{\text { Conditioned mass }- \text { Dry mass }}{\text { Dry mass }} \times 100
$$

The sample during water absorption test of composites is shown in Figure 4.12. Three replicate specimens were tested and the results were presented as average of the tested specimens.

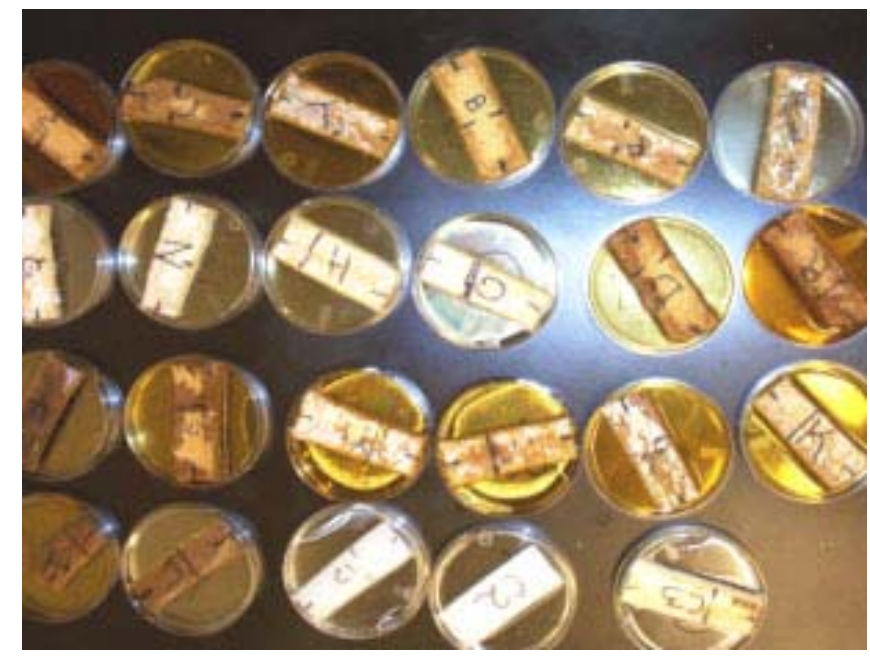

Figure 4.12 Water absorption test of composites.

\subsubsection{Melting points of composites}

DSC is a thermoanalytical technique in which heat flow is measured as a function of temperature or time. Thermal analysis on pure materials, as well as on composites was performed using a DSC. The thermograms were then analyzed for any changes in the thermal behavior of the fibers. The DSC instrument is shown in Figure 4.13. A PerkinElmer DSC system (TA instruments, New Castle, DE) was used in this test. 
Untreated and treated fiber composite sample weighing between 6 to $10 \mathrm{mg}$ were placed in an aluminum pan and sealed with the crucible sealing press. The DSC system was operated in a dynamic mode with a heating scheme of -50 to $400^{\circ} \mathrm{C}$, heating rate of $10^{\circ} \mathrm{C} / \mathrm{min}$ and a chart of heat flow versus temperature was produced.

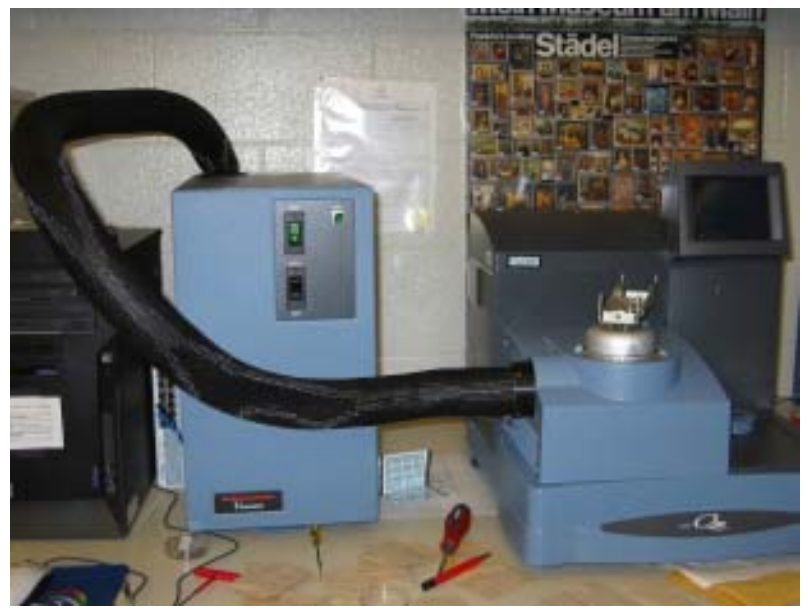

Figure 4.13 DSC melting point test of composites. 


\section{RESULTS AND DISCUSSION}

The effects of three chemical treatments, namely, silane, benzoylation, and peroxide treatment on the performance of flax fibers and fiber-reinforced composites are discussed in this chapter.

\subsection{Morphological Characterization}

The possibility of forming mechanical bonding at the surface is mainly dependent on the surface topology of the fibers. It is important to mention that the changes of surface topography affect the interfacial adhesion. Fiber-matrix interface plays an important role in composite properties.

\subsubsection{Fiber surface topology}

Scanning electron microscopic analysis examined the surface topology of untreated and treated fibers. The removal of surface impurities on plant fibers is advantageous for fiber-matrix adhesion as it facilitates both mechanical interlocking and the bonding reaction due to the exposure of the hydroxyl groups to the chemicals used in treatment. Figure 5.1 shows the SEM photographs of fiber surfaces after chemical treatment. A porous structure is observed for untreated fibers. Figure 5.1b, c, and d shows the SEM photographs of fiber surfaces after silane treatment, benzoylation and dicumyl peroxide treatment. 


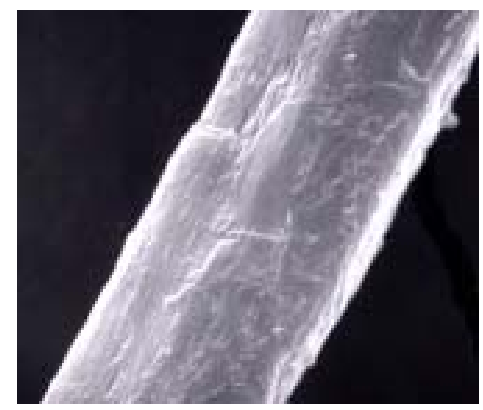

a) Untreated flax fibers

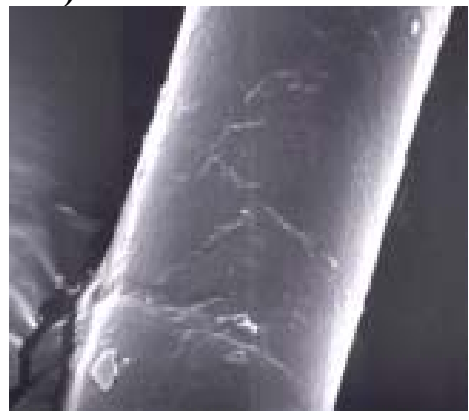

c) Benzoylation

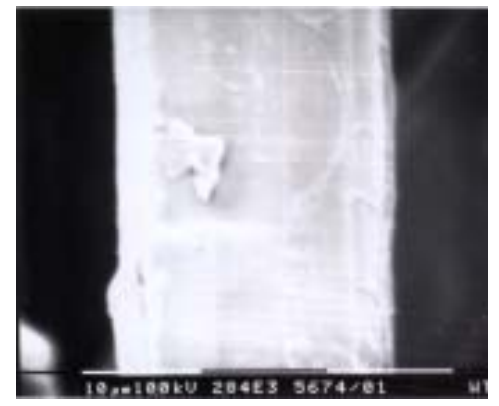

b) Silane treatment

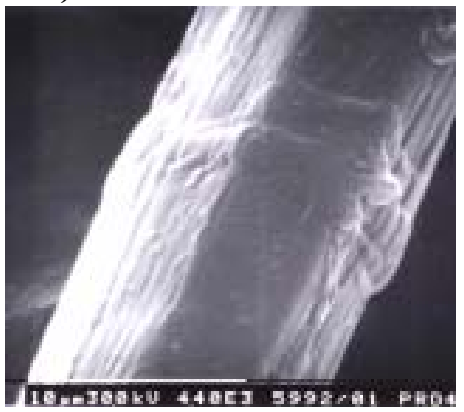

d) Dicumyl peroxide treatment

Figure 5.1 SEM photographs of fiber surfaces after chemical treatment.

These imagines indicate that after chemical treatment, the surfaces of the fibers became rougher enhancing the mechanical interlocking with resins. There is strong evidence that physical microstructure changes occurred at the fiber surface. The untreated flax fibers are in separated bundles with a smooth surface (Figure 5.1a). It is observed that silane treatment gave surface coating to the fibers, and surface features of fibers were not clearly visible. Since flax fibers exhibited micropores on theirs surface, the coupling agent penetrated into the pores and formed a mechanically interlocked coating on their surface. Benzoylation treatment led to major changes on the fiber surface. Smooth fiber surface is observed due to the substances deposited on the surface of the fiber. The surface topography is entirely modified after dicumyl peroxide treatment. The fibrillar structure of the individual ultimate fibers is revealed from the photograph and may be due to the leaching out of waxes and pectic substances. Micropores, particles adhering to 
the surface, groove like portions and protruding structures made the fiber surface very rough. These effects on natural fibers are of particular importance for fiber-matrix adhesion and the creation of high fiber surface area required for the optimization of fiber-resin reinforcement. Therefore, the modification of cellulose fibers develops into changes in morphology and increase in hydroxyl groups. These changes will effectively result in improved surface tension, wetting ability, swelling, adhesion and compatibility with polymeric materials (Mohanty et al. 2001).

\subsubsection{Composite microstructure}

When it comes to using natural fibers as reinforcement in composite materials, many problems occur at the interface due to imperfect bonding. Interfacial properties of flax/polymer composites are largely determined by the strength and nature of secondary interactions that are established across the phase boundary. Interfacial stress transfer is therefore limited to relatively weak dispersion forces (Joseph et al. 2000). A strong fiber-matrix interface bond is critical for high mechanical properties of composites. When manufacturing composite materials, compatibility of the matrix and the fibers is also a problem. Therefore, modification of the fibers by chemical treatments is conducted to improve compatibility. These chemical reactions modify the properties of the fiber, and one of the roles of the cellulose fibers in composites is to give stiffness and strength to the polymeric matrix. 


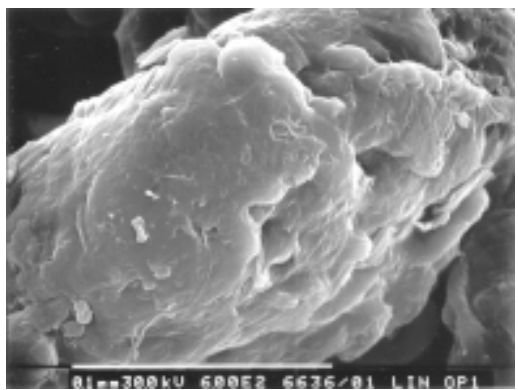

a) Untreated flax in composites

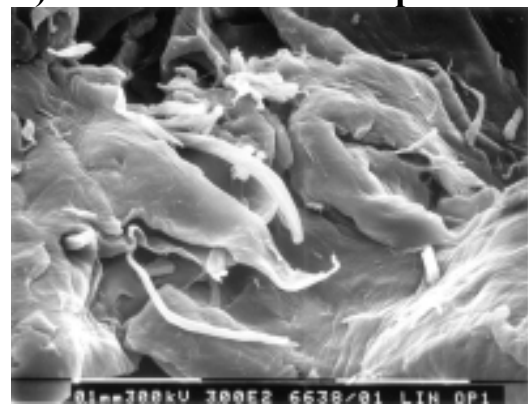

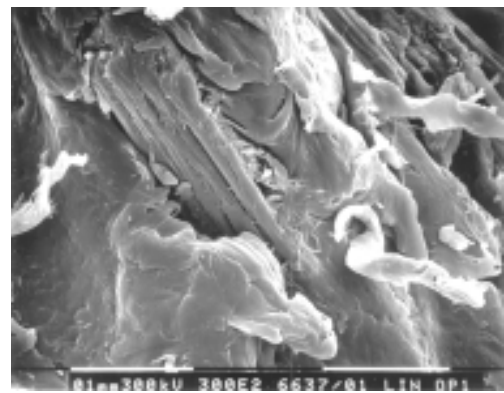

b) Silane treated flax in composites

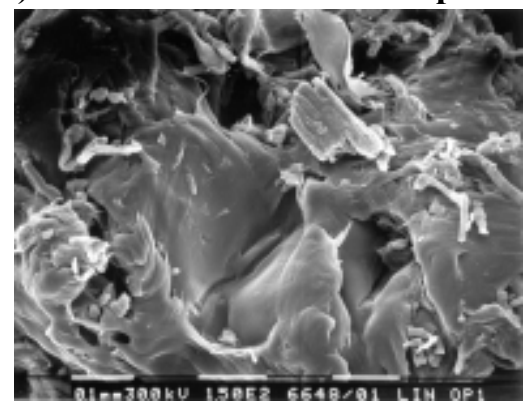

c) Benzoylation treated flax in composites d) Peroxide treated flax in composites

Figure 5.2 SEM micrographs of LLDPE with 10\% treated flax in composites.

Figure 5.2 shows the SEM photographs of the fiber-matrix interaction of untreated and surface treated flax/LLDPE composites. Scanning electron micrographs of the crosssession of the fractured tensile specimen for selected composites were carried out as an attempt to evaluate the fiber distribution within the composite which examined the failure mechanisms. Fiber breakage was the main failure criteria observed. Indeed, the untreated flax composite presented a very poor dispersion of the fiber which also exhibited some fiber agglomeration, small fiber breakage and very poor adhesion between fiber and matrix. On the other hand, chemically treated flax composites showed better fiber-matrix interaction. This is a result of a more uniform dispersion of fibers within the polymer matrix, thereby predicting micropores at the interface. The fibers were less agglomerated, showing the presence of some fibers dissociated into a matrix 
polymer. It is important to mention that dissociation of the fiber into a matrix polymer may increase the surface area of the fibers, which contributes to a greater stress transfer area from the matrix to the fiber upon stress solicitation. The compatibility can be improved by grafting a matrix-compatible polymer onto the fiber surface.

The SEM micrographs of the cross-session of HDPE and LLDPE/HDPE flax fiberreinforced composites are found in Appendix $\mathrm{H}$.

\subsection{Mechanical Properties}

Lignocellulosic fillers offer attractive properties, but are used only to a limited extent in industrial practice (Mishra et al. 2002). Natural fibers are strongly hydrophilic materials and moisture absorption leads to a significant deterioration of their mechanical properties. Furthermore, most polymers are hydrophobic and due to this divergent behaviour, the interface in natural fiber composites is rather poor. Any alteration of the characteristics of the cell wall, either chemical or morphological, has an effect on the mechanical properties of the fibers. By limiting the substitution reaction to the fiber surface, the good mechanical properties are reserved and a degree of biodegradability is maintained.

\subsubsection{Tensile strength of fiber bundle}

Flax fiber properties are controlled by the molecular fine structure of fibers. The chemical processing directly influences the cellulosic fine structure of plant fiber. Consequently, the chemical treatments have a lasting effect on the mechanical behavior 
of flax fibers, especially on fiber strength and stiffness. It is very important to know the strength of the fibers before being combined into the thermoplastic matrix to understand better how the final composite behaves. Flax fiber tensile properties can be obtained by testing either single fibers or fiber bundles. Test results from the two methods are substantially different. Depending on the mechanism of the bundle breakage, this difference may be caused by the variations in fiber breaking elongations, breaking strengths and fiber crimps. From a fundamental point of view, the single or bundle fiber strength testing is not well understood. This is due, in part, to inadequate testing regimes, and because problems exist with the variability of mechanical properties of natural cellulosic fibers such as flax and hemp and are particularly, because it is difficult to measure. The fiber bundle fails within the hemicellulose and pectin layers that connect the single fibers together.

The single fiber testing method is too time-consuming and expensive compared to bundle test method. A method is developed in this thesis to test the tensile strength properties of flax fiber bundle. The average unit break of fiber bundle was tested based on fifty tests and the results are shown in Figure 5.3. The test was conducted on fiber bundle with a gauge length of $40 \mathrm{~mm}$ at standard laboratory atmosphere of $23^{\circ} \mathrm{C}$ and relative humidity of $51 \%$. The data show that the higher strength (although not statistically significant) of silane- and peroxide-treated fibers compared to untreated fibers may be a result of the removal of surface imperfections after the treatment. The increased uniformity of the fibers would give an increase to strength, as points of unconformity are removed during the treatment and this changes the deformation 
behavior of the fibers (Mohanty et al. 2001). On the other hand, the average unit break reached a low of $107.33 \mathrm{mN} / \mathrm{tex}$ when using benzoylated samples, due to breakage of the bond structure. The testing procedure used linear density instead of the area to evaluate the unit break of fiber bundle. Thus, the results can not be reverse engineered to a MPa reading without making assumptions about the fiber bundle, or drastically increasing the testing time. Unfortunately, the results of this test do not lend themselves to comparison with other research results such as those listed in Table 3.1, where the tensile strength of flax was 345-1100 MPa (Mohanty et al. 2000a). This test also used numerous fibers and not individual fibers. This enables some of the errors associated with individual fiber testing to be eliminated, such as assuming the fibers are perfectly round and the breaking point is located at the same spot where the area was measured.

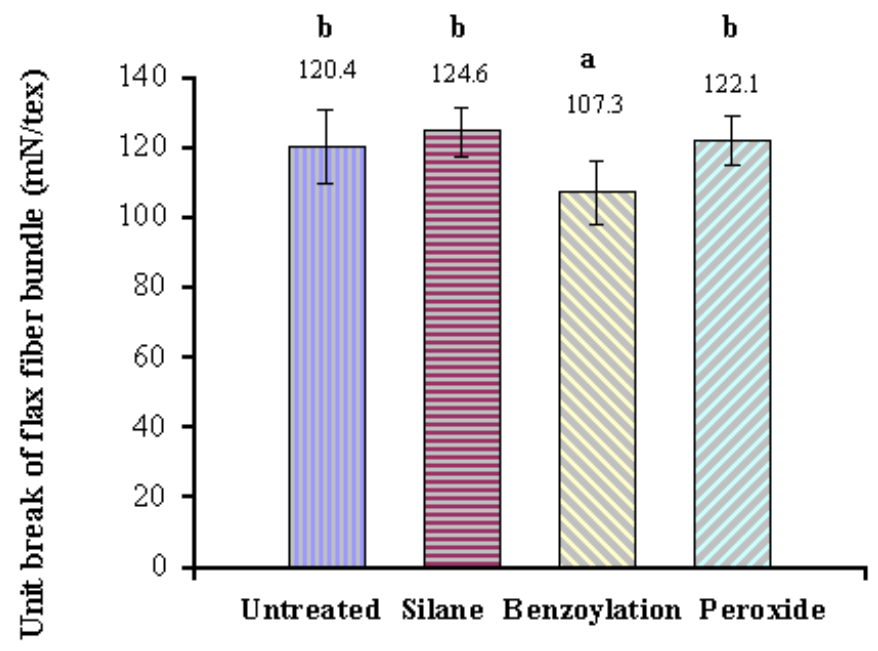

Figure 5.3 Average unit break of flax fiber bundle.

Each bar shows the mean value with a range according to $95 \%$ confidence interval. Means with the same letter designation are not significantly different at $\mathrm{P}=0.05, \mathrm{n}=50$.

\subsubsection{Tensile strength of composites}

Certain plant fibers, notably flax and hemp possess tensile properties which make them 
potentially attractive for use as reinforcement in polymer matrix composites. The effect of chemical treatment on the tensile properties of flax fiber-reinforced composites was investigated. Treatments using chemicals such as triethoxyvinylsilane coupling agent, benzoyl chloride and dicumyl peroxide were carried out to improve the bonding at the fiber-polymer interface. Figure 5.4 shows the tensile strength at yield of fiber-reinforced LLDPE, HDPE and LLDPE/HDPE composites. Compared to the untreated fiber composite having $10 \%$ by weight fiber loading, the pre-treatments slightly enhanced the tensile strength of the composites, but not in a statistically significant amount. For silane-treated fibers with LLDPE, the tensile strength increased from 15.10 to 15.80 $\mathrm{MPa}$ compared to $15.25 \mathrm{MPa}$ for the untreated fiber composite processed in the same manner. This may be due to the increased fiber-matrix adhesion, their rough surface topography and the peroxide-induced grafting. The tensile strength of flax fiberreinforced composites is determined both by the tensile strength of the fiber and by the presence of weak lateral fiber bonds (Mohanty et al. 2001). The variations in the tensile strength at yield of the composites using different fiber treatments were attributed to the changes in the chemical structure and bondability of the fiber. Tests with different flax fiber-reinforced biodegradable matrix polymers showed that the tensile strength of these biocomposites was clearly influenced by the particular matrix and the adhesion between fiber and matrix. In comparison with the virgin polymer, all the treatments showed the same tendency to slightly increase (although not statistically significant) the tensile strengths of modified composites. The processing employed also played an important role on the tensile properties of the composites. 


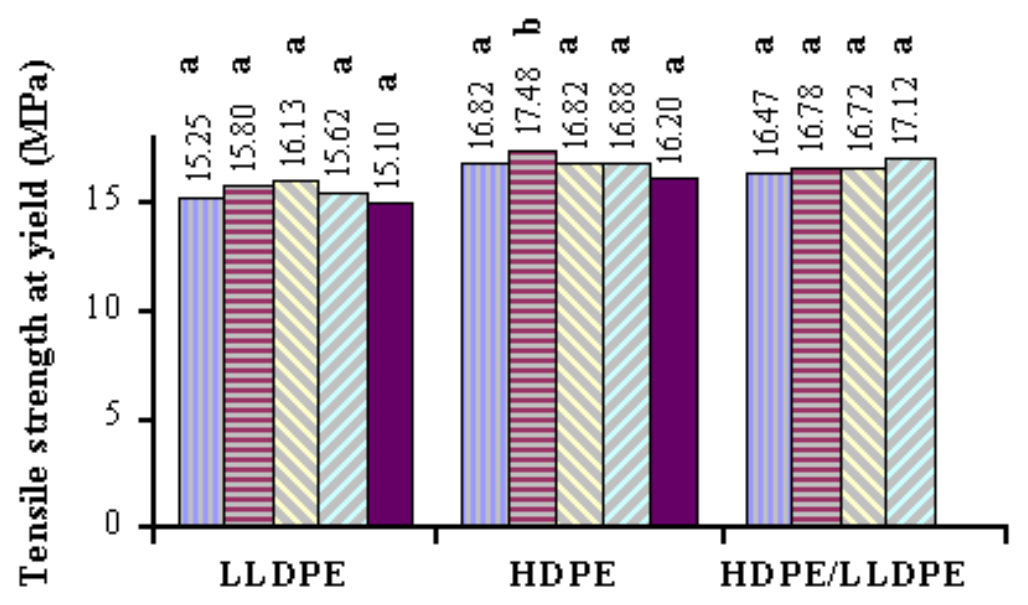

$\square$ untreated 目 silane treatment $\square$ Benzoylation $\square$ Peroxide treatment $\square$ Resin

Figure 5.4 Comparison of tensile strength at yield of $10 \%$ fiber with different thermoplastics within group. Means followed by the same letter are not significantly different at $\mathrm{P}=0.05$ according to Duncan's multiple range test, $\mathrm{n}=5$.

\subsubsection{Tensile-impact strength of composites}

The tensile-impact strength of composites with $10 \%$ pre-treated flax fibers compared to composites with $10 \%$ untreated flax fibers composites with different types of thermoplastic matrix is shown in Figure 5.5. The influence of chemical modification on the tensile-impact strength of composites is also represented in Figure 5.5. It is observed that reinforcement of composites with treated flax fiber slightly enhanced (although not statistically significant) the tensile-impact strength of the resulting composite. 


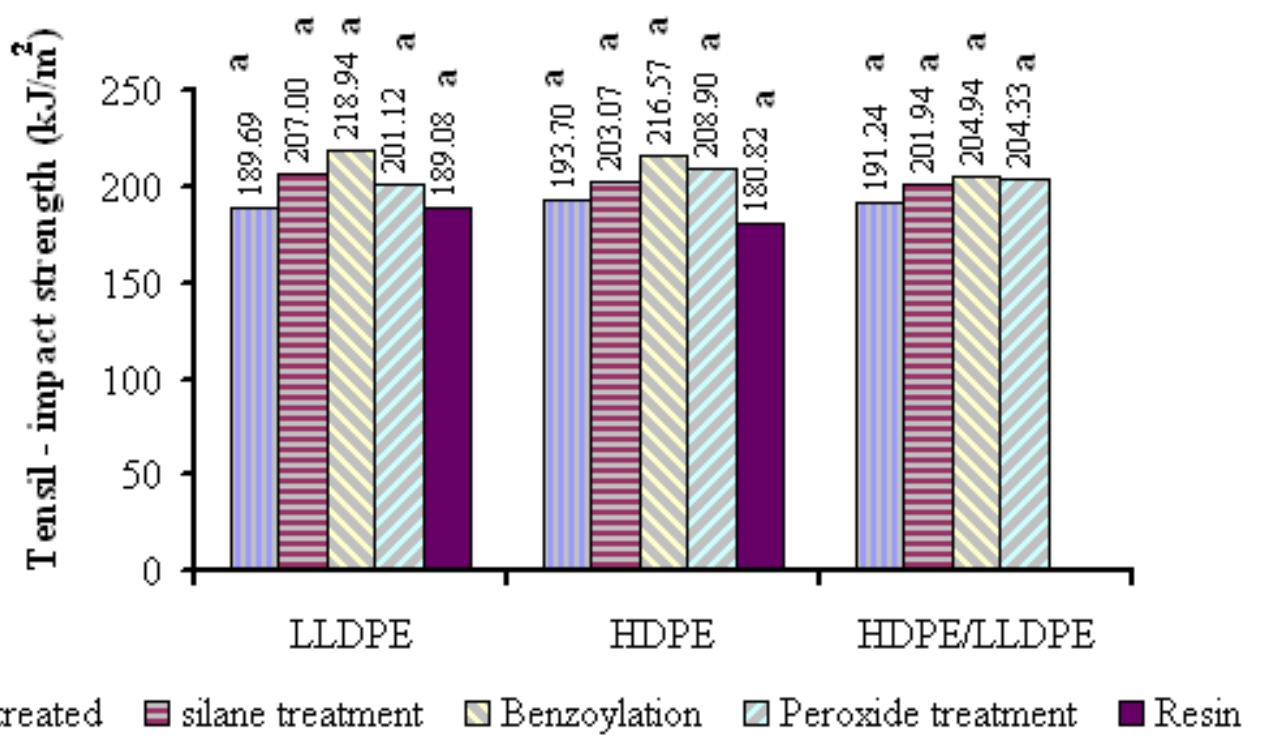

Figure 5.5 Tensile-impact strength of 10\% pre-treated flax fibers compared to untreated flax fibers composites within group. Means followed by the same letter are not significantly different at $\mathrm{P}=0.05$ according to Duncan's multiple range test, $\mathrm{n}=5$.

\subsubsection{Durometer hardness of composites}

The data and numerical results from each Durometer hardness test are presented in this section. Figure 5.6 shows the hardness of $10 \%$ flax fiber composites with different types of thermoplastic matrix. The hardness of plastics is measured by the Shore (Durometer) test. This method measures the resistance of plastics to indentation and provides an empirical hardness value that does not correlate well to other properties or fundamental characteristics. The hardness value is determined by the penetration of the Durometer indenter foot into the sample. The results obtained from this test are a useful measure of relative resistance to indentation of various grades of polymers.

Ten readings were taken for each specimen, as material properties were expected to vary with location on the sample. For the $10 \%$ fiber-based composites, chemically treated 
flax fibers did not increase the hardness of specimens. When compared across fiber pretreatment types, composites containing chemically treated fibers with LLDPE had higher hardness (although not statistically significant) than composites containing untreated fibers.

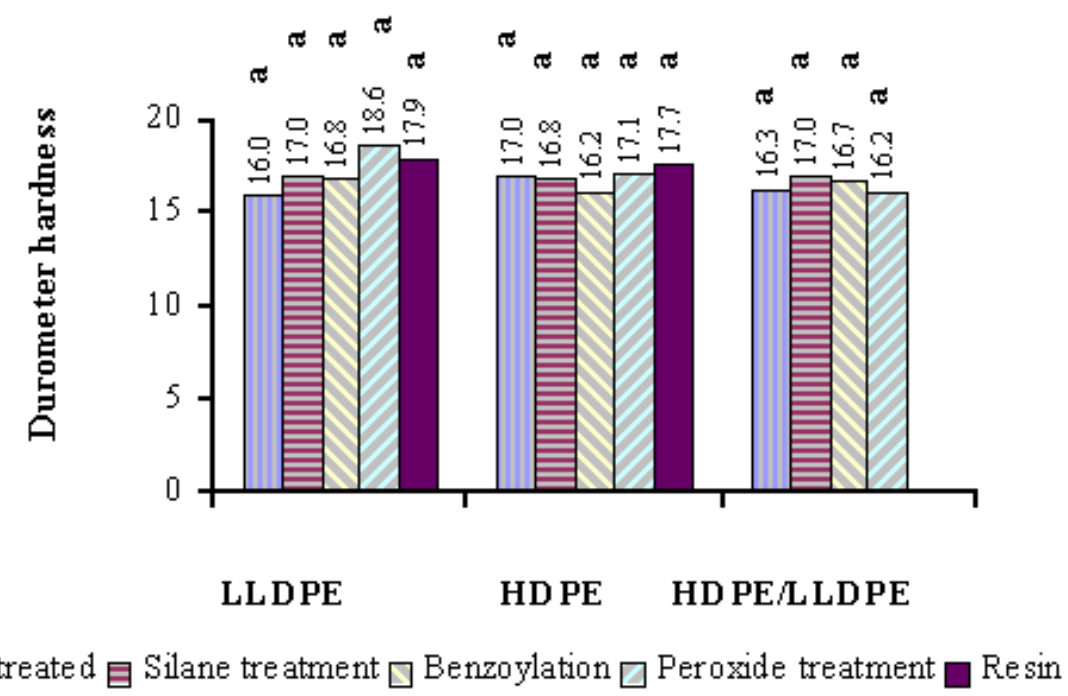

Figure 5.6 Durometer Hardness of 10\% flax fibers composites with different thermoplastics within group. Means followed by the same letter are not significantly different at $\mathrm{P}=0.05$ according to Duncan's multiple range test, $\mathrm{n}=10$.

\subsection{Physical Properties}

The hydrophilic nature of fibers leads to biocomposites having high water absorption characteristics. Before making the composite, the moisture absorption of flax fibers should be reduced. During chemical treatment of the flax fiber, the hemicellulose and lignin were separated and cellulose was used for the biocomposite. Pre-treatment of the flax fiber replaced some of the hydroxyl groups in the cell wall of the flax molecule, which reduced the hygroscopic nature of the flax fiber-reinforced composites (Sreekala et al. 2000). 


\subsubsection{Moisture absorption of fibers}

Figure 5.7 shows the moisture absorption of untreated and treated flax fibers at different relative humidities. The moisture absorption of the chemically treated flax fiber was lower than that of untreated flax fibers. This result shows that chemical treatments can decrease the moisture absorption of the fibers and, hopefully it may also lead to the biocomposites having low moisture absorption characteristics.

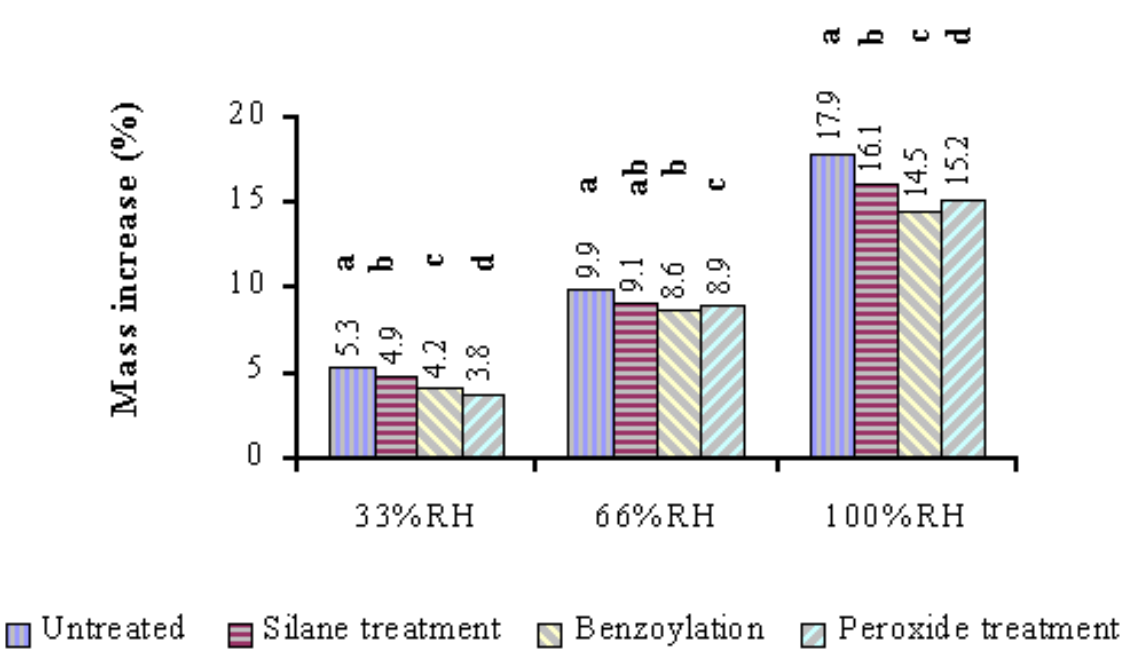

Figure 5.7 Moisture absorption of untreated and treated flax fibers at different relative humidity. Means followed by the different letter are statistically different from the untreated sample at $\mathrm{P}=0.05$ according to Duncan's multiple range test, $\mathrm{n}=3$.

\subsubsection{Water absorption of composites}

The water absorption of untreated and chemically modified flax fiber-based composites is presented in Figure 5.8 as a percentage of dry weight after $24 \mathrm{~h}$ immersion in water. The results show that the water absorption of the chemically treated flax fiber-based composites was lower than that of the untreated fiber-based composites. The untreated composites absorbed the most water and the peroxide-treated composites absorbed the 
least, suggesting that changes in surface chemistry have reduced the affinity of fibers to moisture. Strong intermolecular fiber-matrix bonding decreased the rate of moisture absorption in biocomposites. It shows that chemical treatments of flax fiber can decrease the water absorption of the biocomposites.

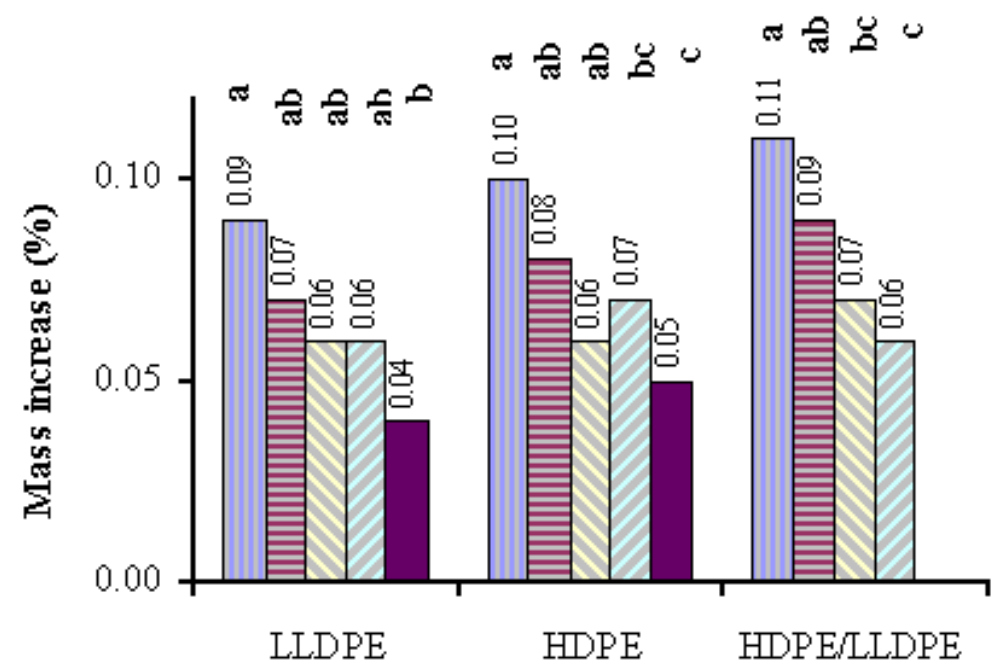

Untreated 目 Silane treatment $\square$ Benzoylation $\square$ Peroxide treatment $\square$ Resin

Figure 5.8 Water absorption of $10 \%$ fiber-based composites within group. Means followed by the different letter are statistically different from the untreated sample at $\mathrm{P}=0.05$ according to Duncan's multiple range test, $\mathrm{n}=3$.

\subsection{Melting Points of Composites}

Analyzing the DSC thermograms showed that the melting range of flax fiber-reinforced composites is displayed as an endothermic peak. DSC analysis enables the identification of chemical activity occurring in the fiber as heat is applied. DSC was used to determine not only the melting point $\left(\mathrm{T}_{\mathrm{m}}\right)$ but also the melting range of the polymer. The glass transition temperature $\left(\mathrm{T}_{\mathrm{g}}\right)$ could not be observed. The $\mathrm{T}_{\mathrm{g}}$ of pure polyethylene is usually below $-100^{\circ} \mathrm{C}$. Composites containing untreated fiber and silane-, benzoyl- and 
peroxide-treated fiber also did not display $\mathrm{T}_{\mathrm{g}}$. Table 5.1 shows the melting points of pure LLDPE, pure HDPE, untreated fiber-polymer composites and treated fiber-polymer composites. The melting point of pure LLDPE and HDPE was found to be $129.9^{\circ} \mathrm{C}$ and $130.7^{\circ} \mathrm{C}$ respectively. Changing in the melting point temperature of the polymers due to the fiber incorporation was observed. The addition of untreated/treated fiber in LLDPE increased the $T_{m}$ of LLDPE compared to that of pure LLDPE. The increase of $T_{m}$ may be attributed to the plasticization effect of the fiber that diffuses or dissolves into the polymer. The incorporation of $10 \%$ chemically treated flax fiber in LLDPE/HDPE composites increased the $T_{m}$ of untreated fiber composites. The extent of increase in $T_{m}$ is more pronounced in the case of silane-treated fiber composites, and this may be attributed to the improved plasticization of silane-treated fiber. The increased melting point of composites meant that thermal resistance increased as elucidated by the DSC method.

Table 5.1. Melting points of composites.

\begin{tabular}{lc}
\hline \multicolumn{1}{c}{ Variable } & Melting Point $\left({ }^{\circ} \mathbf{C}\right)$ \\
\hline LLDPE + U & 130.6 \\
LLDPE + S & 130.3 \\
LLDPE + B & 130.2 \\
LLDPE + P & 129.2 \\
LLDPE (pure) & 129.9 \\
HDPE + U & 133.4 \\
HDPE + S & 133.1 \\
HDPE + B & 132.9 \\
HDPE + P & 132.7 \\
HDPE (pure) & 130.7 \\
HDPE/LLDPE + U & 130.0 \\
HDPE/LLDPE + S & 131.6 \\
HDPE/LLDPE + B & 130.4 \\
HDPE/LLDPE + P & 130.2 \\
\hline
\end{tabular}

There is only one replicate in these tests. 
DSC thermograms of untreated and chemically treated flax fiber-reinforced composites are in Appendix G. 


\section{SUMMARY AND CONCLUSION}

In this chapter, the conclusions based on results obtained from the experiments are illustrated. Statistically significant results were also obtained. The data presented are only representative of those that chose to participate in the study. The major objective of this thesis was to focus on three chemical treatments of flax fibers for use in fiberreinforced composite to achieve improved properties of composites.

Renewable fibers like flax can be used as reinforcing materials for low cost composites, due to the economic and environmental advantages of such materials. However, flax fiber is highly hydrophilic due to the presence of hydroxyl groups from cellulose and lignin. Chemical treatment can reduce the hydrophilicity of the fiber by treating these fibers with suitable chemicals to decrease the hydroxyl groups in the fibers. The first objective of this thesis was to investigate suitable fiber pre-treatment methods on the effects of flax fiber properties. The tensile strength and moisture absorption data were used to address this objective. In terms of moisture absorption of fibers, all three pretreatments were effective in reducing the hydrophilic nature of fibers. In terms of the fiber bundle strength, silane treatment slightly improved the unit break of fiber bundle (although not statistically significant) more than the other fiber pre-treatments.

The composite properties were greatly influenced by the technique as well as the 
processing method used. Processing produces a great variation on the dimension and dispersion of the fiber within the composite. Understanding the relationship between processing and the properties of the composites is of key importance to obtain materials with optimized performance. From initial studies comparing single-screw and twinscrew extruders, the latter worked better in producing good quality strand of composites. Thus, it can be concluded that compounding fiber and polymer-matrix by using a twinscrew extruder could be an effective processing method prior to rotational molding. Chemically treated flax fiber is used as filler to plastics and reinforcement in thermoplastic matrix in rotational molding process. The addition of fibers can potentially lower material costs, as the fibers are available at a cheaper price than glass fibers or other inorganic additives.

The final objective was to study the effects of fiber surface modifications on the performance of the flax fiber-reinforced composites. Morphological study, mechanical properties data, physical properties data and thermal properties data were used to address this objective. Morphological and structural changes of the fibers were investigated by using scanning electron microscopy. The coupling agents were found to be effective in improving the surface properties of flax fiber, forming a mechanically interlocked coating on its surface. Therefore, physical microstructure changes occurred to the fiber surface by chemical treatment. Fiber-matrix interface plays an important role in composite properties. The ability to control the chemical and mechanical properties of the fiber-matrix interface is crucial. Morphological studies showed that the pretreatments improved the fiber-matrix adhesion and the dispersion of the particles. 
A method was developed to test quickly and accurately the tensile strength properties of flax fiber. This involved a procedure where the fibers were parallelized, conditioned and tested with the Instron testing machine. The fiber bundles break in the gauge length zone and not beside the clamping areas showing that fiber strength was not influenced by the testing apparatus. Silane and peroxide treatment on flax fiber bundle lead to a higher (although not statistically significant) tensile strength than that of the untreated fiber bundle. Chemically treated samples with a high tensile strength were considered to be quite acceptable for a biological material. Compared to the untreated fiber-based composite, tensile properties were improved with a suitable fiber surface treatment. Silane-, benzoyl-, and peroxide-treated fiber composites offered superior physical and mechanical properties. Mechanical properties of natural fiber-reinforced plastic composites could be improved by the use of a silane coupling agent.

The hydrophilic nature of biofibers leads to biocomposites with high water absorption characteristics that can be overcome by treating these fibers with suitable chemicals to decrease the hydroxyl groups of the fibers. The water absorption and swelling of the treated flax fiber composites were lower than those of untreated flax fiber composites.

A validation of the method was made on the samples with differential scanning calorimetry (DSC). The incorporation of chemically treated/untreated flax fiber into LLDPE or HDPE considerably increased the melting point $\left(\mathrm{T}_{\mathrm{m}}\right)$ of the composites. Incorporation of $10 \%$ chemically treated flax fiber in LLDPE/HDPE composites increased the $T_{m}$ of untreated fiber composites. The $T_{m}$ increase is more pronounced in 
the case of silane treated fiber.

The flax fiber is already being produced and can be obtained at a relatively low cost compared to glass fiber reinforcements. Flax fiber has a very promising future in the rotational molding industry. This research presently being conducted at the University of Saskatchewan will hopefully benefit flax growers. 


\section{RECOMMENDATIONS}

New materials derived from biofibers and thermoplastic polymers which may substitute for wood flour under particular circumstances of local supplies and cost have attracted considerable attention in recent years. The development of this novel composite type has presented new versions of common problems, such as material handling and processing. Substantial progress has been made toward overcoming the technological problems associated with compounding and extrusion of fiber-reinforced composites.

Normal methods of modifying the interface are usually not applicable in natural fibers for many reasons, cost being the most important. Natural fibers cannot compete in terms of strength with man-made fibers, but their main advantage is their low cost. Therefore, a cost effective modification method is needed to enhance the interface in natural fiber composites.

From the results of these experiments, it is quite evident that flax fiber has a very promising future and can be used as a substitute for glass fibers. Surface modifications of hydrophilic natural fibers have achieved some degree of success in making a superior interface, mechanical properties and thermal properties, but lower cost surface modification needs to be emphasized for biocomposites to replace glass fiber composites in many applications in the future. Natural fiber-reinforced composites should be 
developed and characterized so as to produce cost-competitive biocomposites for industrial applications. A thorough study is needed to evaluate the optimum levels and to make general conclusions to commercialize the use of biorenewable fibers like flax.

The exploitation of natural fibers in industrial applications provides challenges to come up with effective ways of both analyzing the modes of deformation of such materials, and in effecting the adhesion between matrix and fiber. In conjunction with this, there is a need to understand fully the basic structural components of the fibers, and their effect on the mechanical properties. The interface is one such area that has attracted a lot of interest, and new and cost effective ways of treating cellulose fibers, with the desirable end-properties, can only benefit exploitation. In the future, combination of modern testing techniques, such as Raman and miniature tensile testing, and the modification of fiber surface will lead to a better knowledge of desirable properties. The development of better processing for releasing the fibers could be another focus for the research community. Finally, to understand and measure properly the role of the interface, it is thought that a combination of techniques may be the only way to fully achieve this goal.

Processing conditions and surface treatments need to be further optimized to achieve improved properties of fiber-reinforced composites. 


\section{REFERENCES}

Al-Moussawi, H., E.K. Drown and L.T. Drzal. 1993. The silane/sizing composite interphase. Polymer Composites 14(3):195-201.

ASTM, 1993. ASTM Standard D1822-93: Standard Test Method for Tensile-Impact Energy to Break Plastics and Electrical Insulating Materials. In ASTM Standards Vol. 08.01. New York, NY: American Society for Testing and Materials.

ASTM, 1995. ASTM Standard D1294-95a: 2001. Standard Test Method for Tensile Strength and Breaking Tenacity of Wool Fiber Bundles 1-in. (25.4-mm) Gage Length. In ASTM Standards Vol. 07.01. New York, NY: American Society for Testing and Materials.

ASTM, 1995. ASTM Standard D1445-95: 1995. Standard Test Method for Breaking Strength and Elongation of Cotton Fibers (Flat Bundle Method) (Withdrawn 2004). In ASTM Standards Vol. 07.01. New York, NY: American Society for Testing and Materials.

ASTM, 1998. ASTM Standard D2240-97: Standard Test Method for Rubber Property Durometer Hardness. In ASTM Standards Vol. 08.03. New York, NY: American Society for Testing and Materials.

ASTM, 1999. ASTM Standard D638-99: Standard Test Method for Tensile Properties of Plastics. In ASTM Standards Vol. 07.01. New York, NY: American Society for Testing and Materials.

ASTM, 1999. ASTM Standard D570-99: Standard Test Method for Water Absorption of Plastics. In ASTM Standards Vol. 08.01. New York, NY: American Society for Testing and Materials.

Bataille, P., L. Richard and S. Sapieha. 1989. Effects of cellulose fibers in polypropylene composites. Polymer Composites 10(2):103-108.

Beall, G.L. 1998. Rotational Molding Design, Materials, Tooling, and Processing. Munich, Germany: Hanser Publishers. 
Bellehumeur, C.T. and J. Vlachopoulos. 1998. Polymer sintering and its role in rotational molding. In Proceedings ANTEC 98, SPE Special Publications 11121115. Brookfield, WI: SPE.

Brydson, J.A. 1989. Plastics Materials. Borough Green, England: Newnes-Butterworths.

Coutinho, F.M.B., T.H.S. Costa and D.L. Carvalho. 1997. Polypropylene-wood fiber composites: effect of treatment and mixing conditions on mechanical properties. Journal of Applied Polymer Science 65(6):1227-1235.

Crawford, R.J. 1992. Rotational Molding of Plastics. New York, NY: John Wiley and Sons.

Crawford, R.J. and J.L. Throne. 2000. Rotational Molding Technology. Norwich, NY: Plastics Design Library, William Andrew Publishing.

Culler, S.R., H. Ishida and J.L. Koenig. 1986. The silane interphase of composites: effects of process conditions on $\gamma$-aminopropyltriethoxysilane. Polymer Composites 7(4):231-238.

Edwards, H.G.M., D.W. Farwell and D. Webster. 1997. FT Raman microscopy of untreated natural plant fibers. Spectrochimica Acta, Part A: Molecular and Biomolecular Spectroscopy 53(13):2383-2392.

Folkes, M.J. 1982. Short Fiber Reinforced Thermoplastics. New York, NY: John Wiley and Sons.

Gassan, J. and A.K. Bledzki. 1999. Alkali treatment of jute fibers: relationship between structure and mechanical properties. Journal of Applied Polymer Science 71:623629.

George, J., S.S. Bhagawan and S. Thomas. 1998. Improved interactions in chemically modified pineapple leaf fiber reinforced polyethylene composites. Composite Interfaces 5(3):201-223.

George, J., M.S. Sreekala and S. Thomas. 2001. A review on interface modification and characterization of natural fiber reinforced plastic composites. Polymer Engineering and Science 41(9):1471-1485.

Ghatge, N.D. and R.S. Khisti. 1989. Performance of new silane coupling agents alongwith phenolic no-bake binder for sand core. Journal of Polymer Materials 6:145-149.

Ghosh, P. and P.K. Ganguly. 1993. Jute fibre-reinforced polyester resin composites: effect of different types and degrees of chemical modification of jute on 
performance of the composites. Plastics, Rubber and Composites Processing and Applications 20(3):171-177.

González, L., A. Rodríguez, J.L. de Benito and A. Marcos-Fernández. 1997. Applications of an azide sulfonyl silane as elastomer crosslinking and coupling agent. Journal of Applied Polymer Science 63(10):1353-1359.

Hensen, F. 1997. Plastic Extrusion Technology. 2nd ed. New York, NY: Hanser Publishers.

Ichazo, M.N., C. Albano, J. González, R. Perera and M.V. Candal. 2001. Polypropylene/wood flour composites: treatments and properties. Composite Structures 54:207-214.

Jähn, A., M.W. Schröder, M. Füting, K. Schenzel and W. Diepenbrock. 2002. Characterization of alkali treated flax fibers by means of FT Raman spectroscopy and environmental scanning electron microscopy. Spectrochimica Acta, Part A: Molecular and Biomolecular Spectroscopy 58(10):2271-2279.

Jang, B. Z., L.C. Chen, L.R. Hwang, J.E. Hawkes and R.H. Zee. 1990. The response of fibrous composites to impact loading. Polymer Composites 11(3):144-157.

Joseph, K. and S. Thomas. 1993. Dynamic mechanical properties of short sisal fiber reinforced low density polyethylene composites. Journal of Reinforced Plastics and Composites 12(2):139-155.

Joseph, K., L.H.C. Mattoso, R.D. Toledo, S. Thomas, L.H. de Carvalho, L. Pothen, S. Kala and B. James. 2000. Natural fiber reinforced thermoplastic composites. In Natural Polymers and Agrofibers Composites, ed. E. Frollini, A.L. Leão and L.H.C. Mattoso, 159-201. Sãn Carlos, Brazil: Embrapa, USP-IQSC, UNESP.

Karnani, R., M. Krishnan and R. Narayan. 1997. Biofiber-reinforced polypropylene composites. Polymer Engineering and Science 37 (2): 476-483.

Kau, H.T. 1990. A study of the impact behavior of chopped fiber reinforced composite. Polymer Composites 11(5):253-264.

Kenaga, D.L., V.T. Stannett and J.P. Fennessey. 1962. Radiation grafting of vinyl monomers to wood. Forest Products Journal 16(4):161-168.

Kokta, B.V., R. Chen, C. Daneault and J.L. Valade. 1983. Use of wood fibers in thermoplastic composites. Polymer Composites 4(4):229-232.

Kokta, B.V., D. Maldas, C. Daneault and P. Beland. 1990a. Composites of polyvinyl chloride-wood fibers. I. effect of isocyanate as a bonding agent. Polymer-Plastics Technology and Engineering 29(1-2):87-118. 
Kokta, B.V., D. Maldas, C. Daneault and P. Beland. 1990b. Composites of poly(vinyl chloride) and wood fibers. Part II: effect of chemical treatment. Polymer Composites 11(2):84-89.

Lee, S.G. and C.W. Joo. 1999. The crystallization and impact properties of high strength polyethylene fiber reinforced LLDPE composites. Polymers and Polymer Composites 7(3):195-203.

Manikandan Nair, K.C., S.M. Diwan and S. Thomas. 1996. Tensile properties of short sisal fiber reinforced polystyrene composites. Journal of Applied Polymer Science 60(9):1483-1497.

Manrich, S. and J. A. M. Agnelli. 1989. The effect of chemical treatment of wood and polymer characteristics on the properties of wood-polymer composites. Journal of Applied Polymer Science 37:1777-1790.

Mansour, O.Y., A. Nagaty, A.D. Beshay and M.H. Nosseir. 1983. Graft polymerization of monomers onto cellulose and lignocelluloses by chemically induced initiator. Journal of Polymer Science: Polymer Chemistry Edition 21:715-724.

Mishra, S., M. Misra, S.S. Tripathy, S.K. Nayak and A.K. Mohanty. 2001a. Potentiality of pineapple leaf fiber as reinforcement in PALF-Polyester composite: surface modification and mechanical performance. Journal of Reinforced Plastics and Composites 20(4):321-334.

Mishra, S., M. Misra, S.S. Tripathy, S.K. Nayak and A.K. Mohanty. 2001b. Graft copolymerization of acrylonitrile on chemically modified sisal fibers. Macromolecular Material and Engineering 286(2):107-113.

Mishra, S., M. Misra, S.S. Tripathy, S.K. Nayak and A.K. Mohanty. 2002. The influence of chemical surface modification on the performance of sisal-polyester biocomposites. Polymer Composites 23(2):164-170.

Mohanty, A.K., M. Misra and G. Hinrichsen. 2000a. Biofibers, biodegradable polymers and biocomposites: An overview. Macromolecular Materials and Engineering 276/277:1-24.

Mohanty, A.K., M.A. Khan and G. Hinrichsen. 2000b. Influence of chemical surface modification on the properties of biodegradable jute fabrics - polyester amide composites. Composites Part A: Applied Science and Manufacturing 31(2):143150 .

Mohanty, A.K., M. Misra and L.T. Drzal. 2001. Surface modifications of natural fibers and performance of the resulting biocomposites: An overview. Composite Interfaces 8(5):313-343. 
Monte, S.J. and G. Sugerman. 1984. Processing of composites with titanate coupling agents-a review. Polymer Engineering and Science 24(18):1369-1382.

Mooney, C., T. Stolle-Smits, H. Schols and E. de Jong. 2001. Analysis of retted and non retted flax fibers by chemical and enzymatic means. Journal of Biotechnology 89(2, 3):205-216.

Münker, M. and R. Holtmann. 1998. Improvement of the fiber/matrix-adhesion of natural fiber reinforced polymers. In Proceedings the 43rd International Society for the Advancement of Material and Process Engineering (SAMPE) Symposium and Exhibition, 2123-2133. Anaheim, CA: SAMPE.

Mustată, A. 1997. Factors influencing fiber-fiber friction in the case of bleached flax. Cellulose Chemistry and Technology 31:405-413.

Nielsen, L.E. 1974. Mechanical Properties of Polymers and Composites. Vol. 2. New York, NY: Marcel Dekker, Inc.

Oladipo, A.B., I.S. Wichman and J.V. Beck. 1999. Experimental investigation of the thermal properties of wood fiber/thermoplastic composites. Journal of Composite Materials 33(5):480-495.

Panigrahi, S., L.G. Tabil, W.J. Crerar, S. Sokansanj, J. Ward, T. Powell, A.J. Kovacs and L. Braun. 2002. Application of Saskatchewan grown flax fiber in rotational molding of polymer composites. Paper No. 02-302. CSAE, PO Box 316, Mansonville, QC. J0E 1X0.

http://www.engr.usask.ca/societies/csae/PapersAIC2002/CSAE02-302.pdf.

Powell, T., S. Panigrahi, J. ward, L.G. Tabil, W.J. Crerar and S. Sokansanj. 2002. Engineering properties of flax fiber and flax fiber-reinforced thermoplastic in rotational molding, Paper No. MBSK 02-205. ASAE, 2905 Niles Road, St. Joseph, MI 49085-9659 USA. http://www.engr.usask.ca/dept/age/asaecsae/papers/asaepapermbsk02-205.pdf.

Raj, R.G., B.V. Kokta, D. Maldas and C. Daneault. 1988. Use of wood fibers in thermoplastic composites: VI. Isocyanate as a bonding agent for polyethylenewood fiber composites. Polymer Composites 9(6):404-411.

Ray, D., B.K. Sarkar, A.K. Rana and N.R. Bose. 2001. Effect of alkali treated jute fibers on composite properties. Bulletin of Materials Science 24(2):129-135.

Reed, P.E. and L. Bevan. 1993. Impact damage in a composite material. Polymer Composites 14(4):286-291. 
Sapieha, S., J.F. Pupo and H.P. Schreiber. 1989. Thermal degradation of cellulosecontaining composites during processing. Journal of Applied Polymer Science $37: 233-240$.

Sapieha, S., P. Allard and Y.H. Zang. 1990. Dicumyl peroxide-modified cellulose/LLDPE composites. Journal of Applied Polymer Science 41:20392048 .

Scandola, M., G. Frisoni, and M. Baiardo. 2000. Chemically modified cellulosic reinforcements. In Book of Abstracts 219th ACS National Meeting, 26-30. Washington, D.C.: American Chemical Society.

Shah, V. 1998. Handbook of Plastics Testing Technology. 2nd ed. New York, NY: John Wiley and Sons.

Sreekala, M.S., M.G. Kumaran, S. Joseph, M. Jacob and S. Thomas. 2000. Oil palm fiber reinforced phenol formaldehyde composites: influence of fiber surface modifications on the mechanical performance. Applied Composite Materials 7:295-329.

Stamboulis, A., C.A. Baillie, S.K. Garkhail, H.G.H. Van Melick and T. Peijs. 2000. Environmental durability of flax fibers and their composites based on polypropylene matrix. Applied Composite Materials 7:273-294.

Throne, J.L. 1979. Plastics Process Engineering. New York, NY: Marcel Dekker, Inc.

Typical properties of thermoplastics. 2002. http://www.azom.com/materials.asp. Accessed October 21, 2002.

Wielage, B., E. Köhler, S. Odenwald, T. Lampke and A. Bergner. 1999. Flax-reinforced polypropylene-how process parameters affect part properties. KU Kunststoffe Plast Europe 89(8): 18-20.

Williams, G.I. and R. P. Wool. 2000. Composites from natural fibers and soy oil resins. Applied Composite Materials 7:421-432.

Woodhams, R.T., G. Thomas and D.K. Rodgers. 1984. Wood fibers as reinforcing fillers for polyolefins. Polymer Engineering and Science 24(15):1166-1171.

Yuan, X., K. Jayaraman and D. Bhattacharyya. 2002. Plasma treatment of sisal fibers and its effects on tensile strength and interfacial bonding. In Proceedings the Third International Symposium on Polymer Surface Modification: Relevance to Adhesion, Journal of Adhesion Science and Technology Special Publication 00(0):1-25. Newark, NJ: MST Conferences, LLC. 
Zaini, M.J., M.Y.A. Fuad, Z. Ismail, M.S. Mansor and J. Mustafah. 1996. The effect of filler content and size on the mechanical properties of polypropylene/oil palm wood flour composites. Polymer International 40(1):51-56. 
APPENDICES 


\section{APPENDIX A}

\section{Tensile Strength of Fiber Bundle}

Experimental conditions for the tensile strength of fiber bundle presented in Tables A1 to A4.

Temperature $(\mathrm{F}): 73$

Humidity (\%): 50

Version : 1.08

Version date : 30 May 1991

Machine : 1100

Operator : bei

Bar type : yarn

Entry dimens : YES

Units type : SI

Gauge length of $40 \mathrm{~mm}$

Test speed of $5 \mathrm{~mm} / \mathrm{min}$

Table A1. Tensile strength of untreated fiber bundle.

\begin{tabular}{|c|c|c|c|c|c|}
\hline No. & Load at break (N) & Unit Break (mN/tex) & Mass of fiber (mg) & Length of fiber (m) & $D(\operatorname{tex})=W / L$ \\
\hline 1 & 1.59 & 119.14 & 3.60 & 0.27 & 13.33 \\
\hline 2 & 1.04 & 79.75 & 2.60 & 0.20 & 13.00 \\
\hline 3 & 2.76 & 149.37 & 3.70 & 0.20 & 18.50 \\
\hline 4 & 2.85 & 157.63 & 3.80 & 0.21 & 18.10 \\
\hline 5 & 1.51 & 114.77 & 2.90 & 0.22 & 13.18 \\
\hline 6 & 1.13 & 87.56 & 2.70 & 0.21 & 12.86 \\
\hline 7 & 1.45 & 103.61 & 2.80 & 0.20 & 14.00 \\
\hline 8 & 1.11 & 80.09 & 2.50 & 0.18 & 13.89 \\
\hline 9 & 0.77 & 61.29 & 2.40 & 0.19 & 12.63 \\
\hline 10 & 2.96 & 171.57 & 3.80 & 0.22 & 17.27 \\
\hline 11 & 1.95 & 142.92 & 3.00 & 0.22 & 13.64 \\
\hline 12 & 2.64 & 162.98 & 3.40 & 0.21 & 16.19 \\
\hline 13 & 1.85 & 121.64 & 3.50 & 0.23 & 15.22 \\
\hline 14 & 1.33 & 100.59 & 2.90 & 0.22 & 13.18 \\
\hline 15 & 4.05 & 188.34 & 4.30 & 0.20 & 21.50 \\
\hline 16 & 1.64 & 110.93 & 3.10 & 0.21 & 14.76 \\
\hline 17 & 0.77 & 59.56 & 2.60 & 0.20 & 13.00 \\
\hline 18 & 1.36 & 102.12 & 2.80 & 0.21 & 13.33 \\
\hline 19 & 2.49 & 150.75 & 3.30 & 0.20 & 16.50 \\
\hline 20 & 1.35 & 105.94 & 2.80 & 0.22 & 12.73 \\
\hline 21 & 1.51 & 105.90 & 3.00 & 0.21 & 14.29 \\
\hline 22 & 0.84 & 71.70 & 2.10 & 0.18 & 11.67 \\
\hline 23 & 1.30 & 96.25 & 2.70 & 0.20 & 13.50 \\
\hline 24 & 1.93 & 116.77 & 3.30 & 0.20 & 16.50 \\
\hline 25 & 1.40 & 94.95 & 3.10 & 0.21 & 14.76 \\
\hline
\end{tabular}




\begin{tabular}{|c|c|c|c|c|c|}
\hline \multicolumn{6}{|c|}{ Table A1 continued } \\
\hline 26 & 2.79 & 161.52 & 3.80 & 0.22 & 17.27 \\
\hline 27 & 1.00 & 83.43 & 2.40 & 0.20 & 12.00 \\
\hline 28 & 1.48 & 103.96 & 2.70 & 0.19 & 14.21 \\
\hline 29 & 2.95 & 182.22 & 3.40 & 0.21 & 16.19 \\
\hline 30 & 1.49 & 112.95 & 2.50 & 0.19 & 13.16 \\
\hline 31 & 2.83 & 172.67 & 3.60 & 0.22 & 16.36 \\
\hline 32 & 2.11 & 147.95 & 3.00 & 0.21 & 14.29 \\
\hline 33 & 3.09 & 166.22 & 3.90 & 0.21 & 18.57 \\
\hline 34 & 2.07 & 115.88 & 3.40 & 0.19 & 17.89 \\
\hline 35 & 1.45 & 100.04 & 2.90 & 0.20 & 14.50 \\
\hline 36 & 1.86 & 122.35 & 3.20 & 0.21 & 15.24 \\
\hline 37 & 1.20 & 84.54 & 2.70 & 0.19 & 14.21 \\
\hline 38 & 3.46 & 182.20 & 3.80 & 0.20 & 19.00 \\
\hline 39 & 3.95 & 207.45 & 4.00 & 0.21 & 19.05 \\
\hline 40 & 0.84 & 75.29 & 2.00 & 0.18 & 11.11 \\
\hline 41 & 1.84 & 114.07 & 2.90 & 0.18 & 16.11 \\
\hline 42 & 2.89 & 155.50 & 3.90 & 0.21 & 18.57 \\
\hline 43 & 2.01 & 121.90 & 3.30 & 0.20 & 16.50 \\
\hline 44 & 1.40 & 102.43 & 2.60 & 0.19 & 13.68 \\
\hline 45 & 2.47 & 167.60 & 3.10 & 0.21 & 14.76 \\
\hline 46 & 0.86 & 65.84 & 3.00 & 0.23 & 13.04 \\
\hline 47 & 2.09 & 143.48 & 3.20 & 0.22 & 14.55 \\
\hline 48 & 1.36 & 113.47 & 2.40 & 0.20 & 12.00 \\
\hline 49 & 0.94 & 71.98 & 3.00 & 0.23 & 13.04 \\
\hline 50 & 1.35 & 86.98 & 3.10 & 0.20 & 15.50 \\
\hline \multicolumn{2}{|l|}{ SUM } & 6018.06 & & & \\
\hline \multicolumn{2}{|c|}{ Average (UB ave $_{\text {e }}$ ) } & 120.36 & & & \\
\hline \multicolumn{2}{|c|}{ Standard Deviation (S) } & 37.31 & & & \\
\hline \multicolumn{2}{|c|}{ Coef. Var. (CV) } & 31.00 & & & \\
\hline \multirow{2}{*}{\multicolumn{2}{|c|}{$95 \%$ confidence interval }} & Upper & Lower & & \\
\hline & & 131.07 & 109.65 & & \\
\hline
\end{tabular}

Linear Density or more commonly tex is calculated by:

$$
\mathrm{D}=\frac{\mathrm{W}}{\mathrm{L}}
$$

Where: $\mathrm{D}=$ linear density or tex $(\mathrm{mg} / \mathrm{m})$

$$
\begin{aligned}
\mathrm{W} & =\text { mass of fibers }(\mathrm{mg}) \\
\mathrm{L} & =\text { length of fiber }(\mathrm{m})
\end{aligned}
$$

Unit Break is calculated by:

$$
\mathrm{UB}=\frac{\mathrm{F}}{\mathrm{D}}
$$

Where: $\mathrm{F}=$ maximum breaking load $(\mathrm{mN})$

$\mathrm{D}=$ linear density or tex $(\mathrm{mg} / \mathrm{m})$

$\mathrm{UB}=$ unit break $(\mathrm{mN} / \mathrm{tex})$

$\mathrm{UB}_{\text {ave }}=$ average unit break $(\mathrm{mN} / \mathrm{tex})$ 
Table A2. Tensile strength of silane treated fiber bundle.

\begin{tabular}{|c|c|c|c|c|c|}
\hline No. & Load at break (N) & Unit Break (mN/tex) & Mass of fiber (mg) & Length of fiber (m) & $D(\operatorname{tex})=W / L$ \\
\hline 1 & 2.07 & 162.00 & 3.20 & 0.25 & 12.80 \\
\hline 2 & 1.64 & 131.00 & 3.00 & 0.24 & 12.50 \\
\hline 3 & 1.94 & 115.36 & 3.70 & 0.22 & 16.82 \\
\hline 4 & 1.85 & 115.07 & 3.70 & 0.23 & 16.09 \\
\hline 5 & 1.55 & 138.83 & 2.90 & 0.26 & 11.15 \\
\hline 6 & 2.84 & 199.49 & 3.70 & 0.26 & 14.23 \\
\hline 7 & 1.16 & 106.46 & 2.40 & 0.22 & 10.91 \\
\hline 8 & 1.96 & 130.87 & 3.00 & 0.20 & 15.00 \\
\hline 9 & 1.55 & 114.70 & 2.70 & 0.20 & 13.50 \\
\hline 10 & 1.39 & 109.08 & 2.80 & 0.22 & 12.73 \\
\hline 11 & 1.44 & 110.19 & 3.00 & 0.23 & 13.04 \\
\hline 12 & 2.85 & 176.17 & 3.40 & 0.21 & 16.19 \\
\hline 13 & 2.18 & 166.82 & 3.00 & 0.23 & 13.04 \\
\hline 14 & 1.86 & 128.58 & 2.90 & 0.20 & 14.50 \\
\hline 15 & 2.01 & 129.76 & 3.10 & 0.20 & 15.50 \\
\hline 16 & 1.02 & 102.34 & 2.00 & 0.20 & 10.00 \\
\hline 17 & 2.16 & 156.60 & 2.90 & 0.21 & 13.81 \\
\hline 18 & 1.56 & 124.95 & 2.50 & 0.20 & 12.50 \\
\hline 19 & 1.25 & 105.03 & 2.50 & 0.21 & 11.90 \\
\hline 20 & 1.98 & 131.71 & 3.30 & 0.22 & 15.00 \\
\hline 21 & 1.28 & 106.42 & 2.40 & 0.20 & 12.00 \\
\hline 22 & 1.56 & 126.15 & 2.60 & 0.21 & 12.38 \\
\hline 23 & 1.17 & 107.26 & 2.30 & 0.21 & 10.95 \\
\hline 24 & 0.77 & 93.73 & 1.90 & 0.23 & 8.26 \\
\hline 25 & 1.33 & 108.05 & 2.70 & 0.22 & 12.27 \\
\hline 26 & 1.16 & 101.62 & 2.40 & 0.21 & 11.43 \\
\hline 27 & 0.97 & 92.58 & 2.00 & 0.19 & 10.53 \\
\hline 28 & 2.83 & 206.15 & 3.70 & 0.27 & 13.70 \\
\hline 29 & 1.15 & 120.49 & 2.20 & 0.23 & 9.57 \\
\hline 30 & 1.10 & 125.61 & 2.10 & 0.24 & 8.75 \\
\hline 31 & 1.59 & 120.47 & 2.90 & 0.22 & 13.18 \\
\hline 32 & 1.64 & 116.96 & 2.80 & 0.20 & 14.00 \\
\hline 33 & 1.66 & 138.68 & 3.00 & 0.25 & 12.00 \\
\hline 34 & 1.17 & 122.58 & 2.30 & 0.24 & 9.58 \\
\hline 35 & 1.91 & 127.56 & 3.30 & 0.22 & 15.00 \\
\hline 36 & 1.66 & 109.21 & 3.20 & 0.21 & 15.24 \\
\hline 37 & 1.56 & 120.92 & 3.10 & 0.24 & 12.92 \\
\hline 38 & 1.68 & 116.92 & 3.30 & 0.23 & 14.35 \\
\hline 39 & 1.15 & 100.22 & 2.30 & 0.20 & 11.50 \\
\hline 40 & 1.51 & 145.24 & 2.50 & 0.24 & 10.42 \\
\hline 41 & 1.76 & 127.60 & 2.90 & 0.21 & 13.81 \\
\hline 42 & 1.34 & 104.82 & 2.30 & 0.18 & 12.78 \\
\hline 43 & 1.13 & 97.23 & 2.20 & 0.19 & 11.58 \\
\hline 44 & 0.94 & 103.77 & 1.90 & 0.21 & 9.05 \\
\hline 45 & 1.37 & 143.23 & 2.40 & 0.25 & 9.60 \\
\hline 46 & 1.25 & 104.20 & 2.40 & 0.20 & 12.00 \\
\hline
\end{tabular}




\begin{tabular}{|c|c|c|c|c|c|}
\hline \multicolumn{6}{|c|}{ Table A2 continued } \\
\hline 47 & 1.02 & 94.16 & 2.50 & 0.23 & 10.87 \\
\hline 48 & 1.33 & 126.84 & 2.30 & 0.22 & 10.45 \\
\hline 49 & 1.59 & 146.64 & 2.60 & 0.24 & 10.83 \\
\hline 50 & 1.49 & 118.90 & 2.50 & 0.20 & 12.50 \\
\hline SUM & & 6229.17 & & & \\
\hline Aver: & & 124.58 & & & \\
\hline Stand & ion $(S)$ & 24.86 & & & \\
\hline Coef. & & 19.95 & & & \\
\hline \multirow{2}{*}{\multicolumn{2}{|c|}{$95 \%$ confidence interval }} & Upper & Lower & & \\
\hline & & 131.72 & 117.45 & & \\
\hline
\end{tabular}


Table A3. Tensile strength of benzoylation treated fiber bundle.

\begin{tabular}{|c|c|c|c|c|c|}
\hline No. & Load at break (N) & Unit Break (mN/tex) & Mass of fiber (mg) & Length of fiber (m) & $D(\operatorname{tex})=W / L$ \\
\hline 1 & 1.40 & 128.95 & 2.50 & 0.23 & 10.87 \\
\hline 2 & 1.15 & 137.20 & 2.10 & 0.25 & 8.40 \\
\hline 3 & 0.93 & 112.04 & 1.90 & 0.23 & 8.26 \\
\hline 4 & 0.81 & 114.96 & 1.70 & 0.24 & 7.08 \\
\hline 5 & 0.81 & 104.05 & 1.80 & 0.23 & 7.83 \\
\hline 6 & 1.05 & 125.02 & 2.10 & 0.25 & 8.40 \\
\hline 7 & 1.10 & 120.90 & 2.00 & 0.22 & 9.09 \\
\hline 8 & 0.56 & 80.60 & 1.60 & 0.23 & 6.96 \\
\hline 9 & 1.01 & 110.28 & 2.30 & 0.25 & 9.20 \\
\hline 10 & 1.03 & 107.38 & 2.10 & 0.22 & 9.55 \\
\hline 11 & 0.69 & 90.52 & 1.60 & 0.21 & 7.62 \\
\hline 12 & 0.55 & 80.93 & 1.50 & 0.22 & 6.82 \\
\hline 13 & 0.56 & 82.23 & 1.50 & 0.22 & 6.82 \\
\hline 14 & 1.02 & 114.00 & 1.70 & 0.19 & 8.95 \\
\hline 15 & 0.78 & 71.50 & 2.40 & 0.22 & 10.91 \\
\hline 16 & 1.11 & 155.40 & 1.50 & 0.21 & 7.14 \\
\hline 17 & 0.59 & 47.65 & 2.60 & 0.21 & 12.38 \\
\hline 18 & 0.67 & 63.65 & 2.00 & 0.19 & 10.53 \\
\hline 19 & 0.85 & 58.62 & 2.90 & 0.20 & 14.50 \\
\hline 20 & 0.87 & 130.50 & 1.40 & 0.21 & 6.67 \\
\hline 21 & 1.20 & 120.00 & 1.90 & 0.19 & 10.00 \\
\hline 22 & 0.66 & 60.00 & 2.20 & 0.20 & 11.00 \\
\hline 23 & 0.59 & 72.88 & 1.70 & 0.21 & 8.10 \\
\hline 24 & 1.00 & 100.00 & 1.80 & 0.18 & 10.00 \\
\hline 25 & 1.04 & 93.60 & 2.00 & 0.18 & 11.11 \\
\hline 26 & 0.98 & 171.50 & 1.20 & 0.21 & 5.71 \\
\hline 27 & 0.96 & 101.05 & 1.90 & 0.20 & 9.50 \\
\hline 28 & 0.74 & 74.00 & 1.90 & 0.19 & 10.00 \\
\hline 29 & 0.83 & 79.39 & 2.30 & 0.22 & 10.45 \\
\hline 30 & 0.96 & 138.00 & 1.60 & 0.23 & 6.96 \\
\hline 31 & 1.02 & 106.86 & 2.10 & 0.22 & 9.55 \\
\hline 32 & 0.95 & 118.75 & 2.00 & 0.25 & 8.00 \\
\hline 33 & 1.04 & 199.33 & 1.20 & 0.23 & 5.22 \\
\hline 34 & 0.87 & 116.00 & 1.50 & 0.20 & 7.50 \\
\hline 35 & 1.06 & 111.89 & 1.80 & 0.19 & 9.47 \\
\hline 36 & 0.69 & 90.79 & 1.90 & 0.25 & 7.60 \\
\hline 37 & 0.59 & 71.83 & 2.30 & 0.28 & 8.21 \\
\hline 38 & 0.79 & 82.29 & 2.40 & 0.25 & 9.60 \\
\hline 39 & 0.89 & 97.90 & 2.00 & 0.22 & 9.09 \\
\hline 40 & 1.20 & 184.00 & 1.50 & 0.23 & 6.52 \\
\hline 41 & 0.83 & 72.17 & 2.30 & 0.20 & 11.50 \\
\hline 42 & 0.94 & 119.07 & 1.50 & 0.19 & 7.89 \\
\hline 43 & 0.97 & 152.43 & 1.40 & 0.22 & 6.36 \\
\hline 44 & 0.76 & 104.50 & 1.60 & 0.22 & 7.27 \\
\hline 45 & 0.93 & 103.33 & 1.80 & 0.20 & 9.00 \\
\hline 46 & 1.01 & 132.89 & 1.90 & 0.25 & 7.60 \\
\hline
\end{tabular}




\begin{tabular}{|c|c|c|c|c|c|}
\hline \multicolumn{6}{|c|}{ Table A3 continued } \\
\hline 47 & 1.09 & 103.55 & 2.00 & 0.19 & 10.53 \\
\hline 48 & 0.85 & 115.36 & 1.40 & 0.19 & 7.37 \\
\hline 49 & 0.96 & 114.29 & 2.10 & 0.25 & 8.40 \\
\hline 50 & 0.99 & 122.29 & 1.70 & 0.21 & 8.10 \\
\hline SUM & & 5366.32 & & & \\
\hline Aver & ave) & 107.33 & & & \\
\hline Stan & iation $(\mathrm{S})$ & 31.61 & & & \\
\hline Coef & & 29.45 & & & \\
\hline \multirow{2}{*}{\multicolumn{2}{|c|}{$95 \%$ confidence interval }} & Upper & Lower & & \\
\hline & & 116.40 & 98.25 & & \\
\hline
\end{tabular}


Table A4. Tensile strength of peroxide treated fiber bundle.

\begin{tabular}{|c|c|c|c|c|c|}
\hline No. & Load at break (N) & Unit Break (mN/tex) & Mass of fiber (mg) & Length of fiber (m) & $D(\operatorname{tex})=W / L$ \\
\hline 1 & 2.25 & 174.31 & 3.10 & 0.24 & 12.92 \\
\hline 2 & 0.77 & 91.09 & 1.70 & 0.20 & 8.50 \\
\hline 3 & 1.02 & 113.12 & 1.90 & 0.21 & 9.05 \\
\hline 4 & 1.55 & 137.12 & 2.60 & 0.23 & 11.30 \\
\hline 5 & 1.33 & 126.84 & 2.30 & 0.22 & 10.45 \\
\hline 6 & 2.14 & 172.61 & 3.10 & 0.25 & 12.40 \\
\hline 7 & 1.29 & 123.01 & 2.30 & 0.22 & 10.45 \\
\hline 8 & 1.02 & 102.34 & 1.90 & 0.19 & 10.00 \\
\hline 9 & 1.73 & 147.07 & 2.70 & 0.23 & 11.74 \\
\hline 10 & 0.77 & 95.64 & 1.70 & 0.21 & 8.10 \\
\hline 11 & 1.80 & 146.84 & 2.70 & 0.22 & 12.27 \\
\hline 12 & 1.90 & 142.50 & 2.80 & 0.21 & 13.33 \\
\hline 13 & 1.79 & 139.13 & 2.70 & 0.21 & 12.86 \\
\hline 14 & 2.22 & 170.57 & 3.00 & 0.23 & 13.04 \\
\hline 15 & 1.51 & 128.01 & 2.60 & 0.22 & 11.82 \\
\hline 16 & 1.09 & 124.86 & 2.00 & 0.23 & 8.70 \\
\hline 17 & 1.49 & 130.04 & 2.40 & 0.21 & 11.43 \\
\hline 18 & 0.55 & 73.57 & 1.50 & 0.20 & 7.50 \\
\hline 19 & 1.48 & 135.91 & 2.50 & 0.23 & 10.87 \\
\hline 20 & 1.35 & 134.83 & 2.40 & 0.24 & 10.00 \\
\hline 21 & 2.15 & 157.61 & 3.00 & 0.22 & 13.64 \\
\hline 22 & 1.94 & 145.51 & 2.80 & 0.21 & 13.33 \\
\hline 23 & 0.57 & 75.34 & 1.60 & 0.21 & 7.62 \\
\hline 24 & 1.55 & 126.17 & 2.70 & 0.22 & 12.27 \\
\hline 25 & 0.68 & 79.57 & 1.70 & 0.20 & 8.50 \\
\hline 26 & 1.50 & 118.71 & 2.40 & 0.19 & 12.63 \\
\hline 27 & 1.65 & 117.92 & 2.80 & 0.20 & 14.00 \\
\hline 28 & 0.96 & 105.73 & 2.00 & 0.22 & 9.09 \\
\hline 29 & 2.07 & 153.85 & 3.10 & 0.23 & 13.48 \\
\hline 30 & 1.44 & 143.73 & 2.40 & 0.24 & 10.00 \\
\hline 31 & 1.21 & 116.20 & 2.30 & 0.22 & 10.45 \\
\hline 32 & 1.62 & 138.35 & 2.70 & 0.23 & 11.74 \\
\hline 33 & 1.56 & 144.62 & 2.70 & 0.25 & 10.80 \\
\hline 34 & 0.85 & 94.43 & 1.80 & 0.20 & 9.00 \\
\hline 35 & 1.19 & 124.46 & 2.10 & 0.22 & 9.55 \\
\hline 36 & 1.30 & 124.03 & 2.20 & 0.21 & 10.48 \\
\hline 37 & 0.81 & 105.38 & 1.70 & 0.22 & 7.73 \\
\hline 38 & 0.66 & 95.31 & 1.60 & 0.23 & 6.96 \\
\hline 39 & 0.70 & 87.33 & 1.60 & 0.20 & 8.00 \\
\hline 40 & 0.94 & 113.66 & 1.90 & 0.23 & 8.26 \\
\hline 41 & 1.28 & 121.90 & 2.20 & 0.21 & 10.48 \\
\hline 42 & 1.02 & 113.12 & 1.90 & 0.21 & 9.05 \\
\hline 43 & 0.99 & 119.58 & 1.90 & 0.23 & 8.26 \\
\hline 44 & 1.01 & 121.74 & 2.00 & 0.24 & 8.33 \\
\hline 45 & 1.26 & 126.37 & 2.20 & 0.22 & 10.00 \\
\hline 46 & 0.91 & 100.82 & 1.90 & 0.21 & 9.05 \\
\hline
\end{tabular}




\begin{tabular}{|c|c|c|c|c|c|}
\hline \multicolumn{6}{|c|}{ Table A4 continued } \\
\hline 47 & 1.08 & 117.94 & 2.10 & 0.23 & 9.13 \\
\hline 48 & 1.08 & 118.45 & 2.00 & 0.22 & 9.09 \\
\hline 49 & 0.59 & 69.75 & 1.60 & 0.19 & 8.42 \\
\hline 50 & 1.01 & 116.67 & 2.00 & 0.23 & 8.70 \\
\hline SUM & & 6103.64 & & & \\
\hline Aver & ave) & 122.07 & & & \\
\hline Stan & iation $(\mathrm{S})$ & 24.57 & & & \\
\hline Coef & & 20.13 & & & \\
\hline \multirow{2}{*}{\multicolumn{2}{|c|}{$95 \%$ confidence interval }} & Upper & Lower & & \\
\hline & & 129.13 & 115.02 & & \\
\hline
\end{tabular}


Table A5. Statistical analysis of tensile strength of fiber bundle.

\begin{tabular}{|c|c|c|c|c|c|c|c|c|}
\hline \multirow[t]{2}{*}{ Variable } & \multirow[t]{2}{*}{$\mathbf{N}$} & \multirow{2}{*}{$\begin{array}{c}\text { Mean } \\
(\mathrm{mN} / \mathrm{tex})\end{array}$} & \multirow{2}{*}{$\begin{array}{c}\text { Std. } \\
\text { Deviation } \\
(\mathrm{mN} / \mathrm{tex})\end{array}$} & \multirow{2}{*}{$\begin{array}{c}\text { Std. } \\
\text { Error } \\
(\mathrm{mN} / \mathrm{tex})\end{array}$} & \multicolumn{2}{|c|}{$\begin{array}{l}\text { 95\% Confidence Interval } \\
\text { for Mean ( } \mathrm{mN} / \text { tex) }\end{array}$} & \multicolumn{2}{|c|}{ UB (mN/tex) } \\
\hline & & & & & Lower & Upper & Minimum & Maximum \\
\hline Untreated & 50 & 120.36 & 37.31 & 5.28 & 109.76 & 130.96 & 59.56 & 207.45 \\
\hline Silane & 50 & 124.58 & 24.86 & 3.52 & 117.52 & 131.65 & 92.58 & 206.15 \\
\hline Benzoylation & 50 & 107.33 & 31.42 & 4.44 & 98.40 & 116.26 & 47.65 & 199.33 \\
\hline Peroxide & 50 & 122.07 & 24.57 & 3.47 & 115.09 & 129.06 & 69.75 & 174.31 \\
\hline Total & 200 & 118.59 & 30.52 & 2.16 & 114.33 & 122.84 & 47.65 & 207.45 \\
\hline
\end{tabular}

\section{One way Analysis of Variance}

\begin{tabular}{lccccc}
\hline & df & Sum of Squares & Mean Square & Computed & Computed \\
\cline { 4 - 5 } & & & & $\boldsymbol{F}$ & Sig. (0.05) \\
\hline Between Groups & 3 & 8903.49 & 2967.83 & $3.30^{*}$ & 0.022 \\
Within Groups & 196 & 176438.09 & 900.19 & \\
$\quad$ Total & 199 & 185341.58 & & & \\
\hline ns $=$ not significant, & & & \\
\hline
\end{tabular}

\section{Multiple Comparisons}

\begin{tabular}{|c|c|c|c|c|c|c|c|}
\hline & \multirow{2}{*}{ (I) } & \multirow{2}{*}{$(J)$} & \multirow{2}{*}{$\begin{array}{c}\text { Mean } \\
\text { Difference } \\
\text { (I-J) }\end{array}$} & \multirow{2}{*}{$\begin{array}{l}\text { Std. } \\
\text { Error }\end{array}$} & \multirow{2}{*}{$\begin{array}{l}\text { Computed } \\
\text { Sig. (0.05) }\end{array}$} & \multicolumn{2}{|c|}{ 95\% Confidence Interval for Mean } \\
\hline & & & & & & Lower & Upper \\
\hline \multirow[t]{6}{*}{ LSD } & Untreated & Silane & -4.22 & 6.00 & $0.482^{\text {ns }}$ & -16.0577 & 7.6105 \\
\hline & & Benzoylation & $13.03\left(^{*}\right)$ & 6.00 & $0.031^{*}$ & 1.2003 & 24.8685 \\
\hline & & Peroxide & -1.71 & 6.00 & $0.776^{\mathrm{ns}}$ & -13.5465 & 10.1217 \\
\hline & Silane & Benzoylation & $17.26\left(^{*}\right)$ & 6.00 & $0.004^{* *}$ & 5.4239 & 29.0921 \\
\hline & & Peroxide & 2.51 & 6.00 & $0.676^{\mathrm{ns}}$ & -9.3229 & 14.3453 \\
\hline & Benzoylation & Peroxide & $-14.75\left(^{*}\right)$ & 6.00 & $0.015^{*}$ & -26.5809 & -2.9127 \\
\hline
\end{tabular}




\section{APPENDIX B}

\section{Tensile Strength of Composites}

Experimental conditions for the tensile strength of composites presented in Tables B1 and B2.

Temperature $\left({ }^{\circ} \mathrm{C}\right): 23$

Humidity (\%): 50

ASTM procedure: D638-99 (ASTM 1999)

Type I specimen: familiar dog-bone shape

Machine : Instron Universal testing machine (SATEC Systems, Inc., Grove City, PA)

Operator : bei

Units type : SI

Test speed of $5 \mathrm{~mm} / \mathrm{min}$

Table B1. Tensile strength at yield $\left(\sigma_{\mathrm{ty}}\right)$ of composites $(10 \%$ fiber).

\begin{tabular}{|c|c|c|c|c|c|}
\hline Composite & $\begin{array}{l}\text { Load at Yield } \\
\text { (N) }\end{array}$ & $\begin{array}{l}\text { Width } \\
(\mathrm{mm})\end{array}$ & $\begin{array}{l}\text { Thickness } \\
\text { (mm) }\end{array}$ & $\begin{array}{c}\text { Cross Sectional Area } \\
\left(\mathrm{mm}^{2}\right)\end{array}$ & $\begin{array}{c}\sigma_{\mathrm{ty}}=\mathrm{F} / \mathrm{A} \\
(\mathrm{MPa})\end{array}$ \\
\hline \multirow[t]{5}{*}{ LLDPE+U } & 875 & 0.0129 & 0.00449 & $5.78761 \mathrm{E}-05$ & 15.12 \\
\hline & 900 & 0.0128 & 0.00461 & $5.87775 \mathrm{E}-05$ & 15.31 \\
\hline & 925 & 0.0131 & 0.00455 & 0.000059696 & 15.50 \\
\hline & 900 & 0.0127 & 0.00485 & $6.16435 \mathrm{E}-05$ & 14.60 \\
\hline & 875 & 0.0124 & 0.00449 & $5.56311 \mathrm{E}-05$ & 15.73 \\
\hline \multirow[t]{5}{*}{ LLDPE+S } & 900 & 0.0126 & 0.00456 & $5.75472 \mathrm{E}-05$ & 15.64 \\
\hline & 875 & 0.0127 & 0.00422 & $5.34252 \mathrm{E}-05$ & 16.38 \\
\hline & 825 & 0.0125 & 0.00426 & 5.34204E-05 & 15.44 \\
\hline & 800 & 0.0116 & 0.00421 & 4.87939E-05 & 16.40 \\
\hline & 1000 & 0.0135 & 0.00490 & 0.000066101 & 15.13 \\
\hline \multirow[t]{5}{*}{ LLDPE+B } & 800 & 0.0114 & 0.00449 & $5.13207 \mathrm{E}-05$ & 15.59 \\
\hline & 875 & 0.0119 & 0.00453 & 5.40429E-05 & 16.19 \\
\hline & 950 & 0.0123 & 0.00504 & $6.18912 \mathrm{E}-05$ & 15.35 \\
\hline & 850 & 0.0112 & 0.00458 & $5.12044 \mathrm{E}-05$ & 16.60 \\
\hline & 850 & 0.0113 & 0.00447 & $5.02875 \mathrm{E}-05$ & 16.90 \\
\hline \multirow[t]{5}{*}{ LLDPE+P } & 975 & 0.0115 & 0.00458 & $5.28532 \mathrm{E}-05$ & 18.45 \\
\hline & 975 & 0.0126 & 0.00534 & 0.000067284 & 14.49 \\
\hline & 925 & 0.0123 & 0.00508 & 0.00006223 & 14.86 \\
\hline & 900 & 0.0118 & 0.00513 & $6.07392 \mathrm{E}-05$ & 14.82 \\
\hline & 975 & 0.0125 & 0.00504 & 0.000063 & 15.48 \\
\hline \multirow[t]{5}{*}{ HDPE+U } & 870 & 0.0117 & 0.00428 & 5.00332E-05 & 17.39 \\
\hline & 850 & 0.0124 & 0.00439 & $5.46116 \mathrm{E}-05$ & 15.56 \\
\hline & 900 & 0.0120 & 0.00423 & $5.05908 \mathrm{E}-05$ & 17.79 \\
\hline & 910 & 0.0116 & 0.00478 & $5.52568 \mathrm{E}-05$ & 16.47 \\
\hline & 920 & 0.0116 & 0.00472 & 0.000054516 & 16.88 \\
\hline \multirow[t]{4}{*}{$\mathrm{HDPE}+\mathrm{S}$} & 780 & 0.0106 & 0.00430 & 0.000045752 & 17.05 \\
\hline & 825 & 0.0123 & 0.00395 & $4.86245 \mathrm{E}-05$ & 16.97 \\
\hline & 890 & 0.0120 & 0.00394 & 0.000047083 & 18.90 \\
\hline & 825 & 0.0116 & 0.00411 & 4.76349E-05 & 17.32 \\
\hline
\end{tabular}




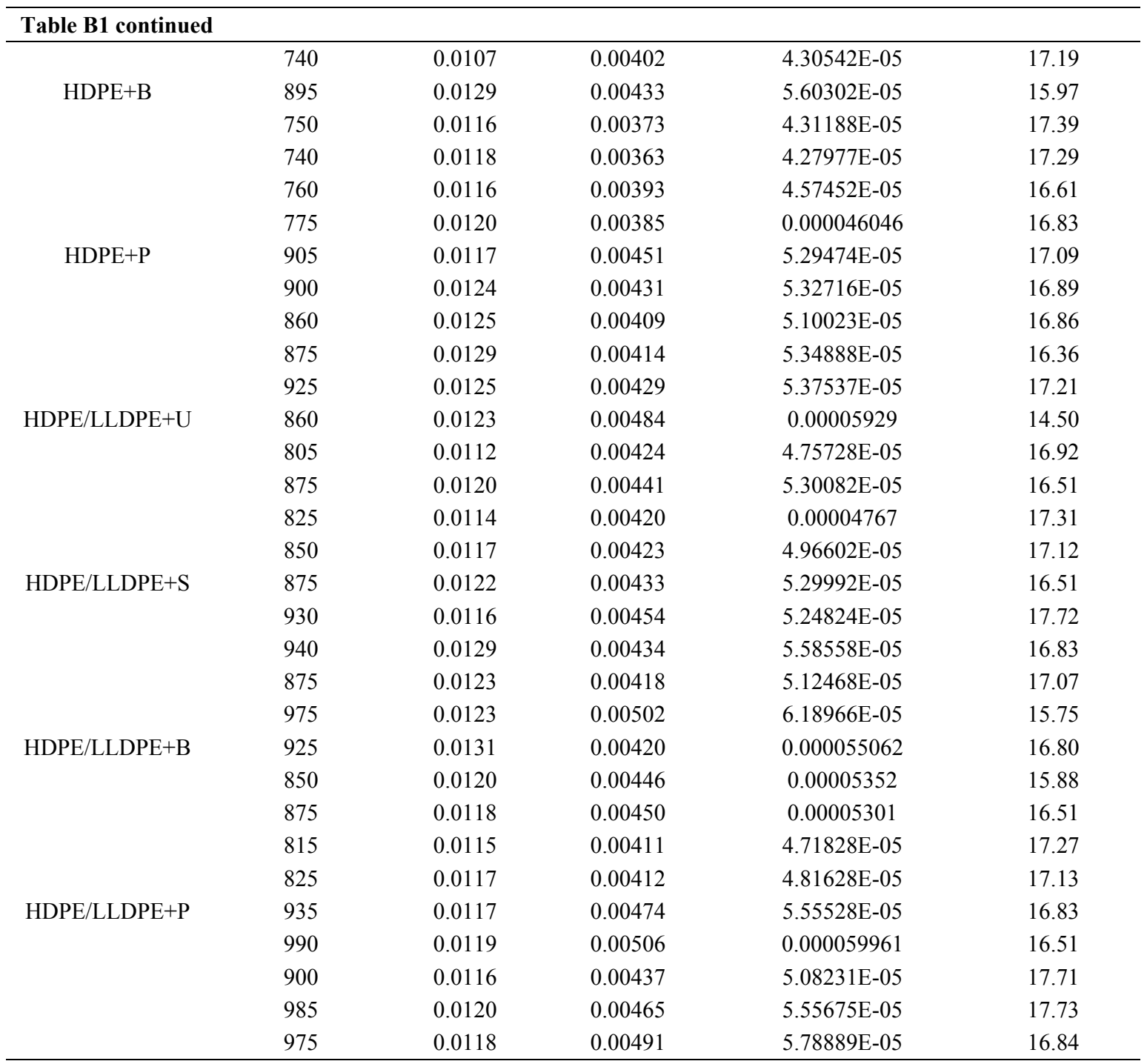

The tensile strength at yield $\left(\sigma_{\mathrm{ty}}\right)$ is calculated from the following:

$$
\sigma_{\mathrm{ty}}=\frac{\mathrm{F}_{\mathrm{max}}}{\mathrm{A}}
$$

Where: $F_{\max }=$ the maximum (peak) load value (force)

$\mathrm{A}=$ the cross sectional area $\left(\mathrm{m}^{2}\right)$ 
Table B2. Tensile strength at yield $\left(\sigma_{\mathrm{ty}}\right)$ of composites (pure thermoplastic).

\begin{tabular}{cccccc}
\hline Composite & $\begin{array}{c}\text { Load at Yield } \\
(\mathbf{N})\end{array}$ & $\begin{array}{c}\text { Width } \\
(\mathbf{m m})\end{array}$ & $\begin{array}{c}\text { Thickness } \\
(\mathbf{m m})\end{array}$ & $\begin{array}{c}\text { Cross Sectional Area } \\
\left(\mathbf{m m}^{\mathbf{2}}\right)\end{array}$ & $\begin{array}{c}\boldsymbol{\sigma}_{\mathrm{tv}}=\mathbf{F} / \mathbf{A} \\
(\mathbf{M P a})\end{array}$ \\
\hline LLDPE & 900 & 0.0113 & 0.00470 & 0.000053157 & 16.93 \\
& 850 & 0.0112 & 0.00512 & 0.000057344 & 14.82 \\
& 825 & 0.0118 & 0.00489 & $5.76042 \mathrm{E}-05$ & 14.32 \\
& 975 & 0.0117 & 0.00509 & 0.000059553 & 16.37 \\
HDPE & 825 & 0.0125 & 0.00506 & 0.00006325 & 13.04 \\
& 875 & 0.0119 & 0.00464 & 0.000055216 & 15.85 \\
& 900 & 0.0116 & 0.00456 & 0.000052896 & 17.01 \\
& 815 & 0.0129 & 0.00427 & 0.000055083 & 14.80 \\
& 985 & 0.0123 & 0.00455 & 0.000055965 & 17.60 \\
& 875 & 0.0118 & 0.00471 & $5.55309 \mathrm{E}-05$ & 15.76 \\
\hline
\end{tabular}

Table B3. Summary of tensile strength at yield $\left(\sigma_{\mathrm{ty}}\right)$ of composites.

\begin{tabular}{|c|c|c|c|c|c|}
\hline \multirow{2}{*}{ Composite } & \multirow{2}{*}{$\begin{array}{l}\text { Average } \\
\text { (MPa) }\end{array}$} & \multirow{2}{*}{$\begin{array}{c}\text { Standard Deviation } \\
\text { (MPa) }\end{array}$} & \multirow{2}{*}{$\begin{array}{l}\text { Coef. Var. } \\
(\%)\end{array}$} & \multicolumn{2}{|c|}{ 95\% Confidence Interval (MPa) } \\
\hline & & & & Upper & Lower \\
\hline $\mathrm{LLDPE}+\mathrm{U}$ & 15.25 & 0.43 & 2.81 & 15.85 & 14.66 \\
\hline $\mathrm{LLDPE}+\mathrm{S}$ & 15.80 & 0.57 & 3.60 & 16.59 & 15.01 \\
\hline LLDPE + B & 16.13 & 0.66 & 4.07 & 17.04 & 15.21 \\
\hline LLDPE + P & 15.62 & 1.62 & 10.38 & 17.87 & 13.37 \\
\hline $\mathrm{HDPE}+\mathrm{U}$ & 16.82 & 0.86 & 5.12 & 18.01 & 15.62 \\
\hline $\mathrm{HDPE}+\mathrm{S}$ & 17.48 & 0.80 & 4.60 & 18.60 & 16.37 \\
\hline $\mathrm{HDPE}+\mathrm{B}$ & 16.82 & 0.57 & 3.40 & 17.61 & 16.03 \\
\hline $\mathrm{HDPE}+\mathrm{P}$ & 16.88 & 0.33 & 1.93 & 17.34 & 16.43 \\
\hline HDPE/LLDPE + U & 16.47 & 1.14 & 6.91 & 18.05 & 14.89 \\
\hline HDPE/LLDPE + S & 16.78 & 0.73 & 4.32 & 17.78 & 15.77 \\
\hline HDPE/LLDPE + B & 16.72 & 0.63 & 3.79 & 17.60 & 15.84 \\
\hline HDPE/LLDPE + P & 17.12 & 0.56 & 3.26 & 17.90 & 16.35 \\
\hline LLDPE (pure) & 15.10 & 1.57 & 10.41 & 17.28 & 12.92 \\
\hline HDPE (pure) & 16.20 & 1.11 & 6.84 & 17.74 & 14.66 \\
\hline
\end{tabular}


Table B4. Statistical analysis of tensile strength at yield of composites.

\begin{tabular}{|c|c|c|c|c|c|c|c|c|}
\hline \multirow{2}{*}{ Variable } & \multirow{2}{*}{$\mathbf{N}$} & \multirow{2}{*}{$\begin{array}{l}\text { Mean } \\
\text { (MPa) }\end{array}$} & \multirow{2}{*}{$\begin{array}{c}\text { Std. } \\
\text { Deviation } \\
(\mathrm{MPa})\end{array}$} & \multirow{2}{*}{$\begin{array}{l}\text { Std. } \\
\text { Error } \\
(\mathrm{MPa})\end{array}$} & \multicolumn{2}{|c|}{$\begin{array}{c}\text { 95\% Confidence Interval for } \\
\text { Mean (MPa) } \\
\end{array}$} & \multicolumn{2}{|c|}{$\sigma_{\text {ty }(\mathrm{MPa})}$} \\
\hline & & & & & Lower & Upper & Minimum & Maximum \\
\hline $\mathrm{LLDPE}+\mathrm{U}$ & 5 & 15.25 & 0.43 & 0.19 & 14.72 & 15.78 & 14.60 & 15.73 \\
\hline $\mathrm{LLDPE}+\mathrm{S}$ & 5 & 15.80 & 0.57 & 0.26 & 15.09 & 16.51 & 15.13 & 16.4 \\
\hline LLDPE + B & 5 & 16.13 & 0.66 & 0.29 & 15.31 & 16.94 & 15.35 & 16.9 \\
\hline $\mathrm{LLDPE}+\mathrm{P}$ & 5 & 15.62 & 1.62 & 0.73 & 13.61 & 17.63 & 14.49 & 18.45 \\
\hline LLDPE & 5 & 15.58 & 1.57 & 0.70 & 13.14 & 17.05 & 13.04 & 16.93 \\
\hline Total & 25 & 15.58 & 1.07 & 0.21 & 15.14 & 16.02 & 13.04 & 18.45 \\
\hline $\mathrm{HDPE}+\mathrm{U}$ & 5 & 16.82 & 0.86 & 0.39 & 15.75 & 17.89 & 15.56 & 17.79 \\
\hline $\mathrm{HDPE}+\mathrm{S}$ & 5 & 17.49 & 0.80 & 0.36 & 16.49 & 18.48 & 16.97 & 18.9 \\
\hline $\mathrm{HDPE}+\mathrm{B}$ & 5 & 16.82 & 0.57 & 0.26 & 16.11 & 17.53 & 15.97 & 17.39 \\
\hline $\mathrm{HDPE}+\mathrm{P}$ & 5 & 16.88 & 0.33 & 0.15 & 16.48 & 17.29 & 16.36 & 17.21 \\
\hline HDPE & 5 & 16.20 & 1.11 & 0.49 & 14.83 & 17.58 & 14.80 & 17.6 \\
\hline Total & 25 & 16.84 & 0.82 & 0.16 & 16.50 & 17.18 & 14.80 & 18.9 \\
\hline HDPE/LLDPE + U & 5 & 16.47 & 1.14 & 0.51 & 15.05 & 17.89 & 14.50 & 17.31 \\
\hline HDPE/LLDPE + S & 5 & 16.78 & 0.73 & 0.32 & 15.88 & 17.68 & 15.75 & 17.72 \\
\hline HDPE/LLDPE + B & 5 & 16.72 & 0.55 & 0.25 & 16.03 & 17.41 & 15.88 & 17.27 \\
\hline HDPE/LLDPE + P & 5 & 17.12 & 0.56 & 0.25 & 16.43 & 17.82 & 16.51 & 17.73 \\
\hline Total & 20 & 16.77 & 0.76 & 0.17 & 16.42 & 17.13 & 14.50 & 17.73 \\
\hline
\end{tabular}

\section{One way Analysis of Variance}

\begin{tabular}{|c|c|c|c|c|c|c|}
\hline & & \multirow{2}{*}{ df } & \multirow{2}{*}{$\begin{array}{c}\text { Sum of } \\
\text { Squares }\end{array}$} & \multirow{2}{*}{ Mean Square } & Computed & Computed \\
\hline & & & & & $F$ & Sig. (0.05) \\
\hline \multirow[t]{3}{*}{ LLDPE } & Between Groups & 4 & 3.45 & 0.86 & $0.71^{\mathrm{ns}}$ & 0.593 \\
\hline & Within Groups & 20 & 24.17 & 1.21 & & \\
\hline & Total & 24 & 27.61 & & & \\
\hline \multirow[t]{3}{*}{ HDPE } & Between Groups & 4 & 4.12 & 1.03 & $1.69^{\mathrm{ns}}$ & 0.191 \\
\hline & Within Groups & 20 & 12.18 & 0.61 & & \\
\hline & Total & 24 & 16.30 & & & \\
\hline \multirow[t]{3}{*}{ HDPE/LLDPE } & Between Groups & 3 & 1.08 & 0.36 & $0.59^{\mathrm{ns}}$ & 0.63 \\
\hline & Within Groups & 16 & 9.80 & 0.61 & & \\
\hline & Total & 19 & 10.88 & & & \\
\hline
\end{tabular}

\section{Homogeneous Subsets}

\begin{tabular}{cccc}
\hline & Fiber Treatment & N & P $=\mathbf{0 ~ . 0 5}$ \\
\hline LLDPE & Pure & 5 & Mean (MPa) \\
& U & 5 & $15.580^{\mathrm{a}}$ \\
P & 5 & $15.252^{\mathrm{a}}$ \\
S & 5 & $15.620^{\mathrm{a}}$ \\
& B & 5 & $15.798^{\mathrm{a}}$ \\
& 5 & $16.126^{\mathrm{a}}$ \\
\hline
\end{tabular}




\begin{tabular}{cccc}
\hline Table B4 continued & & & \\
\hline HDPE & Pure & 5 & $16.204^{\mathrm{a}}$ \\
& $\mathrm{B}$ & 5 & $16.818^{\mathrm{a}}$ \\
$\mathrm{U}$ & 5 & $16.818^{\mathrm{a}}$ \\
$\mathrm{P}$ & 5 & $16.882^{\mathrm{a}}$ \\
& $\mathrm{S}$ & 5 & $17.486^{\mathrm{b}}$ \\
\hline HDPE/LLDPE & $\mathrm{U}$ & 5 & $16.472^{\mathrm{a}}$ \\
& $\mathrm{B}$ & 5 & $16.718^{\mathrm{a}}$ \\
& $\mathrm{S}$ & 5 & $16.776^{\mathrm{a}}$ \\
& $\mathrm{P}$ & 5 & $17.124^{\mathrm{a}}$ \\
\hline
\end{tabular}

Means for groups in homogeneous subsets are displayed.

Uses Harmonic Mean Sample Size = 5.000. 


\section{APPENDIX C}

\section{Tensile-Impact Strength of Composites}

Experimental conditions for the tensile-impact strength of composites presented in Tables $\mathrm{C} 1$ and $\mathrm{C} 2$.

Temperature $\left({ }^{\circ} \mathrm{C}\right): 23$

Humidity (\%): 50

ASTM procedure: D1822-93 (ASTM 1993)

Type L (long) specimen: dumbbell-shaped

Machine : tensile impact tester (Tinius Olsen Testing Machines Co., Willow Grove, PA) Operator : bei

Units type : SI

Table C1. Tensile-impact strength of composites ( $10 \%$ fiber).

\begin{tabular}{|c|c|c|c|c|c|c|}
\hline \multirow{2}{*}{ Composite } & \multirow{2}{*}{ Width (in) } & \multirow{2}{*}{ Depth (in) } & \multicolumn{2}{|c|}{ Impact Energy } & \multicolumn{2}{|c|}{ Tensile-Impact Strength } \\
\hline & & & (in·lbf) & $(\mathbf{N} \cdot \mathbf{m})$ & $\left(\mathbf{f t} \cdot \mathbf{l b f} / \mathbf{i n}^{2}\right)$ & $\left(\mathrm{kJ} / \mathrm{m}^{2}\right)$ \\
\hline \multirow[t]{5}{*}{ LLDPE+U } & 0.1020 & 0.1305 & 14.00 & 1.59 & 87.65 & 184.15 \\
\hline & 0.1050 & 0.1495 & 20.00 & 2.26 & 106.17 & 223.07 \\
\hline & 0.1335 & 0.1305 & 18.50 & 2.09 & 88.49 & 185.92 \\
\hline & 0.1160 & 0.1280 & 15.00 & 1.69 & 84.19 & 176.88 \\
\hline & 0.1025 & 0.1340 & 14.00 & 1.59 & 84.94 & 178.46 \\
\hline \multirow[t]{5}{*}{ LLDPE+S } & 0.0925 & 0.1345 & 15.50 & 1.75 & 103.82 & 218.13 \\
\hline & 0.0945 & 0.1545 & 14.50 & 1.64 & 82.76 & 173.88 \\
\hline & 0.0985 & 0.1420 & 16.00 & 1.80 & 95.33 & 200.28 \\
\hline & 0.0750 & 0.1390 & 14.50 & 1.64 & 115.91 & 243.52 \\
\hline & 0.0900 & 0.1465 & 15.00 & 1.69 & 94.80 & 199.18 \\
\hline \multirow[t]{5}{*}{ LLDPE+B } & 0.0950 & 0.1395 & 15.00 & 1.69 & 94.32 & 198.17 \\
\hline & 0.0930 & 0.1350 & 10.00 & 1.13 & 66.37 & 139.45 \\
\hline & 0.0850 & 0.1180 & 14.00 & 1.59 & 116.32 & 244.38 \\
\hline & 0.1010 & 0.1220 & 20.50 & 2.32 & 138.64 & 291.28 \\
\hline & 0.0820 & 0.1350 & 14.00 & 1.59 & 105.39 & 221.42 \\
\hline \multirow[t]{5}{*}{ LLDPE+P } & 0.0965 & 0.1375 & 16.00 & 1.80 & 100.49 & 211.12 \\
\hline & 0.0945 & 0.1425 & 14.00 & 1.59 & 86.64 & 182.02 \\
\hline & 0.0975 & 0.1315 & 15.00 & 1.69 & 97.49 & 204.84 \\
\hline & 0.0970 & 0.1320 & 16.00 & 1.80 & 104.13 & 218.79 \\
\hline & 0.0990 & 0.1405 & 15.00 & 1.69 & 89.87 & 188.81 \\
\hline \multirow[t]{5}{*}{$\mathrm{HDPE}+\mathrm{U}$} & 0.1170 & 0.1480 & 20.00 & 2.26 & 96.25 & 202.22 \\
\hline & 0.1150 & 0.1420 & 17.00 & 1.93 & 86.75 & 182.27 \\
\hline & 0.1170 & 0.1450 & 20.50 & 2.32 & 100.70 & 211.57 \\
\hline & 0.1110 & 0.1450 & 14.00 & 1.59 & 72.49 & 152.29 \\
\hline & 0.1035 & 0.1460 & 19.00 & 2.14 & 104.78 & 220.14 \\
\hline \multirow[t]{5}{*}{$\mathrm{HDPE}+\mathrm{S}$} & 0.1035 & 0.1335 & 15.00 & 1.69 & 90.47 & 190.07 \\
\hline & 0.1035 & 0.1330 & 14.00 & 1.59 & 84.75 & 178.07 \\
\hline & 0.0950 & 0.1385 & 15.00 & 1.69 & 95.00 & 199.60 \\
\hline & 0.0965 & 0.1320 & 16.00 & 1.80 & 104.67 & 219.92 \\
\hline & 0.1110 & 0.1420 & 20.50 & 2.32 & 108.38 & 227.71 \\
\hline
\end{tabular}




\begin{tabular}{|c|c|c|c|c|c|c|}
\hline \multicolumn{7}{|c|}{ Table $C 1$ continued } \\
\hline \multirow[t]{5}{*}{$\mathrm{HDPE}+\mathrm{B}$} & 0.1095 & 0.1390 & 21.00 & 2.37 & 114.98 & 241.57 \\
\hline & 0.1110 & 0.1415 & 20.50 & 2.32 & 108.77 & 228.52 \\
\hline & 0.1070 & 0.1400 & 22.00 & 2.48 & 122.39 & 257.13 \\
\hline & 0.1035 & 0.1455 & 14.50 & 1.64 & 80.24 & 168.58 \\
\hline & 0.1115 & 0.1385 & 16.50 & 1.86 & 89.04 & 187.07 \\
\hline \multirow[t]{5}{*}{$\mathrm{HDPE}+\mathrm{P}$} & 0.1225 & 0.1400 & 17.00 & 1.93 & 82.60 & 173.55 \\
\hline & 0.1165 & 0.1290 & 16.00 & 1.80 & 88.72 & 186.40 \\
\hline & 0.1140 & 0.1255 & 13.00 & 1.46 & 75.72 & 159.09 \\
\hline & 0.1105 & 0.1220 & 22.00 & 2.48 & 135.99 & 285.72 \\
\hline & 0.1115 & 0.1310 & 20.00 & 2.26 & 114.10 & 239.73 \\
\hline \multirow[t]{5}{*}{ HDPE/LLDPE+U } & 0.1240 & 0.1120 & 15.50 & 1.75 & 93.01 & 195.41 \\
\hline & 0.1250 & 0.1175 & 14.00 & 1.59 & 79.43 & 166.89 \\
\hline & 0.1270 & 0.1115 & 17.50 & 1.98 & 102.99 & 216.37 \\
\hline & 0.1220 & 0.1195 & 15.00 & 1.69 & 85.74 & 180.14 \\
\hline & 0.1295 & 0.1130 & 16.50 & 1.86 & 93.96 & 197.42 \\
\hline \multirow[t]{5}{*}{ HDPE/LLDPE+S } & 0.1210 & 0.1100 & 17.00 & 1.93 & 106.44 & 223.62 \\
\hline & 0.1190 & 0.0975 & 13.50 & 1.52 & 96.96 & 203.72 \\
\hline & 0.1285 & 0.1005 & 14.50 & 1.64 & 93.57 & 196.58 \\
\hline & 0.1230 & 0.1045 & 14.50 & 1.64 & 94.01 & 197.51 \\
\hline & 0.1295 & 0.1185 & 16.50 & 1.86 & 89.60 & 188.25 \\
\hline \multirow[t]{5}{*}{ HDPE/LLDPE+B } & 0.1125 & 0.1180 & 15.00 & 1.69 & 94.16 & 197.83 \\
\hline & 0.1265 & 0.1190 & 17.00 & 1.93 & 94.11 & 197.72 \\
\hline & 0.1145 & 0.1135 & 15.50 & 1.75 & 99.39 & 208.82 \\
\hline & 0.1310 & 0.1195 & 16.50 & 1.86 & 87.83 & 184.54 \\
\hline & 0.1100 & 0.1215 & 18.00 & 2.03 & 112.23 & 235.80 \\
\hline \multirow[t]{5}{*}{ HDPE/LLDPE+P } & 0.1200 & 0.1215 & 23.00 & 2.60 & 131.46 & 276.19 \\
\hline & 0.1280 & 0.1220 & 20.00 & 2.26 & 106.73 & 224.24 \\
\hline & 0.1275 & 0.1225 & 15.00 & 1.69 & 80.03 & 168.15 \\
\hline & 0.1300 & 0.1205 & 15.00 & 1.69 & 79.80 & 167.65 \\
\hline & 0.1275 & 0.1185 & 16.00 & 1.80 & 88.25 & 185.41 \\
\hline
\end{tabular}

The tensile-impact strength is calculated from the following:

Tensile - impact strength $\left(\mathrm{kJ} / \mathrm{m}^{2}\right)=\frac{\text { Impact energy }}{\mathrm{A}}$

Where: $\mathrm{A}=$ the cross sectional area $\left(\mathrm{in}^{2}\right)$ 
Table C2. Tensile-impact strength of composites (pure thermoplastic).

\begin{tabular}{|c|c|c|c|c|c|c|}
\hline \multirow{2}{*}{ Composite } & \multirow{2}{*}{ Width (in) } & \multirow{2}{*}{ Depth (in) } & \multicolumn{2}{|c|}{ Impact Energy } & \multicolumn{2}{|c|}{ Tensile-Impact Strength } \\
\hline & & & (in.·lbf) & $(\mathbf{N} \cdot \mathbf{m})$ & $\left(\mathbf{f t} \cdot \mathbf{l b f} /\right.$ in. $\left.^{2}\right)$ & $\left(\mathrm{kJ} / \mathrm{m}^{2}\right)$ \\
\hline \multirow[t]{5}{*}{ LLDPE } & 0.1025 & 0.1399 & 16.00 & 1.81 & 92.98 & 195.35 \\
\hline & 0.1045 & 0.1425 & 17.00 & 1.93 & 95.13 & 199.88 \\
\hline & 0.1075 & 0.1316 & 15.00 & 1.70 & 88.36 & 185.64 \\
\hline & 0.1170 & 0.1320 & 15.50 & 1.75 & 83.64 & 175.72 \\
\hline & 0.0990 & 0.1405 & 15.00 & 1.70 & 89.87 & 188.81 \\
\hline \multirow[t]{5}{*}{ HDPE } & 0.1035 & 0.1355 & 15.00 & 1.70 & 89.13 & 187.26 \\
\hline & 0.1015 & 0.1379 & 13.50 & 1.52 & 80.38 & 168.87 \\
\hline & 0.1050 & 0.1385 & 15.00 & 1.70 & 85.95 & 180.59 \\
\hline & 0.1165 & 0.1320 & 16.00 & 1.81 & 86.70 & 182.16 \\
\hline & 0.1110 & 0.1320 & 15.50 & 1.75 & 88.16 & 185.22 \\
\hline
\end{tabular}

Table C3. Summary of tensile-impact strength of composites.

\begin{tabular}{cccccc}
\hline Composite & Average $\mathbf{( k J / \mathbf { m } ^ { 2 } )}$ & $\begin{array}{c}\text { Standard Deviation } \\
\left(\mathbf{k J} / \mathbf{m}^{\mathbf{2}}\right)\end{array}$ & $\begin{array}{c}\text { Coef. Var. } \\
\mathbf{( \% )}\end{array}$ & $\begin{array}{c}\mathbf{9 5 \%} \text { Confidence Interval } \\
\left(\mathbf{k J} / \mathbf{m}^{\mathbf{2}}\right)\end{array}$ \\
\cline { 5 - 6 } LLDPE + U & 189.69 & 19.04 & 10.04 & 216.12 & 163.27 \\
LLDPE + S & 207.00 & 25.79 & 12.46 & 242.80 & 171.20 \\
LLDPE + B & 218.94 & 56.21 & 25.67 & 296.97 & 140.92 \\
LLDPE + P & 201.12 & 15.35 & 7.63 & 222.42 & 179.81 \\
HDPE + U & 193.70 & 27.09 & 13.99 & 231.31 & 156.09 \\
HDPE + S & 203.07 & 20.60 & 10.14 & 231.67 & 174.48 \\
HDPE + B & 216.57 & 37.37 & 17.25 & 268.45 & 164.70 \\
HDPE + P & 208.90 & 52.65 & 25.20 & 281.99 & 135.81 \\
HDPE/LLDPE + U & 191.24 & 18.73 & 9.79 & 217.25 & 165.24 \\
HDPE/LLDPE + S & 201.94 & 13.31 & 6.59 & 220.42 & 183.46 \\
HDPE/LLDPE + B & 204.94 & 19.28 & 9.41 & 231.70 & 178.18 \\
HDPE/LLDPE + P & 204.33 & 46.30 & 22.66 & 268.60 & 140.06 \\
LLDPE (pure) & 189.08 & 9.31 & 4.92 & 202.00 & 176.16 \\
HDPE (pure) & 180.82 & 7.17 & 3.96 & 190.77 & 170.87 \\
\hline
\end{tabular}


Table C4. Statistical analysis of tensile-impact strength of composites.

\begin{tabular}{|c|c|c|c|c|c|c|c|c|}
\hline \multirow{2}{*}{ Variable } & \multirow{2}{*}{$\mathbf{N}$} & \multirow{2}{*}{$\begin{array}{c}\text { Mean } \\
\left(\mathrm{kJ} / \mathrm{m}^{2}\right)\end{array}$} & \multirow{2}{*}{$\begin{array}{c}\text { Std. } \\
\text { Deviation } \\
\left(\mathbf{k J} / \mathbf{m}^{2}\right)\end{array}$} & \multirow{2}{*}{$\begin{array}{c}\text { Std. } \\
\text { Error } \\
\left(\mathbf{k J} / \mathbf{m}^{2}\right)\end{array}$} & \multicolumn{2}{|c|}{$\begin{array}{l}\text { 95\% Confidence Interval } \\
\text { for Mean }\left(\mathrm{kJ} / \mathrm{m}^{2}\right)\end{array}$} & \multicolumn{2}{|c|}{$\begin{array}{c}\text { Tensile-Impact Strength } \\
\left(\mathrm{kJ} / \mathrm{m}^{2}\right)\end{array}$} \\
\hline & & & & & Lower & Upper & Minimum & Maximum \\
\hline $\mathrm{LLDPE}+\mathrm{U}$ & 5 & 189.70 & 19.04 & 8.51 & 166.06 & 213.33 & 176.88 & 223.07 \\
\hline $\mathrm{LLDPE}+\mathrm{S}$ & 5 & 207.00 & 25.79 & 11.53 & 174.97 & 239.02 & 173.88 & 243.52 \\
\hline LLDPE + B & 5 & 218.94 & 56.21 & 25.14 & 149.15 & 288.73 & 139.45 & 291.28 \\
\hline LLDPE + P & 5 & 201.12 & 15.35 & 6.86 & 182.06 & 220.17 & 182.02 & 218.79 \\
\hline LLDPE & 5 & 189.08 & 9.31 & 4.16 & 177.53 & 200.63 & 175.72 & 199.88 \\
\hline Total & 25 & 201.17 & 29.70 & 5.94 & 188.91 & 213.43 & 139.45 & 291.28 \\
\hline $\mathrm{HDPE}+\mathrm{U}$ & 5 & 193.70 & 27.09 & 12.12 & 160.06 & 227.34 & 152.29 & 220.14 \\
\hline $\mathrm{HDPE}+\mathrm{S}$ & 5 & 203.07 & 20.60 & 9.21 & 177.50 & 228.65 & 178.07 & 227.71 \\
\hline $\mathrm{HDPE}+\mathrm{B}$ & 5 & 216.57 & 37.37 & 16.71 & 170.17 & 262.98 & 168.58 & 257.13 \\
\hline $\mathrm{HDPE}+\mathrm{P}$ & 5 & 208.90 & 52.65 & 23.55 & 143.52 & 274.27 & 159.09 & 285.72 \\
\hline HDPE & 5 & 180.82 & 7.17 & 3.21 & 171.92 & 189.72 & 168.87 & 187.26 \\
\hline Total & 25 & 200.61 & 32.51 & 6.50 & 187.20 & 214.03 & 152.29 & 285.72 \\
\hline HDPE/LLDPE + U & 5 & 191.25 & 18.73 & 8.38 & 167.99 & 214.50 & 166.89 & 216.37 \\
\hline HDPE/LLDPE + S & 5 & 201.94 & 13.31 & 5.95 & 185.41 & 218.47 & 188.25 & 223.62 \\
\hline HDPE/LLDPE + B & 5 & 204.94 & 19.28 & 8.62 & 181.01 & 228.88 & 184.54 & 235.80 \\
\hline HDPE/LLDPE + P & 5 & 204.33 & 46.29 & 20.70 & 146.85 & 261.81 & 167.65 & 276.19 \\
\hline Total & 20 & 200.61 & 25.94 & 5.80 & 188.47 & 212.75 & 166.89 & 276.19 \\
\hline
\end{tabular}

\section{One way Analysis of Variance}

\begin{tabular}{|c|c|c|c|c|c|c|}
\hline & & df & Sum of & Mean Square & Computed & $\begin{array}{l}\text { Computed } \\
\text { Sis }\end{array}$ \\
\hline \multirow[t]{3}{*}{ LLDPE } & Between Groups & 4 & 3137.81 & 784.45 & $0.87^{\mathrm{ns}}$ & 0.50 \\
\hline & Within Groups & 20 & 18035.41 & 901.77 & & \\
\hline & Total & 24 & 21173.22 & & & \\
\hline \multirow[t]{3}{*}{ HDPE } & Between Groups & 4 & 3845.16 & 961.29 & $0.89^{\mathrm{ns}}$ & 0.49 \\
\hline & Within Groups & 20 & 21513.93 & 1075.70 & & \\
\hline & Total & 24 & 25359.08 & & & \\
\hline \multirow[t]{3}{*}{ HDPE/LLDPE } & Between Groups & 3 & 610.16 & 203.39 & $0.27^{\mathrm{ns}}$ & 0.85 \\
\hline & Within Groups & 16 & 12171.08 & 760.69 & & \\
\hline & Total & 19 & 12781.24 & & & \\
\hline
\end{tabular}




\section{APPENDIX D}

\section{Durometer Hardness of Composites}

Experimental conditions for the Durometer hardness of composites presented in Table D1.

Temperature $\left({ }^{\circ} \mathrm{C}\right): 23$

Humidity (\%): 50

ASTM procedure: D2240-97 (ASTM 1998)

Types of durometer : Type D gauge

Machine : Durometer hardness tester (Shore Instrument and MFG Co., Freeport, NY)

Operator : bei

Units type : SI

Table D1. Durometer hardness of composites (10\% fiber and pure thermoplastic).

\begin{tabular}{ccccccccccc}
\hline \multirow{2}{*}{ Composite } & \multicolumn{10}{c}{ Hardness Test (SD) } \\
\cline { 2 - 12 } & $\mathbf{1}$ & $\mathbf{2}$ & $\mathbf{3}$ & $\mathbf{4}$ & $\mathbf{5}$ & $\mathbf{6}$ & $\mathbf{7}$ & $\mathbf{8}$ & $\mathbf{9}$ & $\mathbf{1 0}$ \\
\hline LLDPE+U & 15 & 19 & 14 & 14 & 13 & 19 & 16 & 17 & 15 & 18 \\
LLDPE+S & 9 & 19 & 15 & 20 & 24 & 20 & 11 & 20 & 15 & 17 \\
LLDPE+B & 12 & 11 & 15 & 24 & 16 & 20 & 19 & 14 & 18 & 19 \\
LLDPE+P & 16 & 15 & 19 & 18 & 17 & 21 & 20 & 21 & 20 & 19 \\
HDPE+U & 19 & 17 & 16 & 19 & 15 & 14 & 18 & 17 & 20 & 15 \\
HDPE+S & 15 & 9 & 24 & 19 & 16 & 10 & 17 & 18 & 15 & 19 \\
HDPE+B & 19 & 16 & 15 & 20 & 17 & 19 & 15 & 13 & 18 & 10 \\
HDPE+P & 14 & 21 & 14 & 15 & 14 & 15 & 19 & 20 & 19 & 20 \\
HDPE/LLDPE+U & 14 & 16 & 13 & 15 & 20 & 17 & 19 & 20 & 14 & 15 \\
HDPE/LLDPE+S & 20 & 14 & 15 & 15 & 19 & 14 & 16 & 20 & 20 & 17 \\
HDPE/LLDPE+B & 16 & 19 & 15 & 16 & 18 & 16 & 19 & 17 & 17 & 14 \\
HDPE/LLDPE+P & 15 & 21 & 16 & 15 & 7 & 17 & 12 & 20 & 24 & 15 \\
LLDPE & 19 & 18 & 21 & 15 & 16 & 16 & 20 & 18 & 16 & 20 \\
HDPE & 15 & 22 & 17 & 19 & 21 & 16 & 17 & 17 & 18 & 15 \\
\hline
\end{tabular}


Table D2. Summary of Durometer hardness of composites.

\begin{tabular}{cccccc}
\hline \multirow{2}{*}{ Composite } & \multirow{2}{*}{$\begin{array}{c}\text { Average } \\
\text { (SD) }\end{array}$} & $\begin{array}{c}\text { Standard Deviation } \\
\text { (SD) }\end{array}$ & \multirow{2}{*}{$\begin{array}{c}\text { Coef. Var. } \\
\text { (\%) }\end{array}$} & & \multicolumn{2}{c}{\begin{tabular}{c} 
95\% Confidence Interval \\
\cline { 5 - 6 } (SD)
\end{tabular}} \\
\hline LLDPE + U & 16.0 & 2.0 & 11.8 & 18.5 & Upper \\
LLDPE + S & 17.0 & 4.4 & 27.1 & 19.5 & 15.5 \\
LLDPE + B & 16.8 & 3.1 & 19.0 & 18.5 & 13.9 \\
LLDPE + P & 18.6 & 2.9 & 17.1 & 19.3 & 14.9 \\
HDPE + U & 17.0 & 2.6 & 15.9 & 18.3 & 14.4 \\
HDPE + S & 16.2 & 2.5 & 14.9 & 18.9 & 15.1 \\
HDPE + B & 16.2 & 1.6 & 9.8 & 17.9 & 15.5 \\
HDPE + P & 17.1 & 4.8 & 29.5 & 19.8 & 12.6 \\
HDPE/LLDPE + U & 16.3 & 2.2 & 13.5 & 17.6 & 14.4 \\
HDPE/LLDPE + S & 17.0 & 4.6 & 26.9 & 20.5 & 13.6 \\
HDPE/LLDPE + B & 16.7 & 4.0 & 23.6 & 19.8 & 13.8 \\
HDPE/LLDPE + P & 16.2 & 2.1 & 11.1 & 20.2 & 17.0 \\
LLDPE (pure) & 17.9 & 2.1 & 11.6 & 19.5 & 16.3 \\
HDPE (pure) & 17.7 & 2.4 & 13.3 & 19.5 & 15.9 \\
\hline
\end{tabular}


Table D3. Statistical analysis of Durometer hardness of composites.

\begin{tabular}{|c|c|c|c|c|c|c|c|c|}
\hline \multirow{2}{*}{ Variable } & \multirow{2}{*}{$\mathbf{N}$} & \multirow{2}{*}{$\begin{array}{c}\text { Mean } \\
\text { (SD) }\end{array}$} & \multirow{2}{*}{$\begin{array}{l}\text { Std. } \\
\text { Deviation } \\
\text { (SD) }\end{array}$} & \multirow{2}{*}{$\begin{array}{l}\text { Std. } \\
\text { Error } \\
\text { (SD) }\end{array}$} & \multicolumn{2}{|c|}{$\begin{array}{l}\text { 95\% Confidence Interval } \\
\text { for Mean (SD) } \\
\end{array}$} & \multicolumn{2}{|c|}{ Durometer Hardness (SD) } \\
\hline & & & & & Lower & Upper & Minimum & Maximum \\
\hline LLDPE + U & 10 & 16.00 & 2.16 & 0.68 & 14.45 & 17.55 & 13 & 19 \\
\hline LLDPE $+\mathrm{S}$ & 10 & 17.00 & 4.57 & 1.45 & 13.73 & 20.27 & 9 & 24 \\
\hline LLDPE + B & 10 & 16.80 & 3.97 & 1.25 & 13.96 & 19.64 & 11 & 24 \\
\hline $\mathrm{LLDPE}+\mathrm{P}$ & 10 & 18.60 & 2.07 & 0.65 & 17.12 & 20.08 & 15 & 21 \\
\hline LLDPE & 10 & 17.90 & 2.08 & 0.66 & 16.41 & 19.39 & 15 & 21 \\
\hline Total & 50 & 17.26 & 3.16 & 0.45 & 16.36 & 18.16 & 9 & 24 \\
\hline $\mathrm{HDPE}+\mathrm{U}$ & 10 & 17.00 & 2.00 & 0.63 & 15.57 & 18.43 & 14 & 20 \\
\hline $\mathrm{HDPE}+\mathrm{S}$ & 10 & 16.20 & 4.39 & 1.39 & 13.06 & 19.34 & 9 & 24 \\
\hline $\mathrm{HDPE}+\mathrm{B}$ & 10 & 16.20 & 3.08 & 0.98 & 13.99 & 18.41 & 10 & 20 \\
\hline $\mathrm{HDPE}+\mathrm{P}$ & 10 & 17.10 & 2.92 & 0.92 & 15.01 & 19.19 & 14 & 21 \\
\hline HDPE & 10 & 17.70 & 2.36 & 0.75 & 16.01 & 19.39 & 15 & 22 \\
\hline Total & 50 & 16.84 & 2.99 & 0.42 & 15.99 & 17.69 & 9 & 24 \\
\hline HDPE/LLDPE + U & 10 & 16.30 & 2.58 & 0.82 & 14.45 & 18.15 & 13 & 20 \\
\hline HDPE/LLDPE + S & 10 & 17.00 & 2.54 & 0.80 & 15.18 & 18.82 & 14 & 20 \\
\hline HDPE/LLDPE + B & 10 & 16.70 & 1.64 & 0.52 & 15.53 & 17.87 & 14 & 19 \\
\hline HDPE/LLDPE + P & 10 & 16.20 & 4.78 & 1.51 & 12.78 & 19.62 & 7 & 24 \\
\hline Total & 40 & 16.55 & 3.00 & 0.47 & 15.59 & 17.51 & 7 & 24 \\
\hline
\end{tabular}

\section{One way Analysis of Variance}

\begin{tabular}{|c|c|c|c|c|c|c|}
\hline & & \multirow{2}{*}{ df } & \multirow{2}{*}{ Sum of Squares } & \multirow{2}{*}{ Mean Square } & \multirow{2}{*}{$\begin{array}{c}\text { Computed } \\
F\end{array}$} & \multirow{2}{*}{$\begin{array}{c}\text { Computed } \\
\text { Sig. }(0.05)\end{array}$} \\
\hline & & & & & & \\
\hline \multirow[t]{3}{*}{ LLDPE } & Between Groups & 4 & 40.72 & 10.18 & $1.02^{\mathrm{ns}}$ & 0.41 \\
\hline & Within Groups & 45 & 448.90 & 9.98 & & \\
\hline & Total & 49 & 489.62 & & & \\
\hline \multirow[t]{3}{*}{ HDPE } & Between Groups & 4 & 16.52 & 4.13 & $0.44^{\mathrm{ns}}$ & 0.78 \\
\hline & Within Groups & 45 & 422.20 & 9.38 & & \\
\hline & Total & 49 & 438.72 & & & \\
\hline \multirow[t]{3}{*}{ HDPE/LLDPE } & Between Groups & 3 & 4.10 & 1.37 & $0.14^{\mathrm{ns}}$ & 0.93 \\
\hline & Within Groups & 36 & 347.80 & 9.66 & & \\
\hline & Total & 39 & 351.90 & & & \\
\hline
\end{tabular}




\section{APPENDIX E}

\section{Moisture Absorption of Flax Fibers}

Experimental conditions for the moisture absorption of flax fibers presented in Table E1.

Temperature $\left({ }^{\circ} \mathrm{C}\right): 23$

Humidity (\%): 33, 66, 100

Duration: $72 \mathrm{~h}$

Machine : Environmental test chamber (Anglelantoni, ACS, Massa Martana, Italy)

Analytical balance

Operator : bei

Units type : SI

Table E1. Moisture absorption of flax fibers.

\begin{tabular}{|c|c|c|c|c|c|c|}
\hline \multirow{2}{*}{$\begin{array}{c}\text { No. } \\
\text { of } \\
\text { Rep. }\end{array}$} & \multirow{2}{*}{$\begin{array}{c}\text { Fiber } \\
\text { Treatment }\end{array}$} & \multicolumn{4}{|c|}{$33 \%$ RH (Dry bulb temp:23ㄷ, Wet bulb temp: $13.33^{\circ} \mathrm{C}$ ) } & \multirow{2}{*}{$\begin{array}{c}\text { Mass Increase } \\
(\%)\end{array}$} \\
\hline & & $\begin{array}{c}\text { Before } \\
\text { Conditioning (g) }\end{array}$ & $\begin{array}{c}\text { Feb 14, 03, } \\
1: 50 \mathrm{pm}\end{array}$ & $\begin{array}{c}\text { Feb 17, 03, } \\
11: 00 \text { pm }\end{array}$ & $\begin{array}{c}\text { Feb 18, 03, } \\
10: 15 \text { am }\end{array}$ & \\
\hline \multirow{4}{*}{1} & Untreated & 24.242 & 25.237 & 25.462 & 25.477 & 5.09 \\
\hline & Silane & 24.715 & 25.710 & 25.951 & 25.954 & 5.01 \\
\hline & Benzoylation & 24.926 & 25.828 & 25.923 & 25.992 & 4.28 \\
\hline & Peroxide & 24.627 & 25.029 & 25.320 & 25.523 & 3.64 \\
\hline \multirow{6}{*}{2} & \multicolumn{5}{|c|}{$33 \%$ RH (Dry bulb temp:23ㅇ, Wet bulb temp:13.33 ${ }^{\circ} \mathrm{C}$ ) } & \multirow{2}{*}{$\begin{array}{c}\text { Mass Increase } \\
(\%)\end{array}$} \\
\hline & Treatment & $\begin{array}{c}\text { Before } \\
\text { Conditioning (g) }\end{array}$ & $\begin{array}{c}\text { Feb 27, 03, } \\
10: 50 \text { am }\end{array}$ & $\begin{array}{c}\text { Feb 28, 03, } \\
\text { 11:00 am }\end{array}$ & $\begin{array}{c}\text { Mar 01, 03, } \\
\text { 10:55 am }\end{array}$ & \\
\hline & Untreated & 24.584 & 25.698 & 25.770 & 25.952 & 5.56 \\
\hline & Silane & 24.691 & 25.251 & 25.598 & 25.865 & 4.75 \\
\hline & Benzoylation & 24.712 & 24.972 & 25.002 & 25.711 & 4.04 \\
\hline & Peroxide & 24.772 & 25.499 & 25.695 & 25.759 & 3.98 \\
\hline \multirow{6}{*}{3} & \multicolumn{5}{|c|}{$33 \%$ RH (Dry bulb temp:23ㄷ, Wet bulb temp:13.33두) } & \multirow{2}{*}{$\begin{array}{c}\text { Mass Increase } \\
(\%)\end{array}$} \\
\hline & Treatment & $\begin{array}{c}\text { Before } \\
\text { Conditioning (g) }\end{array}$ & $\begin{array}{c}\text { Mar 11, 03, } \\
10: 00 \mathrm{am}\end{array}$ & $\begin{array}{c}\text { Mar 12, 03, } \\
11: 10 \mathrm{am}\end{array}$ & $\begin{array}{c}\text { Mar 13, 03, } \\
10: 45 \mathrm{am}\end{array}$ & \\
\hline & Untreated & 24.806 & 25.026 & 25.352 & 26.129 & 5.33 \\
\hline & Silane & 24.775 & 25.041 & 25.477 & 25.985 & 4.88 \\
\hline & Benzoylation & 24.612 & 24.759 & 25.009 & 25.637 & 4.16 \\
\hline & Peroxide & 24.872 & 25.013 & 25.400 & 25.820 & 3.81 \\
\hline \multirow{6}{*}{1} & \multicolumn{5}{|c|}{$66 \%$ RH (Dry bulb temp:23 ${ }^{\circ} \mathrm{C}$, Wet bulb temp:18.6 ${ }^{\circ} \mathrm{C}$ ) } & \multirow{2}{*}{$\begin{array}{c}\text { Mass Increase } \\
(\%)\end{array}$} \\
\hline & Treatment & $\begin{array}{c}\text { Before } \\
\text { Conditioning (g) }\end{array}$ & $\begin{array}{c}\text { Feb 21, 03, } \\
11: 10 \mathrm{am}\end{array}$ & $\begin{array}{c}\text { Feb 22, 03, } \\
10: 40 \mathrm{am}\end{array}$ & $\begin{array}{l}\text { Feb 23, 03, } \\
\text { 7:30 pm }\end{array}$ & \\
\hline & Untreated & 24.269 & 25.922 & 26.350 & 26.585 & 9.54 \\
\hline & Silane & 24.739 & 25.270 & 26.170 & 27.029 & 9.26 \\
\hline & Benzoylation & 24.940 & 25.229 & 26.232 & 27.067 & 8.53 \\
\hline & Peroxide & 24.256 & 26.640 & 26.642 & 26.443 & 9.02 \\
\hline \multirow[b]{2}{*}{2} & \multirow{2}{*}{$\begin{array}{c}\text { Fiber } \\
\text { Treatment }\end{array}$} & \multicolumn{4}{|c|}{$66 \%$ RH (Dry bulb temp:23으 ${ }^{\circ} \mathrm{Wet}$ bulb temp:18.6 ${ }^{\circ} \mathrm{C}$ ) } & \multirow{2}{*}{$\begin{array}{c}\text { Mass Increase } \\
(\%)\end{array}$} \\
\hline & & $\begin{array}{c}\text { Before } \\
\text { Conditioning (g) }\end{array}$ & $\begin{array}{c}\text { Mar 03, 03, } \\
10: 10 \mathrm{am}\end{array}$ & $\begin{array}{c}\text { Mar 04, 03, } \\
11: 50 \mathrm{am}\end{array}$ & $\begin{array}{c}\operatorname{Mar} 05,03, \\
12: 00 \text { pm }\end{array}$ & \\
\hline
\end{tabular}




\begin{tabular}{|c|c|c|c|c|c|c|}
\hline \multicolumn{7}{|c|}{ Table $\mathbf{E} 1$ continued } \\
\hline \multirow{4}{*}{2} & Untreated & 24.566 & 25.998 & 26.452 & 27.075 & 10.21 \\
\hline & Silane & 24.852 & 25.862 & 26.301 & 27.085 & 8.99 \\
\hline & Benzoylation & 24.760 & 25.968 & 26.635 & 26.902 & 8.65 \\
\hline & Peroxide & 24.699 & 26.001 & 26.052 & 26.861 & 8.75 \\
\hline \multirow{6}{*}{3} & \multicolumn{5}{|c|}{ 66\% RH (Dry bulb temp:23ㄷ, Wet bulb temp:18.6 $\left.{ }^{\circ} \mathrm{C}\right)$} & \multirow{2}{*}{$\begin{array}{c}\text { Mass Increase } \\
(\%)\end{array}$} \\
\hline & Treatment & $\begin{array}{c}\text { Before } \\
\text { Conditioning (g) } \\
\end{array}$ & $\begin{array}{c}\text { Mar 16, 03, } \\
1: 00 \text { pm }\end{array}$ & $\begin{array}{c}\text { Mar 17, 03, } \\
1: 50 \text { pm }\end{array}$ & $\begin{array}{c}\text { Mar 18, 03, } \\
12: 30 \text { pm }\end{array}$ & \\
\hline & Untreated & 24.953 & 25.798 & 26.523 & 27.418 & 9.88 \\
\hline & Silane & 24.641 & 25.995 & 26.465 & 26.891 & 9.13 \\
\hline & Benzoylation & 24.882 & 25.887 & 26.265 & 27.020 & 8.59 \\
\hline & Peroxide & 24.523 & 25.563 & 26.009 & 26.703 & 8.89 \\
\hline \multirow{6}{*}{1} & \multicolumn{5}{|c|}{ 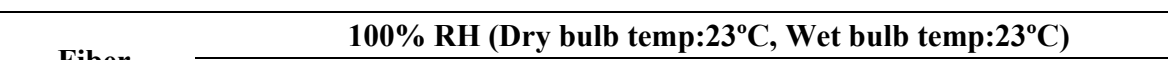 } & \multirow[b]{2}{*}{$\begin{array}{c}\text { Mass Increase } \\
(\%)\end{array}$} \\
\hline & $\begin{array}{l}\text { Fiber } \\
\text { Treatment }\end{array}$ & $\begin{array}{c}\text { Before } \\
\text { Conditioning (g) }\end{array}$ & $\begin{array}{c}\text { Feb 24, 03, } \\
\text { 10:40 am }\end{array}$ & $\begin{array}{c}\text { Feb 25, 03, } \\
\text { 10:00 am }\end{array}$ & $\begin{array}{c}\text { Feb 26, 03, } \\
6: 40 \text { pm }\end{array}$ & \\
\hline & Untreated & 24.177 & 27.365 & 28.300 & 28.447 & 17.66 \\
\hline & Silane & 24.691 & 27.332 & 28.500 & 28.745 & 16.42 \\
\hline & Benzoylation & 24.892 & 27.017 & 28.171 & 28.545 & 14.68 \\
\hline & Peroxide & 24.143 & 27.407 & 27.496 & 27.850 & 15.35 \\
\hline \multirow{6}{*}{2} & \multicolumn{5}{|c|}{ 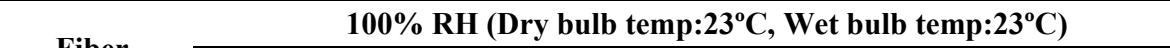 } & \multirow{2}{*}{$\begin{array}{c}\text { Mass Increase } \\
(\%)\end{array}$} \\
\hline & $\begin{array}{c}\text { Fiber } \\
\text { Treatment }\end{array}$ & $\begin{array}{c}\text { Before } \\
\text { Conditioning (g) }\end{array}$ & $\begin{array}{c}\text { Mar 07, 03, } \\
\text { 11:15 am }\end{array}$ & $\begin{array}{c}\text { Mar 08, 03, } \\
1: 00 \text { pm }\end{array}$ & $\begin{array}{c}\text { Mar 09, 03, } \\
12: 30 \text { pm }\end{array}$ & \\
\hline & Untreated & 24.875 & 27.589 & 28.542 & 29.368 & 18.06 \\
\hline & Silane & 24.561 & 27.458 & 28.289 & 28.451 & 15.84 \\
\hline & Benzoylation & 24.922 & 27.550 & 28.320 & 28.491 & 14.32 \\
\hline & Peroxide & 24.530 & 27.693 & 27.879 & 28.227 & 15.07 \\
\hline \multirow{6}{*}{3} & \multicolumn{5}{|c|}{$100 \%$ RH (Dry bulb temp:23 ${ }^{\circ} \mathrm{C}$, Wet bulb temp:23 $\left.{ }^{\circ} \mathrm{C}\right)$} & \multirow{2}{*}{$\begin{array}{c}\text { Mass Increase } \\
(\%)\end{array}$} \\
\hline & Treatment & $\begin{array}{c}\text { Before } \\
\text { Conditioning (g) } \\
\end{array}$ & $\begin{array}{c}\text { Mar 20, 03, } \\
11: 25 \mathrm{am}\end{array}$ & $\begin{array}{c}\text { Mar 21, 03, } \\
1: 05 \text { pm }\end{array}$ & $\begin{array}{c}\text { Mar 22, 03, } \\
12: 55 \text { pm }\end{array}$ & \\
\hline & Untreated & 24.757 & 27.854 & 28.411 & 29.178 & 17.86 \\
\hline & Silane & 24.898 & 27.310 & 28.099 & 28.913 & 16.13 \\
\hline & Benzoylation & 24.694 & 27.420 & 28.215 & 28.274 & 14.50 \\
\hline & Peroxide & 24.901 & 27.369 & 27.799 & 28.688 & 15.21 \\
\hline $\mathrm{RH}$ & tive humidity & & & & & \\
\hline
\end{tabular}

The moisture absorption is calculated according to the following equation:

$$
\text { Increase in mass (percent) }=\left(\frac{M_{t}-M_{0}}{M_{0}}\right) \times 100
$$

Where: $\mathrm{M}_{\mathrm{t}}=$ mass of the sample after conditioning (g) (wet weight)

$$
\mathrm{M}_{0}=\text { mass of the sample before conditioning ( } \mathrm{g} \text { ) (dry weight) }
$$


Table E2. Summary of moisture absorption (mass increase, \%) of flax fibers.

\begin{tabular}{|c|c|c|c|c|c|c|}
\hline \multirow{2}{*}{ RH } & \multirow{2}{*}{$\begin{array}{c}\text { Fiber } \\
\text { Treatment }\end{array}$} & \multirow{2}{*}{$\begin{array}{c}\text { Mean } \\
(\%)\end{array}$} & \multirow{2}{*}{$\begin{array}{c}\text { Standard } \\
\text { Deviation }(\%) \\
\end{array}$} & \multirow{2}{*}{$\begin{array}{c}\text { Coef. Var. } \\
(\%) \\
\end{array}$} & \multicolumn{2}{|c|}{ 95\% Confidence Interval (\%) } \\
\hline & & & & & Upper & Lower \\
\hline \multirow{4}{*}{$33 \%$} & Untreated & 5.33 & 0.24 & 4.41 & 6.04 & 4.61 \\
\hline & Silane & 4.88 & 0.13 & 2.66 & 5.28 & 4.48 \\
\hline & Benzoylation & 4.16 & 0.12 & 2.88 & 4.53 & 3.79 \\
\hline & Peroxide & 3.81 & 0.17 & 4.46 & 4.33 & 3.29 \\
\hline \multirow{4}{*}{$66 \%$} & Untreated & 9.88 & 0.33 & 3.39 & 10.89 & 8.86 \\
\hline & Silane & 9.13 & 0.14 & 1.48 & 9.54 & 8.71 \\
\hline & Benzoylation & 8.59 & 0.06 & 0.7 & 8.77 & 8.41 \\
\hline & Peroxide & 8.89 & 0.13 & 1.52 & 9.3 & 8.47 \\
\hline \multirow{4}{*}{$100 \%$} & Untreated & 17.86 & 0.2 & 1.12 & 18.47 & 17.25 \\
\hline & Silane & 16.13 & 0.29 & 1.8 & 17.01 & 15.25 \\
\hline & Benzoylation & 14.5 & 0.18 & 1.24 & 15.05 & 13.95 \\
\hline & Peroxide & 15.21 & 0.14 & 0.92 & 15.64 & 14.78 \\
\hline
\end{tabular}


Table E3. Statistical analysis of moisture absorption (mass increase, \%) of flax fibers.

\begin{tabular}{|c|c|c|c|c|c|c|c|c|c|}
\hline \multirow{2}{*}{ RH } & \multirow{2}{*}{ Variable } & \multirow[t]{2}{*}{$\mathbf{N}$} & \multirow{2}{*}{$\begin{array}{c}\text { Mean } \\
(\%)\end{array}$} & \multirow{2}{*}{$\begin{array}{c}\text { Std. } \\
\text { Deviatio } \\
\text { n (\%) }\end{array}$} & \multirow{2}{*}{$\begin{array}{c}\text { Std. Error } \\
(\%)\end{array}$} & \multicolumn{2}{|c|}{$\begin{array}{l}95 \% \text { Confidence Interval } \\
\text { for Mean }(\%)\end{array}$} & \multicolumn{2}{|c|}{$\begin{array}{c}\text { Mass Increase } \\
(\%)\end{array}$} \\
\hline & & & & & & Lower & Upper & Min. & Max. \\
\hline \multirow{5}{*}{$33 \%$} & Untreated & 3 & 5.33 & 0.24 & 0.14 & 4.74 & 5.91 & 5.09 & 5.56 \\
\hline & Silane & 3 & 4.88 & 0.13 & 0.08 & 4.56 & 5.20 & 4.75 & 5.01 \\
\hline & Benzoylation & 3 & 4.16 & 0.12 & 0.07 & 3.86 & 4.46 & 4.04 & 4.28 \\
\hline & Peroxide & 3 & 3.81 & 0.17 & 0.10 & 3.39 & 4.23 & 3.64 & 3.98 \\
\hline & Total & 12 & 4.54 & 0.64 & 0.18 & 4.14 & 4.95 & 3.64 & 5.56 \\
\hline \multirow{5}{*}{$66 \%$} & Untreated & 3 & 9.88 & 0.34 & 0.19 & 9.04 & 10.71 & 9.54 & 10.21 \\
\hline & Silane & 3 & 9.13 & 0.14 & 0.08 & 8.79 & 9.46 & 8.99 & 9.26 \\
\hline & Benzoylation & 3 & 8.59 & 0.06 & 0.03 & 8.44 & 8.74 & 8.53 & 8.65 \\
\hline & Peroxide & 3 & 8.89 & 0.14 & 0.08 & 8.55 & 9.22 & 8.75 & 9.02 \\
\hline & Total & 12 & 9.12 & 0.52 & 0.15 & 8.79 & 9.45 & 8.53 & 10.21 \\
\hline \multirow{5}{*}{$100 \%$} & Untreated & 3 & 17.86 & 0.20 & 0.12 & 17.36 & 18.36 & 17.66 & 18.06 \\
\hline & Silane & 3 & 16.13 & 0.29 & 0.17 & 15.41 & 16.85 & 15.84 & 16.42 \\
\hline & Benzoylation & 3 & 14.50 & 0.18 & 0.10 & 14.05 & 14.95 & 14.32 & 14.68 \\
\hline & Peroxide & 3 & 15.21 & 0.14 & 0.08 & 14.86 & 15.56 & 15.07 & 15.35 \\
\hline & Total & 12 & 15.93 & 1.33 & 0.38 & 15.08 & 16.77 & 14.32 & 18.06 \\
\hline
\end{tabular}

\section{One way Analysis of Variance}

\begin{tabular}{|c|c|c|c|c|c|c|}
\hline \multirow{2}{*}{$\mathbf{R H}$} & & \multirow{2}{*}{ df } & \multirow{2}{*}{$\begin{array}{c}\text { Sum of } \\
\text { Squares }\end{array}$} & \multirow{2}{*}{ Mean Square } & Computed & Computed \\
\hline & & & & & $F$ & Sig. (0.05) \\
\hline \multirow[t]{3}{*}{$33 \%$} & Between Groups & 3 & 4.24 & 1.41 & $48.92^{* *}$ & 0.0000 \\
\hline & Within Groups & 8 & 0.23 & 0.03 & & \\
\hline & Total & 11 & 4.47 & & & \\
\hline \multirow[t]{3}{*}{$66 \%$} & Between Groups & 3 & 2.72 & 0.91 & $23.85^{* *}$ & 0.0002 \\
\hline & Within Groups & 8 & 0.30 & 0.04 & & \\
\hline & Total & 11 & 3.03 & & & \\
\hline \multirow[t]{3}{*}{$100 \%$} & Between Groups & 3 & 18.98 & 6.33 & $143.74^{* *}$ & 0.0000 \\
\hline & Within Groups & 8 & 0.35 & 0.04 & & \\
\hline & Total & 11 & 19.34 & & & \\
\hline
\end{tabular}

\section{Multiple Comparisons}

\begin{tabular}{|c|c|c|c|c|c|c|c|c|}
\hline \multirow{2}{*}{$\begin{array}{c}\text { Dependent } \\
\text { Variable }\end{array}$} & & \multirow{2}{*}{ (I) } & \multirow[t]{2}{*}{ (J) } & \multirow{2}{*}{$\begin{array}{c}\text { Mean } \\
\text { Difference } \\
\text { (I-J) }\end{array}$} & \multirow{2}{*}{$\begin{array}{l}\text { Std. } \\
\text { Error }\end{array}$} & \multirow{2}{*}{$\begin{array}{l}\text { Computed } \\
\text { Sig. }(0.05)\end{array}$} & \multicolumn{2}{|c|}{$\begin{array}{l}\text { 95\% Confidence } \\
\text { Interval for Mean }\end{array}$} \\
\hline & & & & & & & Lower & Upper \\
\hline \multirow[t]{6}{*}{$33 \% \mathrm{RH}$} & LSD & Untreated & Silane & $0.45\left(^{*}\right)$ & 0.14 & $0.012^{*}$ & 0.13 & 0.77 \\
\hline & & & Benzoylation & $1.17\left(^{*}\right)$ & 0.14 & $0.000^{* *}$ & 0.85 & 1.49 \\
\hline & & & Peroxide & $1.52\left(^{*}\right)$ & 0.14 & $0.000^{* *}$ & 1.20 & 1.84 \\
\hline & & Silane & Benzoylation & $0.72\left(^{*}\right)$ & 0.14 & $0.001^{* *}$ & 0.40 & 1.04 \\
\hline & & & Peroxide & $1.07\left(^{*}\right)$ & 0.14 & $0.000^{* *}$ & 0.75 & 1.39 \\
\hline & & Benzoylation & Peroxide & $0.35\left(^{*}\right)$ & 0.14 & $0.036^{*}$ & 0.03 & 0.67 \\
\hline $66 \%$ & LSD & Untreated & Silane & $0.75\left(^{*}\right)$ & 0.16 & $0.002^{* *}$ & 0.38 & 1.12 \\
\hline
\end{tabular}




\begin{tabular}{|c|c|c|c|c|c|c|c|c|}
\hline \multicolumn{9}{|c|}{ Table E3 continued } \\
\hline & & \multirow{4}{*}{ Silane } & Benzoylation & $1.29\left(^{*}\right)$ & 0.16 & $0.000^{* *}$ & 0.92 & 1.65 \\
\hline & & & Peroxide & $0.99\left(^{*}\right)$ & 0.16 & $0.000^{* *}$ & 0.62 & 1.36 \\
\hline & & & Benzoylation & $0.54\left(^{*}\right)$ & 0.16 & $0.010^{* *}$ & 0.17 & 0.90 \\
\hline & & & Peroxide & 0.24 & 0.16 & $0.170^{\mathrm{ns}}$ & -0.13 & 0.61 \\
\hline & & Benzoylation & Peroxide & -0.30 & 0.16 & $0.100^{\mathrm{ns}}$ & -0.66 & 0.07 \\
\hline \multirow[t]{6}{*}{$100 \%$} & LSD & Untreated & Silane & $1.73\left(^{*}\right)$ & 0.17 & $0.000^{* *}$ & 1.33 & 2.13 \\
\hline & & & Benzoylation & $3.36\left(^{*}\right)$ & 0.17 & $0.000^{* *}$ & 2.96 & 3.76 \\
\hline & & & Peroxide & $2.65\left(^{*}\right)$ & 0.17 & $0.000^{* *}$ & 2.25 & 3.05 \\
\hline & & Silane & Benzoylation & $1.63\left(^{*}\right)$ & 0.17 & $0.000^{* *}$ & 1.23 & 2.03 \\
\hline & & & Peroxide & $0.92\left(^{*}\right)$ & 0.17 & $0.001^{* *}$ & 0.52 & 1.32 \\
\hline & & Benzoylation & Peroxide & $-0.71\left(^{*}\right)$ & 0.17 & $0.003^{* *}$ & -1.11 & -0.31 \\
\hline
\end{tabular}

${ }^{*}$. The mean difference is significant at the .05 level.

\begin{tabular}{cccc}
\hline Homogeneous Subsets & & \\
\hline \multirow{2}{*}{ RH } & Fiber Treatment & N & Pean (\%) \\
\cline { 3 - 4 } & Peroxide & 3 & $3.81^{\mathrm{a}}$ \\
\multirow{3}{*}{$33 \%$} & 3 & $4.16^{\mathrm{b}}$ \\
& Benzoylation & 3 & $4.88^{\mathrm{c}}$ \\
& Silane & 3 & $5.23^{\mathrm{d}}$ \\
\hline \multirow{3}{*}{$66 \%$} & Untreated & 3 & $8.59^{\mathrm{a}}$ \\
& Benzoylation & 3 & $8.89^{\mathrm{ab}^{\mathrm{b}}}$ \\
& Peroxide & 3 & $9.13^{\mathrm{b}}$ \\
& Silane & 3 & $9.88^{\mathrm{c}}$ \\
\hline \multirow{3}{*}{$100 \%$} & Untreated & 3 & $14.50^{\mathrm{a}}$ \\
& Benzoylation & 3 & $15.21^{\mathrm{b}}$ \\
& Peroxide & 3 & $16.13^{\mathrm{c}}$ \\
& Silane & 3 & $17.86^{\mathrm{d}}$ \\
\hline
\end{tabular}

Means for groups in homogeneous subsets are displayed.

Uses Harmonic Mean Sample Size = 3.000. 


\section{APPENDIX F}

\section{Water Absorption of Composites}

Experimental conditions for the water absorption of composites presented in Table F1.

Temperature $\left({ }^{\circ} \mathrm{C}\right): 23$

Humidity (\%): 50

Duration: $24 \mathrm{~h}$

Machine : Desiccator, oven,

Types of sample : Rectangular specimen $(25.4 \mathrm{~mm} \times 76.2 \mathrm{~mm})$

ASTM procedure: D570-99 (ASTM, 1999)

Operator : bei

Units type : SI

Table F1. Water absorption of composites ( $10 \%$ fiber and pure thermoplastic).

\begin{tabular}{|c|c|c|c|c|}
\hline \multirow{2}{*}{$\begin{array}{c}\text { No. } \\
\text { of } \\
\text { Rep. }\end{array}$} & \multirow{2}{*}{ Composite } & \multicolumn{2}{|c|}{ Mass (g) } & \multirow{2}{*}{$\begin{array}{c}\text { Water absorption } \\
(\%)\end{array}$} \\
\hline & & Before Conditioning & After Conditioning & \\
\hline \multirow{14}{*}{1} & $\mathrm{LLDPE}+\mathrm{U}$ & 6.4561 & 6.4620 & 0.09 \\
\hline & $\mathrm{LLDPE}+\mathrm{S}$ & 6.9015 & 6.9075 & 0.09 \\
\hline & LLDPE + B & 7.3397 & 7.3453 & 0.08 \\
\hline & LLDPE + P & 8.1876 & 8.1943 & 0.08 \\
\hline & HDPE + U & 6.3861 & 6.3931 & 0.11 \\
\hline & $\mathrm{HDPE}+\mathrm{S}$ & 6.1757 & 6.1820 & 0.10 \\
\hline & $\mathrm{HDPE}+\mathrm{B}$ & 7.8593 & 7.8650 & 0.07 \\
\hline & $\mathrm{HDPE}+\mathrm{P}$ & 7.8488 & 7.8541 & 0.07 \\
\hline & HDPE/LLDPE + U & 5.8606 & 5.8676 & 0.12 \\
\hline & HDPE/LLDPE + S & 6.5316 & 6.5383 & 0.10 \\
\hline & HDPE/LLDPE + B & 4.5737 & 4.5771 & 0.07 \\
\hline & HDPE/LLDPE + P & 6.9035 & 6.9075 & 0.06 \\
\hline & LLDPE (pure) & 7.5236 & 7.5260 & 0.03 \\
\hline & HDPE (pure) & 6.9876 & 6.9910 & 0.05 \\
\hline \multirow{14}{*}{2} & LLDPE + U & 8.2918 & 8.2989 & 0.09 \\
\hline & $\mathrm{LLDPE}+\mathrm{S}$ & 8.8344 & 8.8389 & 0.05 \\
\hline & $\mathrm{LLDPE}+\mathrm{B}$ & 9.8284 & 9.8336 & 0.05 \\
\hline & $\mathrm{LLDPE}+\mathrm{P}$ & 7.6031 & 7.6061 & 0.04 \\
\hline & HDPE + U & 6.6867 & 6.6929 & 0.09 \\
\hline & $\mathrm{HDPE}+\mathrm{S}$ & 9.3302 & 9.3363 & 0.07 \\
\hline & $\mathrm{HDPE}+\mathrm{B}$ & 8.5258 & 8.5299 & 0.05 \\
\hline & HDPE + P & 6.8826 & 6.8865 & 0.06 \\
\hline & HDPE/LLDPE + U & 7.9564 & 7.9650 & 0.11 \\
\hline & $\mathrm{HDPE} / \mathrm{LLDPE}+\mathrm{S}$ & 8.5545 & 8.5611 & 0.08 \\
\hline & HDPE/LLDPE + B & 8.1846 & 8.1892 & 0.06 \\
\hline & HDPE/LLDPE + P & 6.3480 & 6.3510 & 0.05 \\
\hline & LLDPE (pure) & 7.6658 & 7.6690 & 0.04 \\
\hline & HDPE (pure) & 7.0523 & 7.0563 & 0.06 \\
\hline
\end{tabular}




\begin{tabular}{cccc}
\hline Table F1 continued & & & \\
\hline LLDPE + U & 6.7799 & 6.7854 & 0.08 \\
LLDPE + S & 7.7682 & 7.7730 & 0.06 \\
LLDPE + B & 8.9982 & 9.0030 & 0.05 \\
LLDPE + P & 7.6132 & 7.6180 & 0.06 \\
HDPE + U & 6.9272 & 6.9332 & 0.09 \\
HDPE + S & 4.0384 & 4.0418 & 0.08 \\
HDPE + B & 4.7376 & 4.7411 & 0.07 \\
HDPE + P & 3.9028 & 3.9056 & 0.07 \\
HDPE/LLDPE + U & 6.9744 & 6.9810 & 0.09 \\
HDPE/LLDPE + S & 8.0598 & 8.0680 & 0.10 \\
HDPE/LLDPE + B & 8.1674 & 8.1750 & 0.09 \\
HDPE/LLDPE + P & 6.5664 & 6.5710 & 0.07 \\
LLDPE (pure) & 7.2543 & 7.2569 & 0.04 \\
HDPE (pure) & 7.2153 & 7.2183 & 0.04 \\
\hline
\end{tabular}

The percentage increase in weight during immersion was calculated according to the nearest $0.01 \%$ as follows:

$$
\text { Increase in mass }(\text { percent })=\frac{\text { Conditioned mass }- \text { Dry mass }}{\text { Dry mass }} \times 100
$$

Table F2. Summary of water absorption (mass increase, \%) of composites.

\begin{tabular}{|c|c|c|c|c|c|}
\hline \multirow{2}{*}{ Composite } & \multirow{2}{*}{$\begin{array}{c}\text { Mean } \\
(\%)\end{array}$} & \multirow{2}{*}{$\begin{array}{c}\text { Standard } \\
\text { Deviation (\%) }\end{array}$} & \multirow{2}{*}{$\begin{array}{c}\text { Coef. Var. } \\
(\%)\end{array}$} & \multicolumn{2}{|c|}{ 95\% Confidence Interval (\%) } \\
\hline & & & & Upper & Lower \\
\hline LLDPE + U & 0.09 & 0.005 & 5.98 & 0.10 & 0.07 \\
\hline $\mathrm{LLDPE}+\mathrm{S}$ & 0.07 & 0.018 & 27.75 & 0.12 & 0.01 \\
\hline LLDPE + B & 0.06 & 0.013 & 21.99 & 0.10 & 0.02 \\
\hline LLDPE + P & 0.06 & 0.021 & 34.55 & 0.13 & 0.00 \\
\hline $\mathrm{HDPE}+\mathrm{U}$ & 0.10 & 0.012 & 12.37 & 0.13 & 0.06 \\
\hline $\mathrm{HDPE}+\mathrm{S}$ & 0.08 & 0.018 & 21.84 & 0.14 & 0.03 \\
\hline $\mathrm{HDPE}+\mathrm{B}$ & 0.06 & 0.015 & 22.39 & 0.11 & 0.02 \\
\hline $\mathrm{HDPE}+\mathrm{P}$ & 0.07 & 0.008 & 11.91 & 0.09 & 0.04 \\
\hline HDPE/LLDPE + U & 0.11 & 0.012 & 11.57 & 0.15 & 0.07 \\
\hline HDPE/LLDPE + S & 0.09 & 0.014 & 15.39 & 0.14 & 0.05 \\
\hline HDPE/LLDPE + B & 0.07 & 0.018 & 24.72 & 0.13 & 0.02 \\
\hline HDPE/LLDPE + P & 0.06 & 0.011 & 19.52 & 0.09 & 0.02 \\
\hline LLDPE (pure) & 0.04 & 0.005 & 13.58 & 0.05 & 0.02 \\
\hline HDPE (pure) & 0.05 & 0.008 & 15.47 & 0.07 & 0.03 \\
\hline
\end{tabular}


Table F3. Statistical analysis of water absorption (mass increase, \%) of composites.

\begin{tabular}{|c|c|c|c|c|c|c|c|c|}
\hline \multirow{2}{*}{ Variable } & \multirow[t]{2}{*}{$\mathbf{N}$} & \multirow{2}{*}{$\begin{array}{c}\text { Mean } \\
(\%)\end{array}$} & \multirow{2}{*}{$\begin{array}{c}\text { Std. } \\
\text { Deviation } \\
(\%)\end{array}$} & \multirow{2}{*}{$\begin{array}{l}\text { Std. } \\
\text { Error } \\
(\%)\end{array}$} & \multicolumn{2}{|c|}{$\begin{array}{c}\text { 95\% Confidence Interval for } \\
\text { Mean (\%) } \\
\end{array}$} & \multicolumn{2}{|c|}{ Mass Increase (\%) } \\
\hline & & & & & Lower & Upper & Minimum & Maximum \\
\hline $\mathrm{LLDPE}+\mathrm{U}$ & 3 & 16.00 & 0.01 & 0.00 & 0.07 & 0.10 & 0.08 & 0.09 \\
\hline $\mathrm{LLDPE}+\mathrm{S}$ & 3 & 17.00 & 0.02 & 0.01 & 0.01 & 0.12 & 0.05 & 0.09 \\
\hline LLDPE + B & 3 & 16.80 & 0.02 & 0.01 & 0.02 & 0.10 & 0.05 & 0.08 \\
\hline LLDPE + P & 3 & 18.60 & 0.02 & 0.01 & 0.01 & 0.11 & 0.04 & 0.08 \\
\hline LLDPE & 3 & 17.90 & 0.01 & 0.00 & 0.02 & 0.05 & 0.03 & 0.04 \\
\hline Total & 15 & 17.26 & 0.02 & 0.01 & 0.05 & 0.07 & 0.03 & 0.09 \\
\hline $\mathrm{HDPE}+\mathrm{U}$ & 3 & 17.00 & 0.01 & 0.01 & 0.07 & 0.13 & 0.09 & 0.11 \\
\hline $\mathrm{HDPE}+\mathrm{S}$ & 3 & 16.20 & 0.02 & 0.01 & 0.05 & 0.12 & 0.07 & 0.10 \\
\hline HDPE + B & 3 & 16.20 & 0.01 & 0.01 & 0.03 & 0.09 & 0.05 & 0.07 \\
\hline $\mathrm{HDPE}+\mathrm{P}$ & 3 & 17.10 & 0.01 & 0.00 & 0.05 & 0.08 & 0.06 & 0.07 \\
\hline HDPE & 3 & 17.70 & 0.01 & 0.01 & 0.03 & 0.07 & 0.04 & 0.06 \\
\hline Total & 15 & 16.84 & 0.02 & 0.00 & 0.06 & 0.08 & 0.04 & 0.11 \\
\hline HDPE/LLDPE + U & 3 & 16.30 & 0.02 & 0.01 & 0.07 & 0.14 & 0.09 & 0.12 \\
\hline HDPE/LLDPE + S & 3 & 17.00 & 0.01 & 0.01 & 0.06 & 0.12 & 0.08 & 0.10 \\
\hline HDPE/LLDPE + B & 3 & 16.70 & 0.02 & 0.01 & 0.04 & 0.11 & 0.06 & 0.09 \\
\hline HDPE/LLDPE + P & 3 & 16.20 & 0.01 & 0.01 & 0.04 & 0.08 & 0.05 & 0.07 \\
\hline Total & 12 & 16.55 & 0.02 & 0.01 & 0.07 & 0.10 & 0.05 & 0.12 \\
\hline
\end{tabular}

One way Analysis of Variance

\begin{tabular}{|c|c|c|c|c|c|c|}
\hline & & \multirow{2}{*}{ df } & \multirow{2}{*}{ Sum of Squares } & \multirow{2}{*}{ Mean Square } & \multirow{2}{*}{$\begin{array}{c}\text { Computed } \\
F\end{array}$} & \multirow{2}{*}{$\begin{array}{l}\text { Computed } \\
\text { Sig. (0.05) }\end{array}$} \\
\hline & & & & & & \\
\hline \multirow[t]{3}{*}{ LLDPE } & Between Groups & 4 & 0.0038 & 0.0010 & $4.0000^{*}$ & 0.0343 \\
\hline & Within Groups & 10 & 0.0024 & 0.0002 & & \\
\hline & Total & 14 & 0.0062 & & & \\
\hline \multirow[t]{3}{*}{ HDPE } & Between Groups & 4 & 0.0040 & 0.0010 & $7.8421^{* *}$ & 0.0040 \\
\hline & Within Groups & 10 & 0.0013 & 0.0001 & & \\
\hline & Total & 14 & 0.0052 & & & \\
\hline \multirow[t]{3}{*}{ HDPE/LLDPE } & Between Groups & 3 & 0.0039 & 0.0013 & $7.3651^{*}$ & 0.0109 \\
\hline & Within Groups & 8 & 0.0014 & 0.0002 & & \\
\hline & Total & 11 & 0.0053 & & & \\
\hline
\end{tabular}

Multiple Comparisons

\begin{tabular}{|c|c|c|c|c|c|c|c|c|}
\hline \multirow{2}{*}{$\begin{array}{c}\text { Dependent } \\
\text { Variable }\end{array}$} & & \multirow{2}{*}{ (I) } & \multirow{2}{*}{ (J) } & \multirow{2}{*}{$\begin{array}{c}\text { Mean } \\
\text { Difference } \\
\text { (I-J) }\end{array}$} & \multirow{2}{*}{$\begin{array}{l}\text { Std. } \\
\text { Error }\end{array}$} & \multirow{2}{*}{$\begin{array}{l}\text { Computed } \\
\text { Sig. (0.05) }\end{array}$} & \multicolumn{2}{|c|}{$\begin{array}{c}\text { 95\% Confidence Interval for } \\
\text { Mean }\end{array}$} \\
\hline & & & & & & & Lower & Upper \\
\hline \multirow[t]{4}{*}{ LLDPE } & LSD & $\mathrm{U}$ & $\mathrm{S}$ & 0.020 & 0.013 & $0.145^{\mathrm{ns}}$ & -0.008 & 0.048 \\
\hline & & & B & 0.027 & 0.013 & $0.061^{\mathrm{ns}}$ & -0.002 & 0.055 \\
\hline & & & $\mathrm{P}$ & 0.027 & 0.013 & $0.061^{\mathrm{ns}}$ & -0.002 & 0.055 \\
\hline & & & Pure & $0.050\left(^{*}\right)$ & 0.013 & $0.003^{* *}$ & 0.022 & 0.078 \\
\hline
\end{tabular}




\begin{tabular}{|c|c|c|c|c|c|c|c|c|}
\hline \multicolumn{9}{|c|}{ Table F3 continued } \\
\hline & & $\mathrm{S}$ & B & 0.007 & 0.013 & $0.610^{\mathrm{ns}}$ & -0.022 & 0.035 \\
\hline & & & $\mathrm{P}$ & 0.007 & 0.013 & $0.610^{\mathrm{ns}}$ & -0.022 & 0.035 \\
\hline & & & Pure & $0.030\left(^{*}\right)$ & 0.013 & $0.039^{*}$ & 0.002 & 0.058 \\
\hline & & B & $\mathrm{P}$ & 0.000 & 0.013 & $1.000^{\mathrm{ns}}$ & -0.028 & 0.028 \\
\hline & & & Pure & 0.023 & 0.013 & $0.095^{\mathrm{ns}}$ & -0.005 & 0.052 \\
\hline & & $\mathrm{P}$ & Pure & 0.023 & 0.013 & $0.095^{\mathrm{ns}}$ & -0.005 & 0.052 \\
\hline \multirow[t]{10}{*}{ HDPE } & LSD & $\mathrm{U}$ & $\mathrm{S}$ & 0.013 & 0.009 & $0.177^{\mathrm{ns}}$ & -0.007 & 0.034 \\
\hline & & & $\mathrm{B}$ & $0.033\left(^{*}\right)$ & 0.009 & $0.005^{* *}$ & 0.013 & 0.054 \\
\hline & & & $\mathrm{P}$ & $0.030\left(^{*}\right)$ & 0.009 & $0.009^{* *}$ & 0.010 & 0.050 \\
\hline & & & Pure & $0.047\left(^{*}\right)$ & 0.009 & $0.000^{* *}$ & 0.026 & 0.067 \\
\hline & & $\mathrm{S}$ & $\mathrm{B}$ & 0.020 & 0.009 & $0.055^{\mathrm{ns}}$ & 0.000 & 0.040 \\
\hline & & & $\mathrm{P}$ & 0.017 & 0.009 & $0.100^{\mathrm{ns}}$ & -0.004 & 0.037 \\
\hline & & & Pure & $0.033\left(^{*}\right)$ & 0.009 & $0.005^{* *}$ & 0.013 & 0.054 \\
\hline & & B & $\mathrm{P}$ & -0.003 & 0.009 & $0.724^{\mathrm{ns}}$ & -0.024 & 0.017 \\
\hline & & & Pure & 0.013 & 0.009 & $0.177^{\mathrm{ns}}$ & -0.007 & 0.034 \\
\hline & & $\mathrm{P}$ & Pure & 0.017 & 0.009 & $0.100^{\mathrm{ns}}$ & -0.004 & 0.037 \\
\hline \multirow[t]{6}{*}{ HDPE/LLDPE } & LSD & $\mathrm{U}$ & $\mathrm{S}$ & 0.013 & 0.011 & $0.252^{\mathrm{ns}}$ & -0.012 & 0.038 \\
\hline & & & B & $0.033\left(^{*}\right)$ & 0.011 & $0.015^{*}$ & 0.008 & 0.058 \\
\hline & & & $\mathrm{P}$ & $0.047\left(^{*}\right)$ & 0.011 & $0.003^{* *}$ & 0.022 & 0.072 \\
\hline & & $\mathrm{S}$ & B & 0.020 & 0.011 & $0.101^{\mathrm{ns}}$ & -0.005 & 0.045 \\
\hline & & & $\mathrm{P}$ & $0.033\left(^{*}\right)$ & 0.011 & $0.015^{*}$ & 0.008 & 0.058 \\
\hline & & $\mathrm{B}$ & $\mathrm{P}$ & 0.013 & 0.011 & $0.252^{\mathrm{ns}}$ & -0.012 & 0.038 \\
\hline
\end{tabular}

\section{Homogeneous Subsets}

\begin{tabular}{cccc}
\hline & Fiber Treatment & N & P $=\mathbf{0 . 0 5}$ \\
\hline LLDPE & Pure & 3 & Mean (\%) \\
& B & 3 & $0.037^{\mathrm{a}}$ \\
& P & 3 & $0.060^{\mathrm{ab}}$ \\
& $\mathrm{S}$ & 3 & $0.060^{\mathrm{ab}}$ \\
& $\mathrm{U}$ & 3 & $0.067^{\mathrm{ab}}$ \\
& Pure & $0.087^{\mathrm{b}}$ \\
\hline HDPE & $\mathrm{B}$ & 3 & $0.050^{\mathrm{a}}$ \\
& $\mathrm{P}$ & 3 & $0.063^{\mathrm{ab}}$ \\
& $\mathrm{S}$ & 3 & $0.067^{\mathrm{ab}}$ \\
& $\mathrm{U}$ & 3 & $0.083^{\mathrm{bc}}$ \\
& $\mathrm{P}$ & 3 & $0.097^{\mathrm{c}}$ \\
\hline HDPE/LLDPE & $\mathrm{B}$ & 3 & $0.060^{\mathrm{a}}$ \\
& $\mathrm{S}$ & 3 & $0.073^{\mathrm{ab}}$ \\
& $\mathrm{U}$ & 3 & $0.093^{\mathrm{bc}}$ \\
& 3 & $0.107^{\mathrm{c}}$ \\
\hline
\end{tabular}

Means for groups in homogeneous subsets are displayed.

Uses Harmonic Mean Sample Size $=3.000$. 


\section{APPENDIX G}

\section{Thermal Property by DSC}

Experimental conditions for all the DSC thermal property presented in Table G1.

Temperature $\left({ }^{\circ} \mathrm{C}\right): 23$

Humidity (\%): 50

Heating rate: $10^{\circ} \mathrm{C} / \mathrm{min}$

Machine: Perkin- Elmer DSC system (TA instruments, New Castle, DE)

Types of sample : 6 to $10 \mathrm{mg}$

Temperature range: $-50-400{ }^{\circ} \mathrm{C}$

Operator : bei

Units type : SI

Table G1. Melting point of composites (10\% fiber and pure thermoplastic).

\begin{tabular}{lcc}
\hline \multicolumn{1}{c}{ Variable } & Mass $(\mathbf{m g})$ & Melting Point $\left({ }^{\circ} \mathbf{C}\right)$ \\
\hline LLDPE + U & 6.3 & 130.6 \\
LLDPE + S & 6.5 & 130.3 \\
LLDPE + B & 6.9 & 130.2 \\
LLDPE + P & 7.3 & 129.2 \\
LLDPE (pure) & 10.0 & 129.9 \\
HDPE + U & 8.7 & 133.4 \\
HDPE + S & 8.4 & 133.1 \\
HDPE + B & 7.7 & 132.9 \\
HDPE + P & 6.4 & 132.7 \\
HDPE (pure) & 7.5 & 130.7 \\
HDPE/LLDPE + U & 6.7 & 130.0 \\
HDPE/LLDPE + S & 6.9 & 131.6 \\
HDPE/LLDPE + B & 8.2 & 130.4 \\
HDPE/LLDPE + P & 8.2 & 130.2 \\
\hline
\end{tabular}




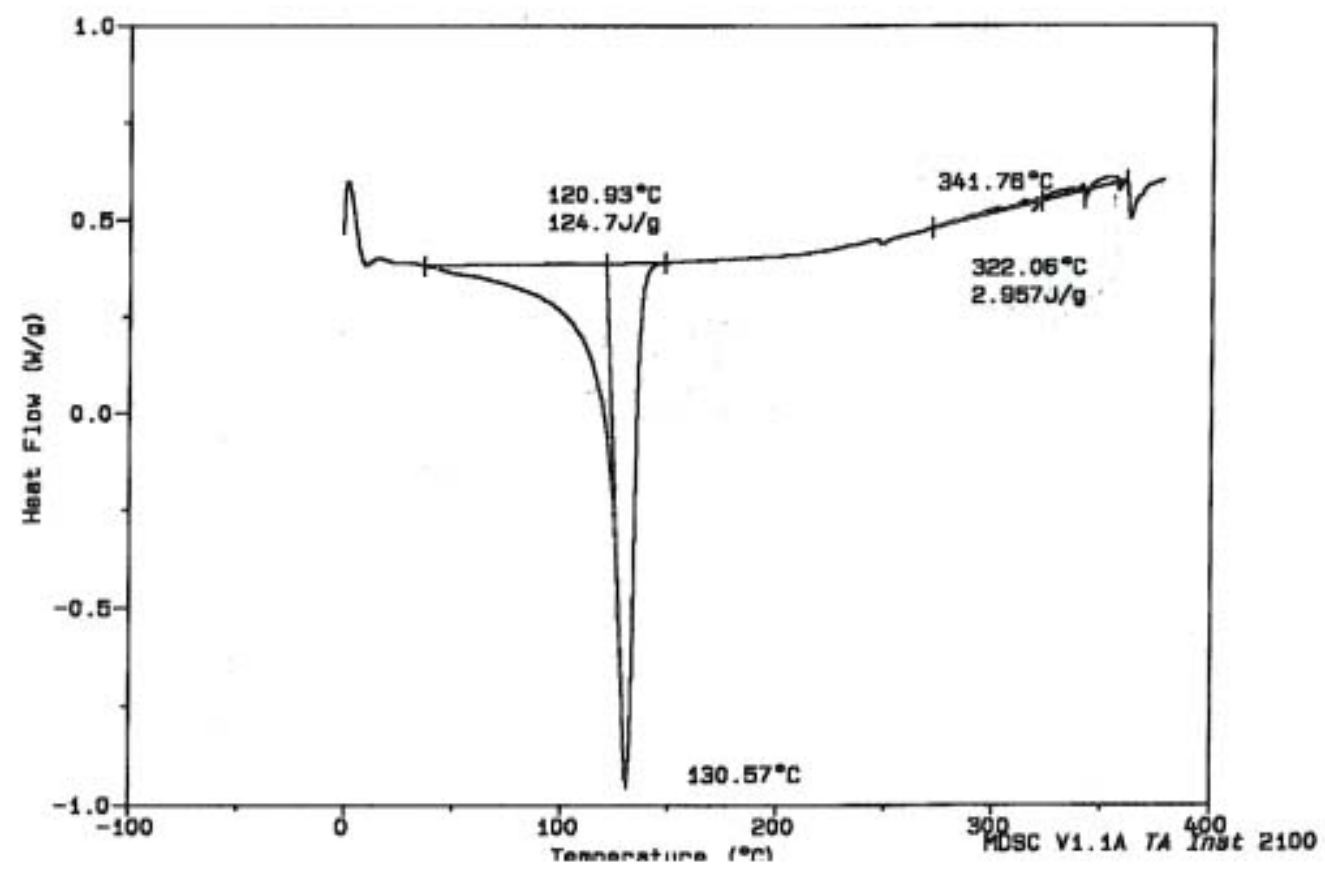

Figure G1. DSC thermogram of untreated flax fiber-reinforced composite with LLDPE.

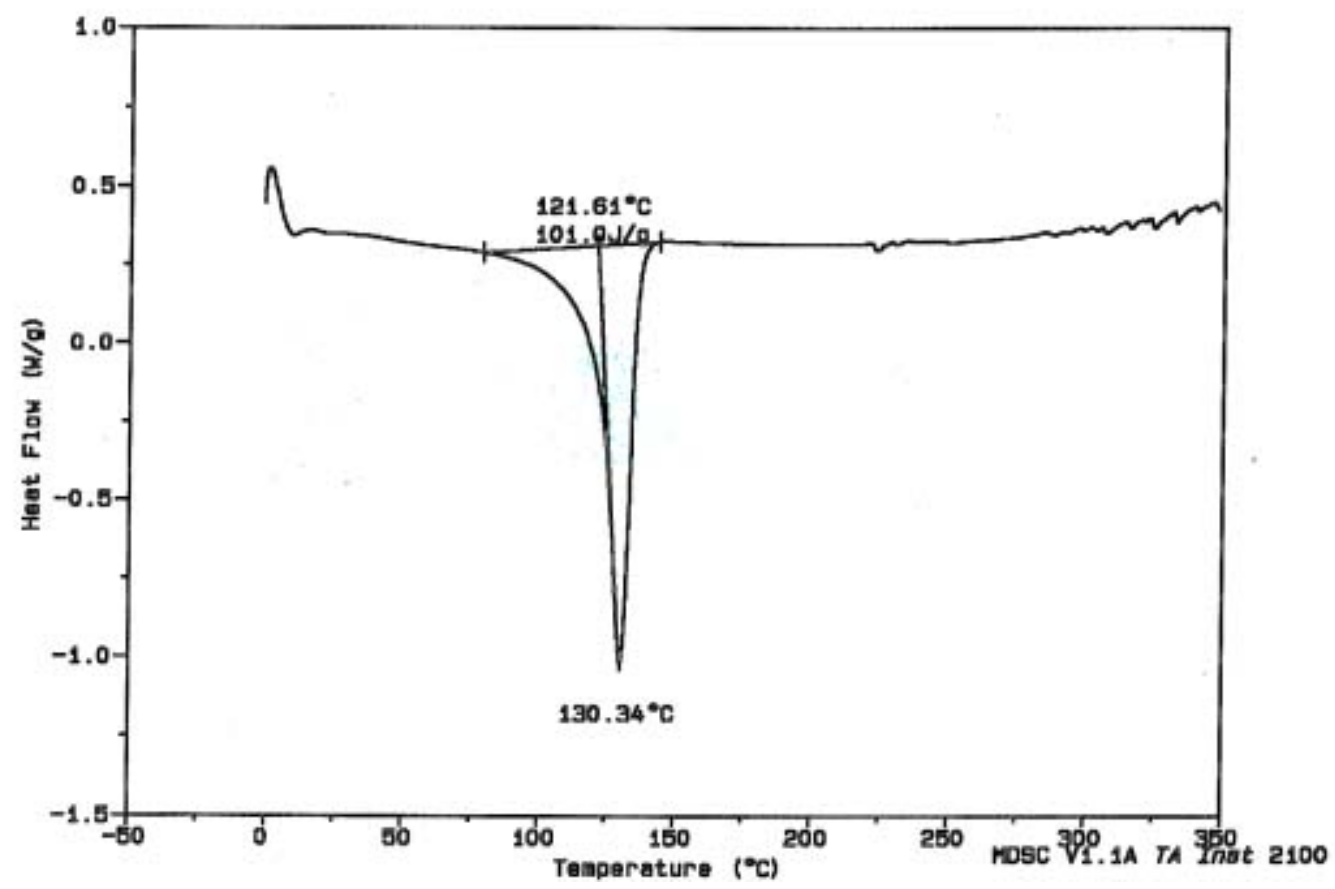

Figure G2. DSC thermogram of silane-treated flax fiber-reinforced composite with LLDPE. 


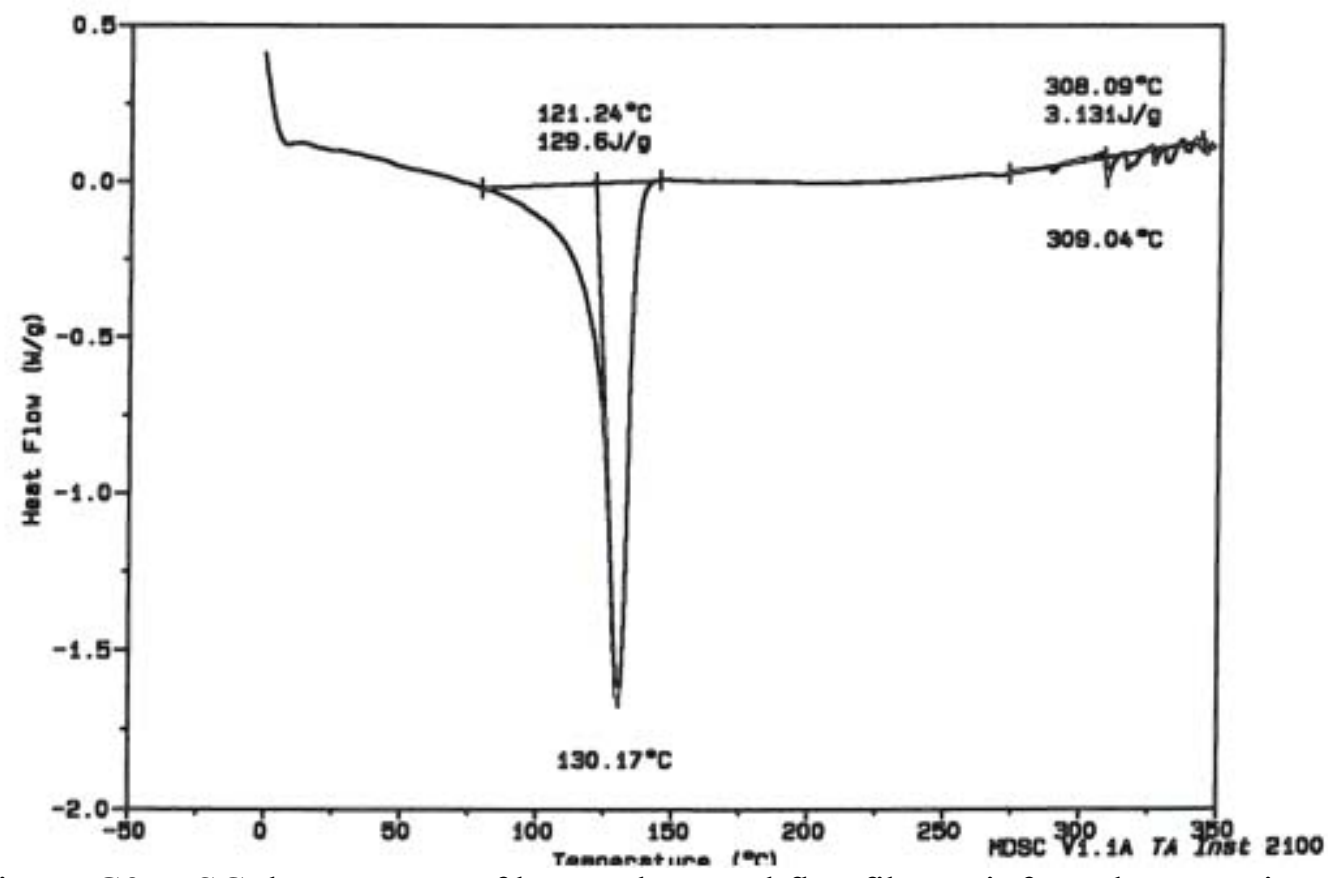

Figure G3. DSC thermogram of benzoyl-treated flax fiber-reinforced composite with LLDPE.

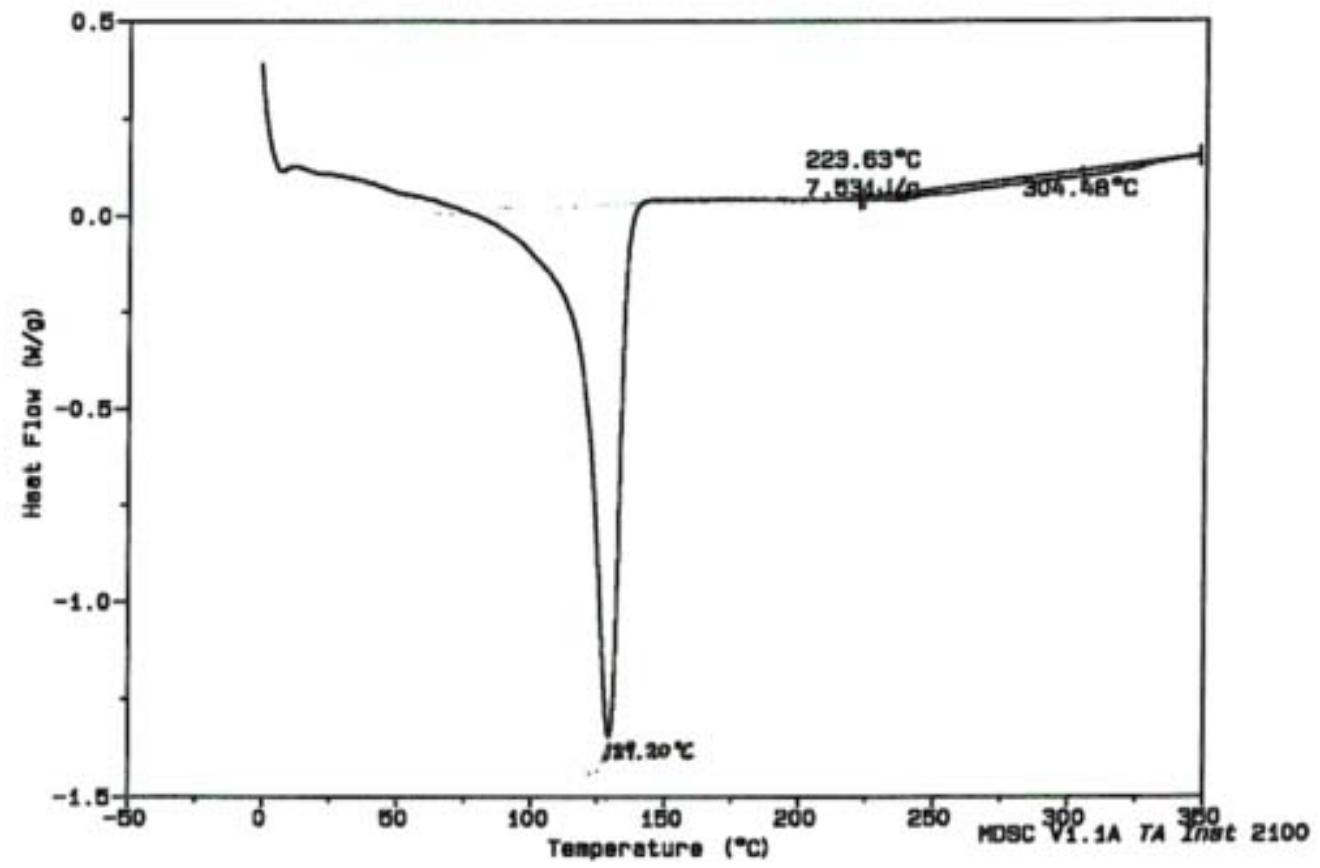

Figure G4. DSC thermogram of peroxide-treated flax fiber-reinforced composite with LLDPE. 


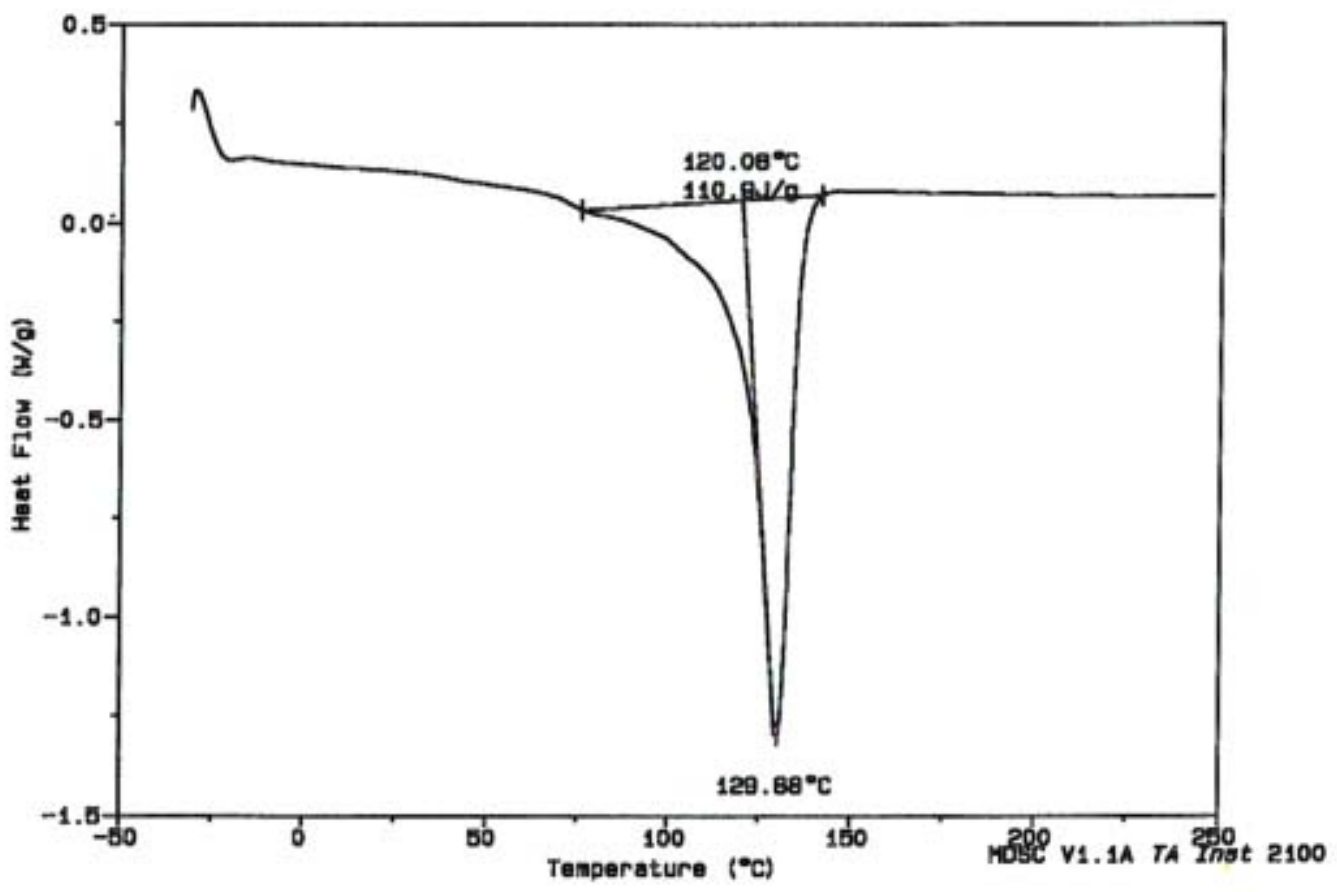

Figure G5. DSC thermogram of pure LLDPE composite.

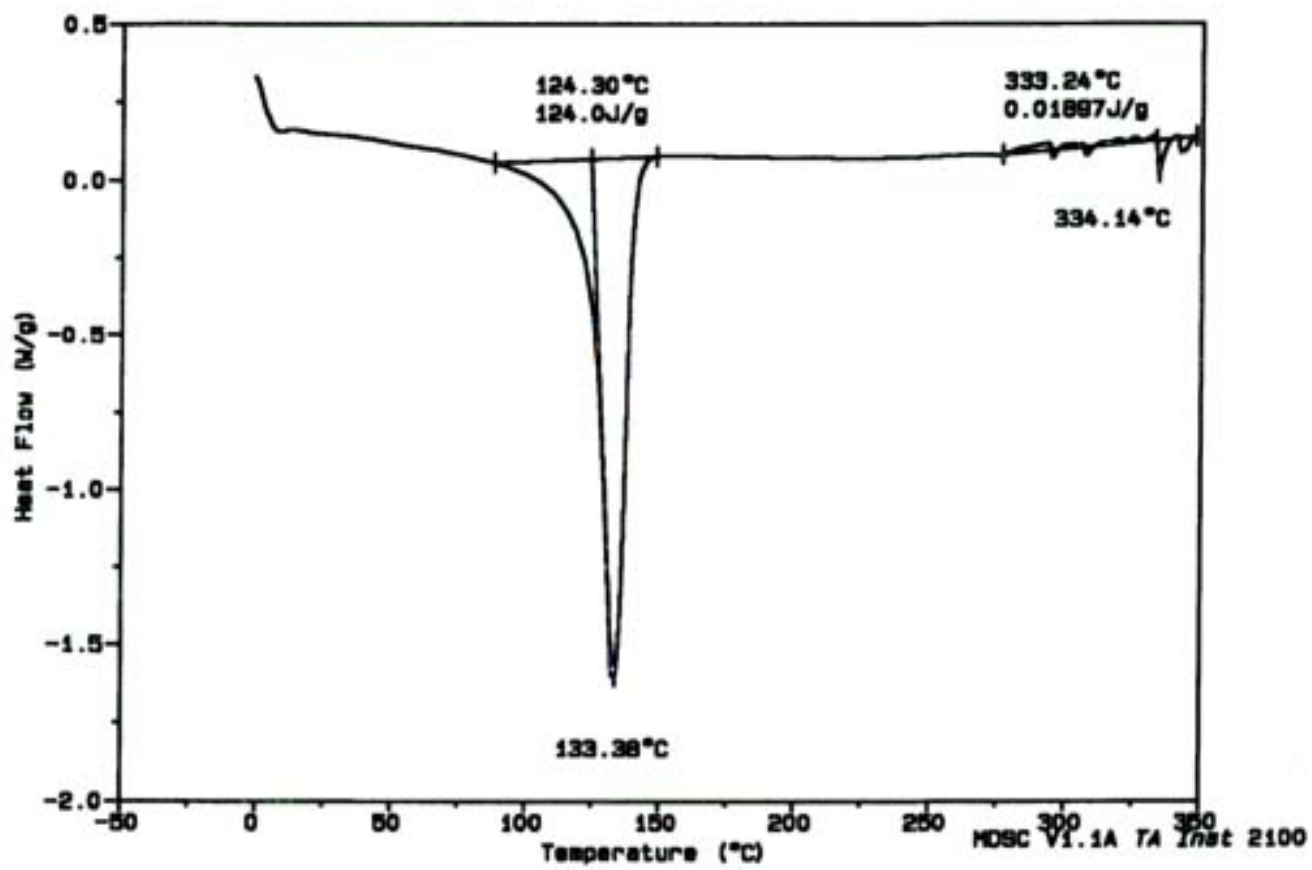

Figure G6. DSC thermogram of untreated flax fiber-reinforced composite with HDPE. 


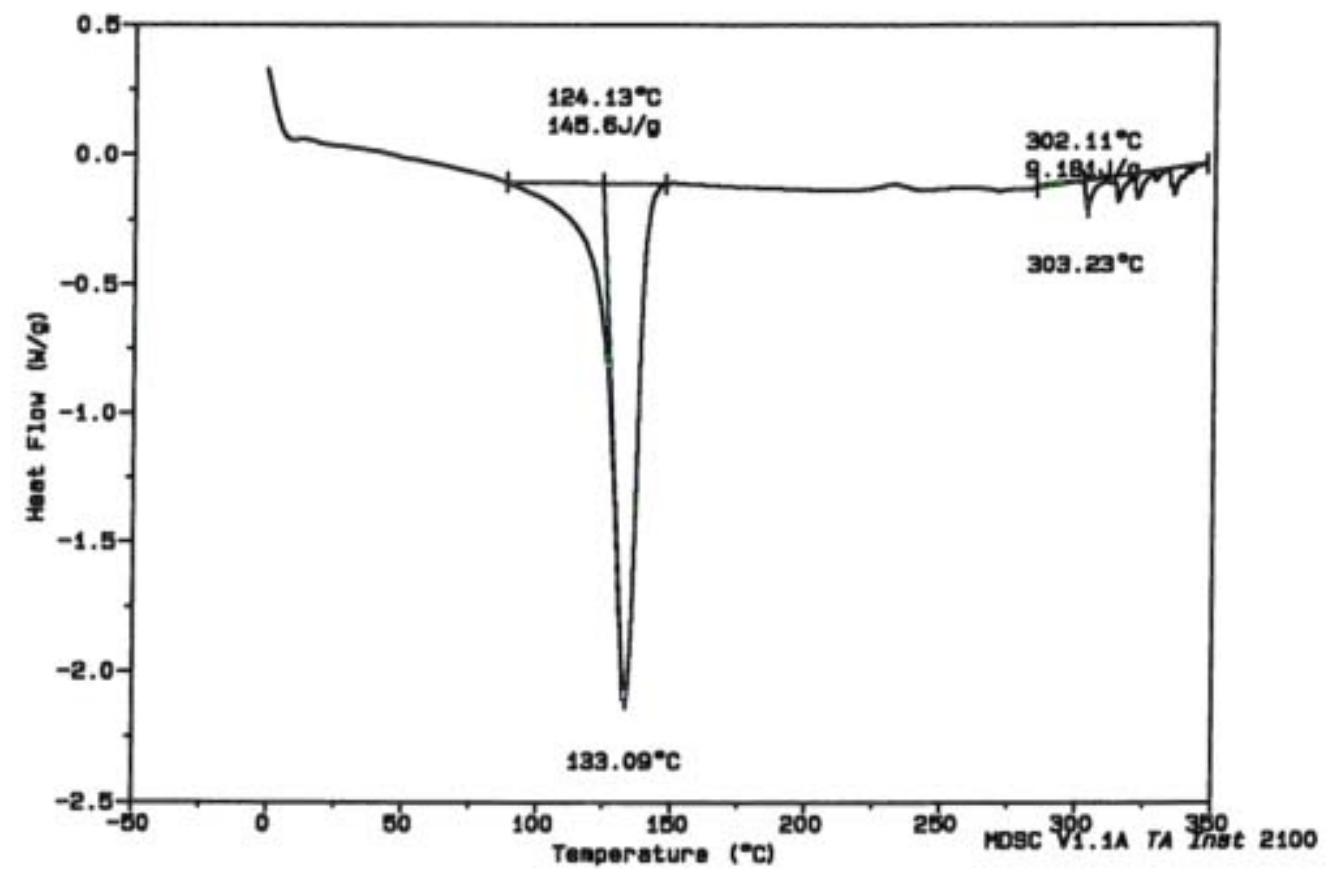

Figure G7. DSC thermogram of silane-treated flax fiber-reinforced composite with HDPE.

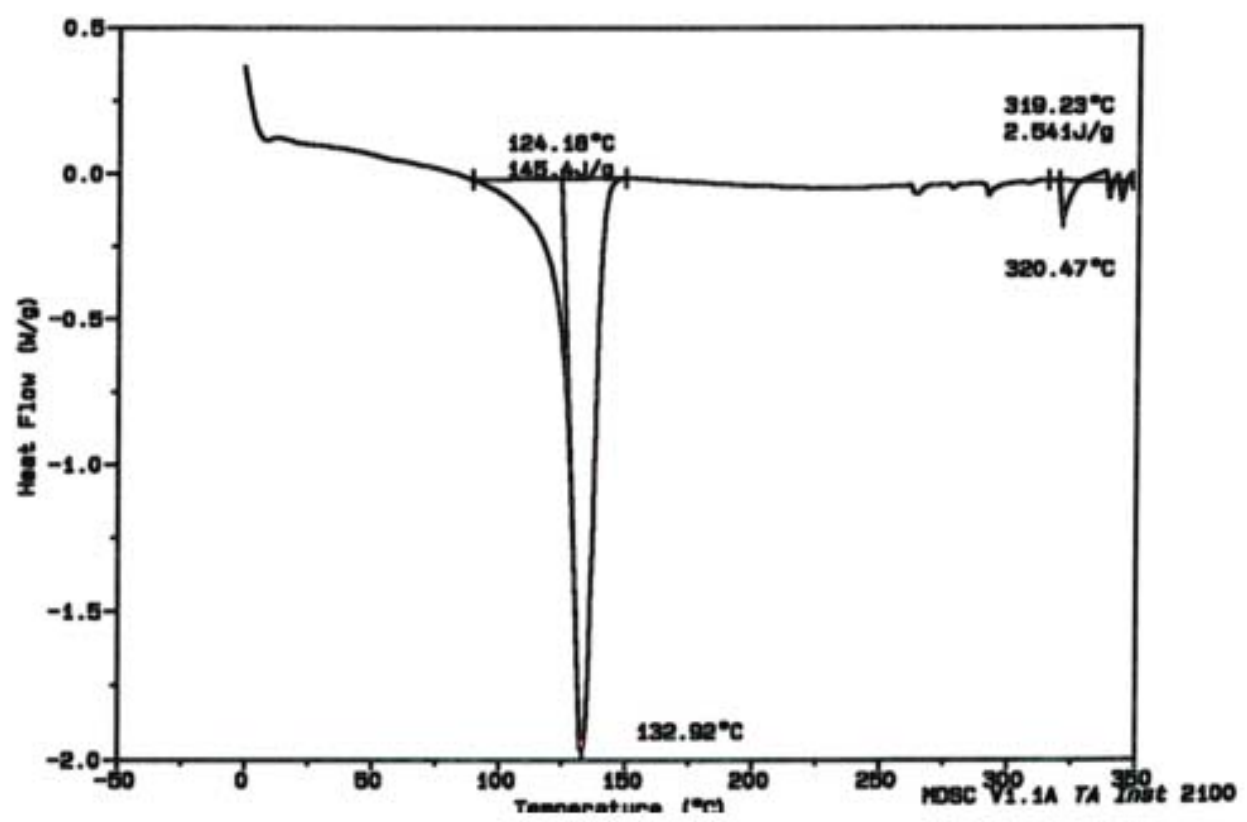

Figure G8. DSC thermogram of benzoyl-treated flax fiber-reinforced composite with HDPE. 


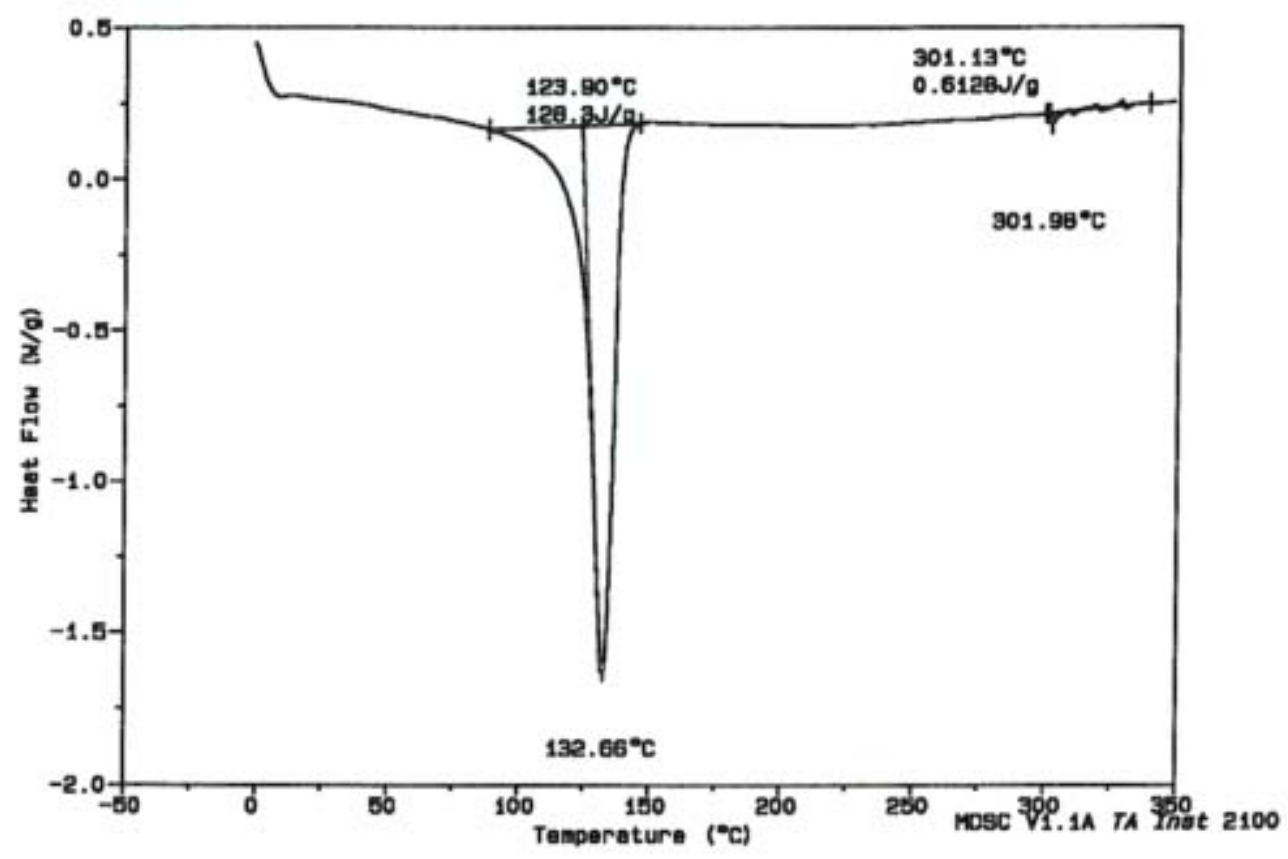

Figure G9. DSC thermogram of peroxide-treated flax fiber-reinforced composite with HDPE.

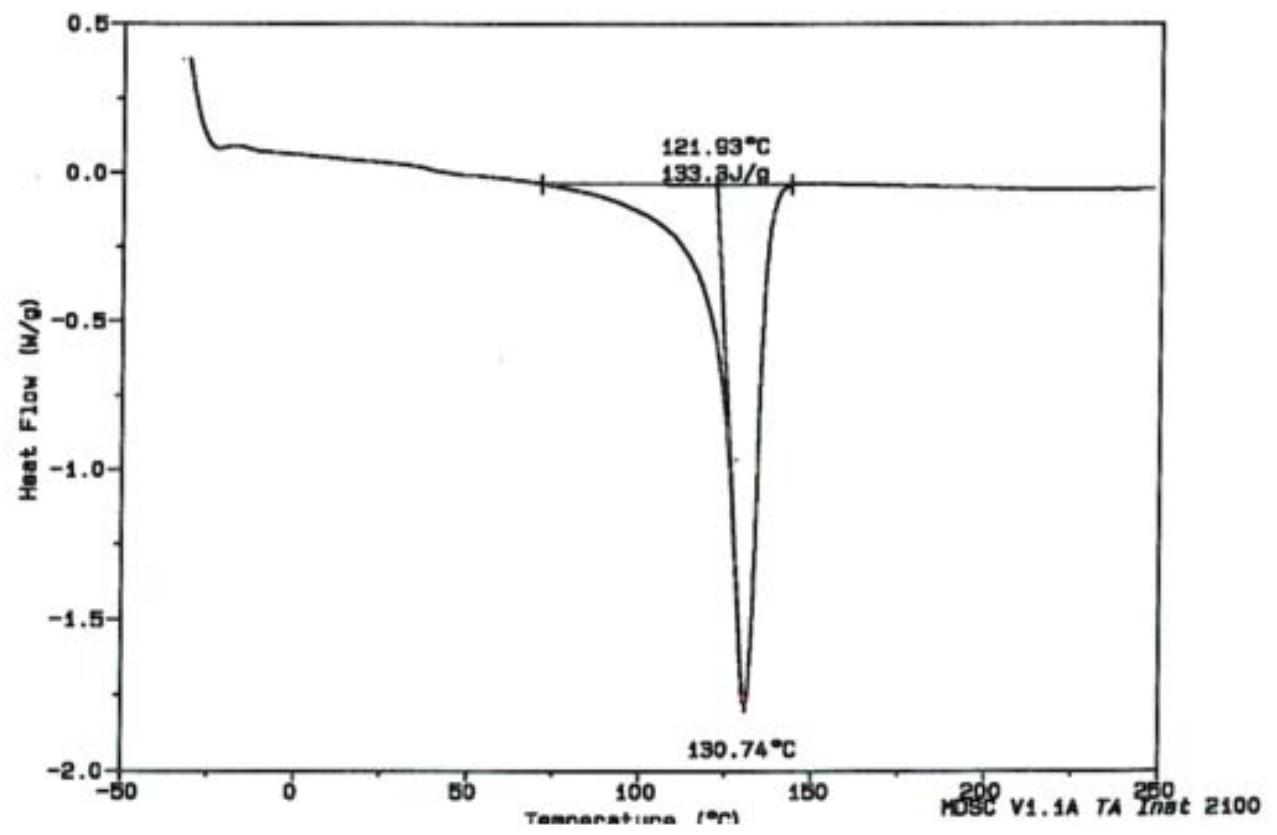

Figure G10. DSC thermogram of pure HDPE composite. 


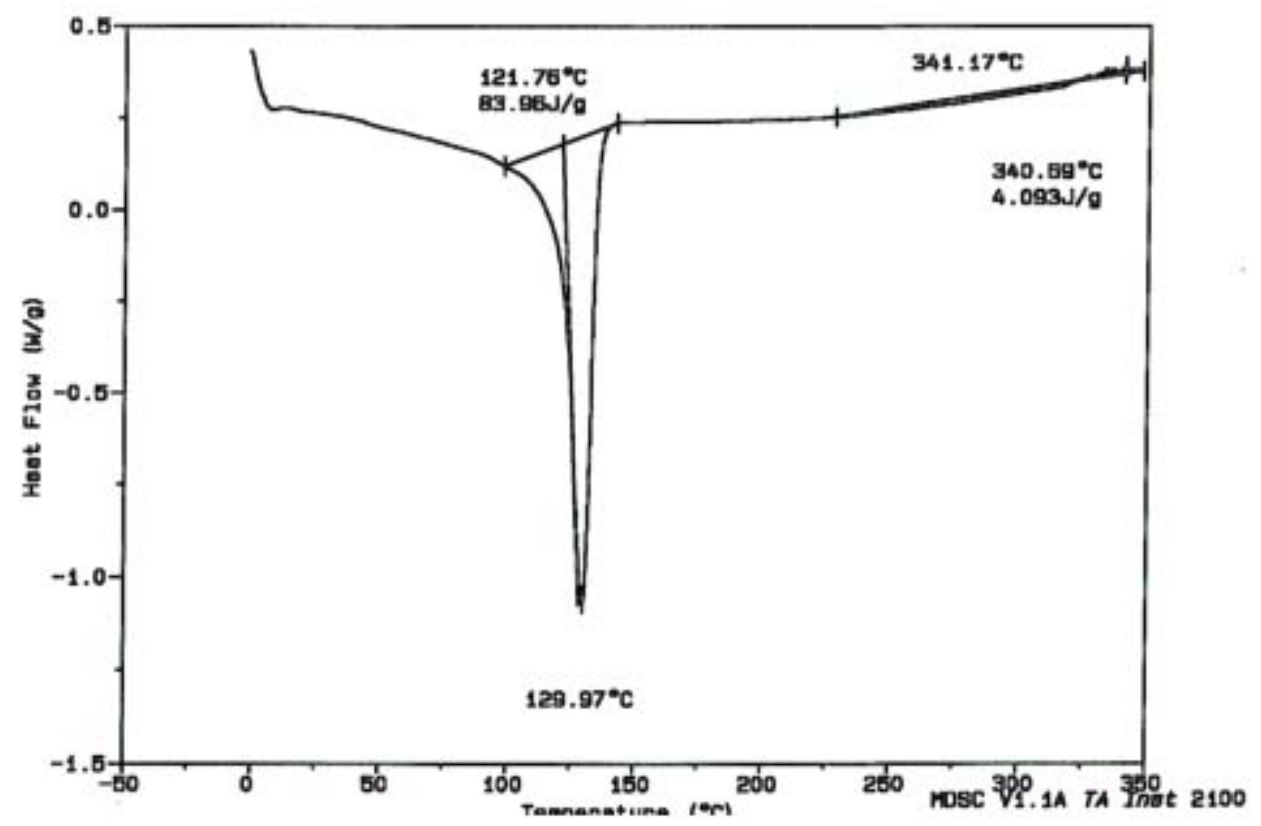

Figure G11. DSC thermogram of untreated flax fiber-reinforced composite with HDPE/LLDPE.

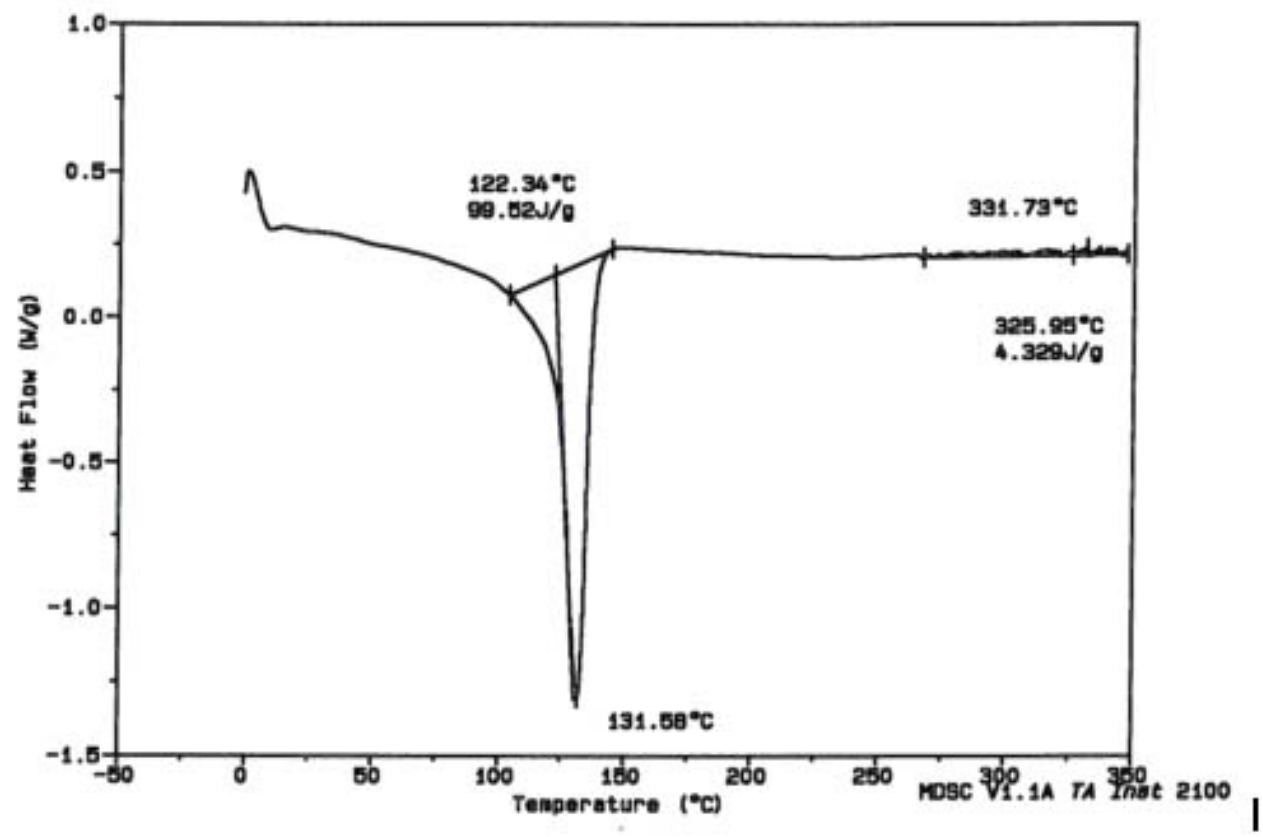

Figure G12. DSC thermogram of silane-treated flax fiber-reinforced composite with HDPE/LLDPE. 


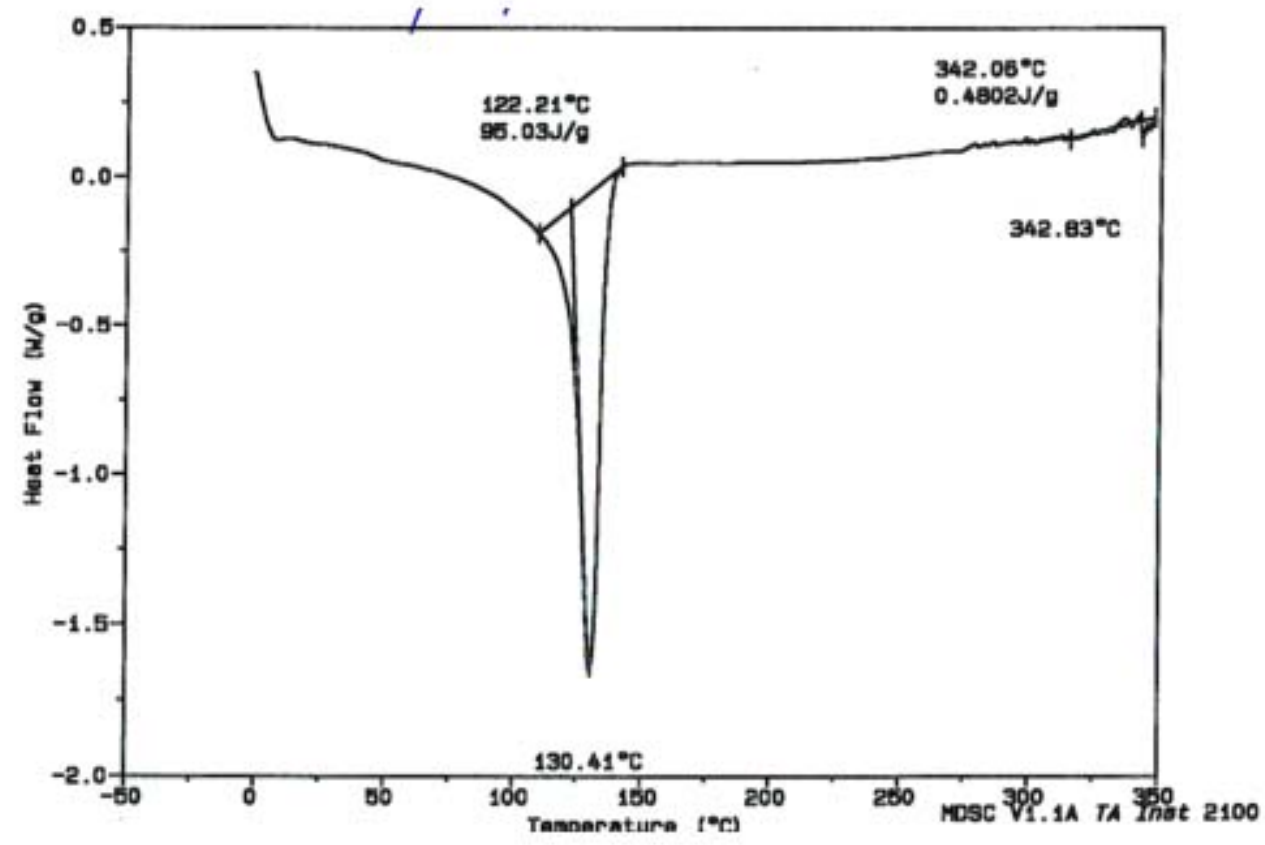

Figure G13. DSC thermogram of benzoyl-treated flax fiber-reinforced composite with HDPE/LLDPE.

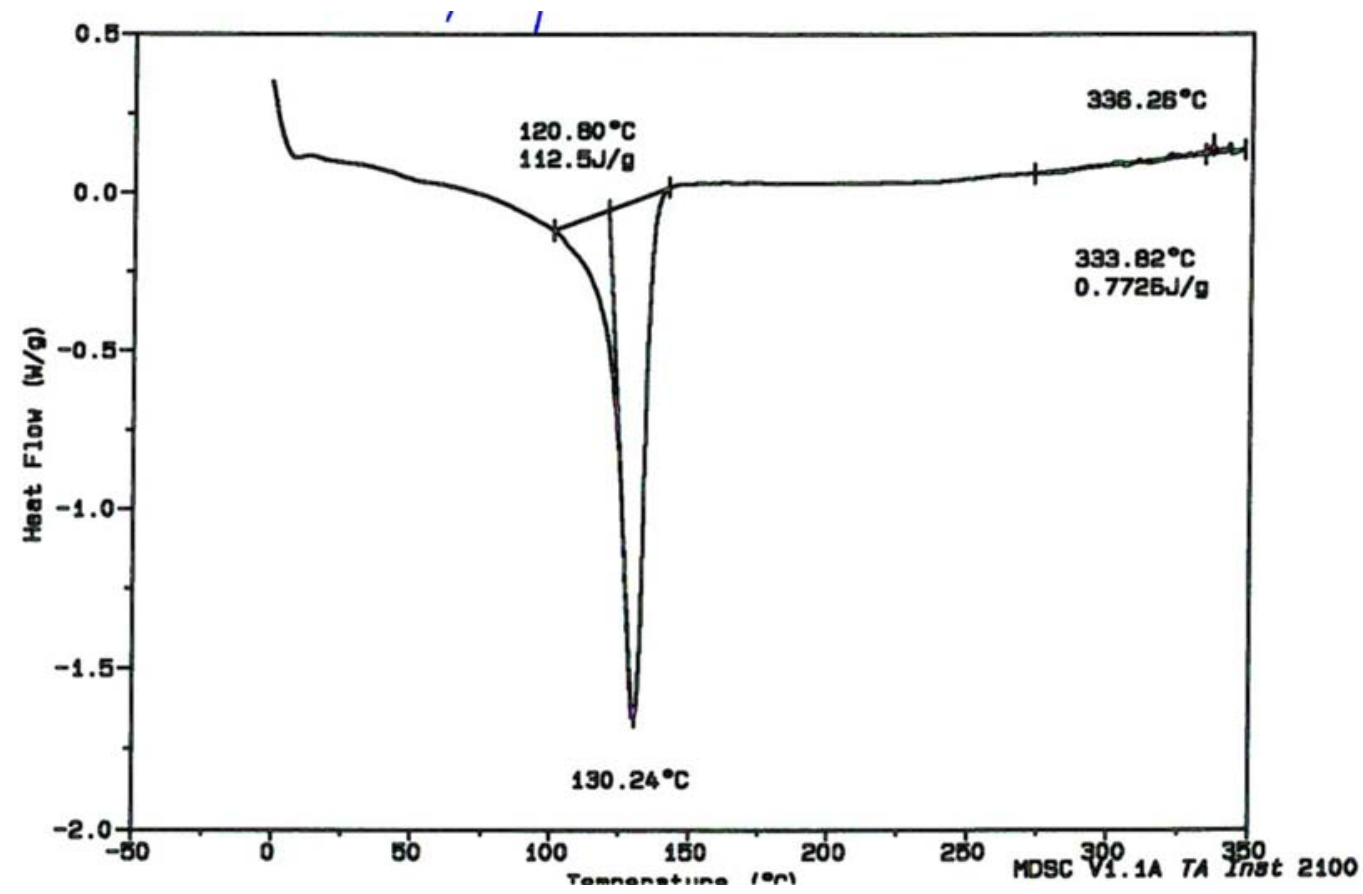

Figure G14. DSC thermogram of peroxide-treated flax fiber-reinforced composite with HDPE/LLDPE. 


\section{APPENDIX H}

The SEM Micrographs of the Cross-session of HDPE and LLDPE/HDPE Flax

\section{Fiber-reinforced Composites}

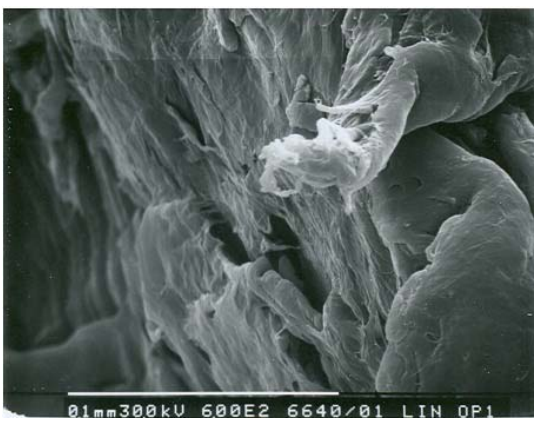

a) Untreated flax in composites

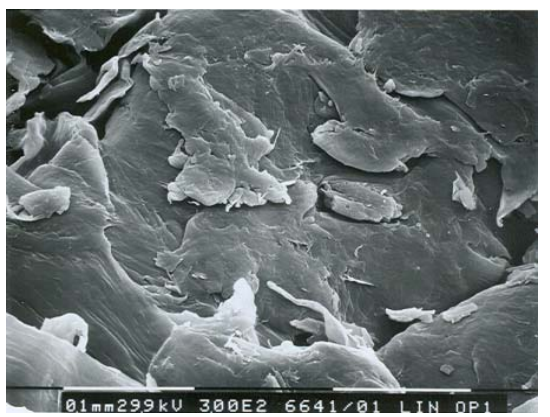

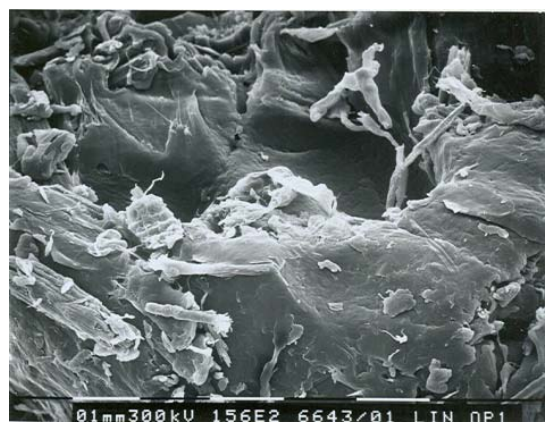

b) Silane treated flax in composites

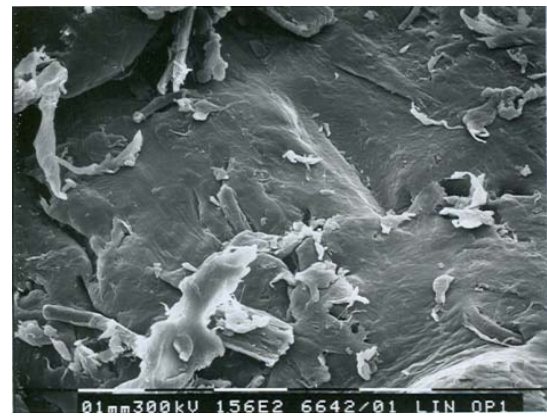

c) Benzoylation treated flax in composites d) Peroxide treated flax in composites

Figure H1. The SEM micrographs of HDPE with $10 \%$ treated flax in composites. 


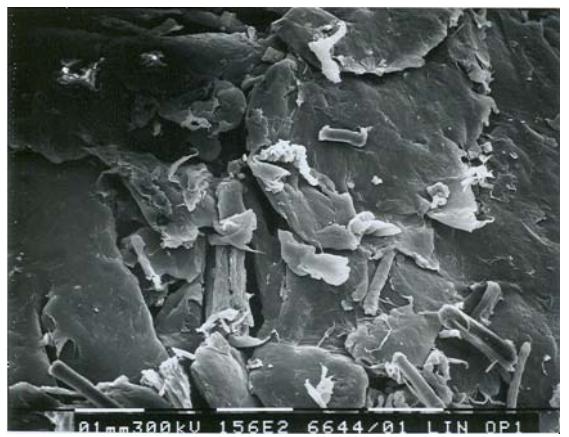

a) Untreated flax in composites

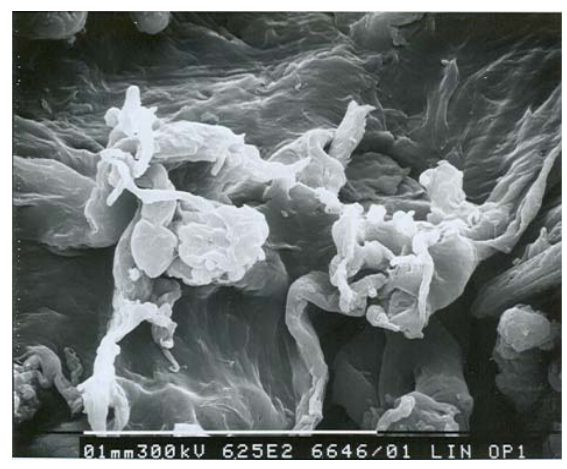

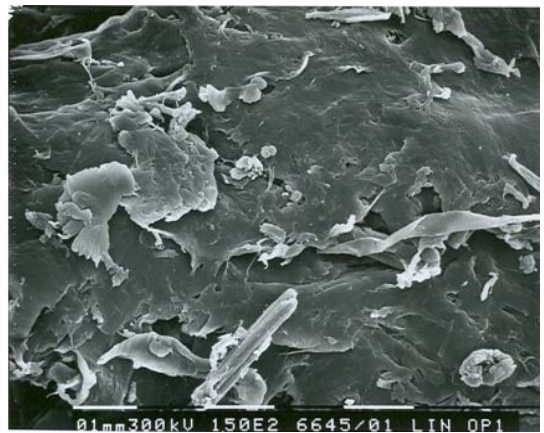

b) Silane treated flax in composites

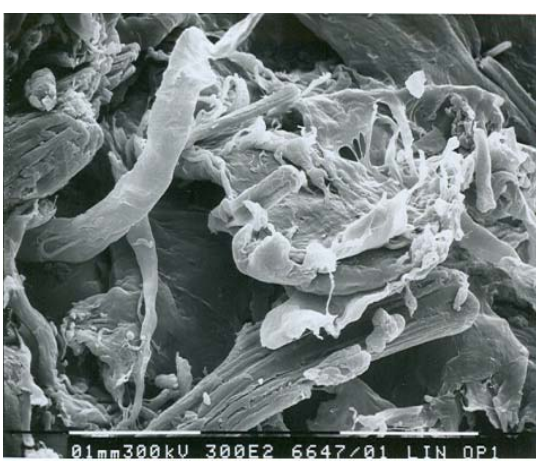

c) Benzoylation treated flax in composites d) Peroxide treated flax in composites

Figure H2. The SEM micrographs of HDPE/LLDPE with $10 \%$ treated flax in composites. 